\title{
Delphi sobre la política sanitaria española en el siglo XXI
}

\section{Jordi Cais, Emilio J. Castilla y Jesús M. de Miguel}

El presente trabajo recoge parte de una investigación sociológica sobre los problemas fundamentales del sector sanitario español utilizando un Delphi. Se realiza durante la década de los noventa a una conjunto de los mejores expertos españoles (varones y mujeres) sobre salud y sanidad. La investigación supone la definición de quince problemas específicos sobre la descentralización y reforma del sistema sanitario español. Todas las personas de la muestra contestan a las quince preguntas base, y las entrevistas son luego transcritas. A continuación aparece un análisis sobre las diversas actitudes, razonamientos, y opiniones sobre la política sanitaria en España de cara al siglo XXI. Se presenta una agenda de problemas para resolver desde la política sanitaria tanto pública como privada. Es un documento indispensable para analizar las políticas públicas respecto del sector sanitario español.

Ya terminando el siglo XX —en el año 1999- se analiza la política pública del sector sanitario, utilizando una muestra de expertos/as españoles, así como las técnicas de Delphi. La sanidad no es la menor de las preocupaciones en un país de democracia moderna ${ }^{1}$. Más bien ula sanidad es una de las funciones más complejas que atiende el Estado" ${ }^{2}$. Mirando hacia el siglo XXI el tema que más preocupa es el control del crecimiento del gasto. La Ministra de Sanidad y Consumo durante el último gobierno socialista declaraba que "No sólo se tiene derecho a vivir: se tiene derecho a vivir sano, y la salud requiere que la vida de las personas discurra en condiciones adecuadas de calidad. Afirmaba también que ano se puede ser neutral frente al dolor, frente a la enfermedad. El sector público es la pieza clave para el futuro: aLo que se garantiza desde el sistema es nada menos que la igualdad en la salud. El sector sanitario está pues en el origen de la discusión sobre políticas públicas igualitarias.

Preocupa el inmenso coste que está suponiendo esta supuesta igualdad, es decir, el coste de la sanidad pública. La últi- ma propuesta del cuarto Gobierno socialista fue que ese coste debía afrontarse desde la solidaridad y corresponsablemente. „Es necesario ordenar mejor el sistema nacional de salud, definir sus objetivos y corresponsabilizar a todos en la correcta utiliza-i ción de los recursos sanitarios; sean éstos una cama, una consulta o una receta ${ }^{3}$. Lo que no se dice es que el coste sanitario es muy bajo (alrededor del $6 \%$ del PIB) ${ }^{4}$ y que - contrario a lo que insistentemente se cree y se declara - la proporción de gasto público es también baja ${ }^{5}$. El sector público en sanidad es débil y gasta poco dinero. Junto con Portugal, España es el país avanzado con mayores carencias de camas hospitalarias; el sector público sólo es propietario del $69 \%$ de esas camas hospitalarias, y cada vez tiene menos ${ }^{6}$. A pesar de esa situación carencial y comparativamente deficitaria, desde la Guerra Civil la tasa de camas hospitalarias en España no sólo no ha crecido sino que incluso ha disminuido?. De todos los países avanzados, España es el que hospitaliza a menos población ${ }^{8}$. Hay bastantes personas que requerirían ayuda (hospitalaria) y por alguna razón no la obtienen. No puede pues afirmarse que en el futuro hay que contener el gasto como sea. Más bien parece -según algunos expertos/as en el tema- que hay que aumentar el gasto en sanidad, el gasto público en sanidad, los hospitales (sobre todo los públicos), y utilizarlos más eficazmente. Es difícil garantizar la igualdad en la salud con niveles tan bajos de recursos, sobre todo si se compara a España con el resto de los países de la Unión Europea, o con los países de la OCDE.

Otra cosa es que los diversos Gobiemos españoles -y seguramente aún más en un futuro próximo, ya al borde del año 2000 - se enfrentan con el problema arduo de la contención del gasto público. Pero definir el sistema sanitario español de los años noventa como de asolidaridad y de acorresponsabilidad son a veces eufemismos para hacer pagar un poco más a la población por el consumo de recursos sanitarios, o utilizar 
un poco menos los escasos recursos públicos. Estas políticas suelen llevar a un incremento de la desigualdad sanitaria en la población. Si eso cristaliza en el futuro los problemas sanitarios del sistema español pueden ser comparativamente (con el resto de los países europeos) todavía más graves. A los políticos/as les preocupa *El enorme coste que representa la asistencia sanitaria. ${ }^{9}$. Pero no es cierto: el coste es barato, poco público, está descendiendo, y comparativamente hablando es bajo, se construye cada vez menos, y el sistema da pocas prestaciones. Hay un cierto margen de progreso en el uso racional de recursos. Pero las desigualdades sanitarias (por clases sociales, regiones, edades y géneros) son enormes en España. Esos sí que son los problemas sanitarios del siglo XXI.

En el análisis del sector sanitario español futuro -referido tanto a los recursos de la sanidad como a las necesidades sanitarias de la población - hay una serie de cuestiones claves que conviene resolver. En el presente artículo se han definido quince de esos problemas principales. Las proyecciones no se pueden realizar fácilmente con estadísticas, pues los datos del futuro no existen. Como señala uno de los expertos entrevistados: Lamentablemente el gravísimo problema de nuestro país es que no tenemos información, no tenemos datos, no se hace investigación ${ }^{10}$. A veces esto puede llevar al espejismo de que no existen problemas ${ }^{11}$. Por un lado, es complicado predecir lo que va a ocurrir, el futuro ${ }^{12}$. Por otro lado, aunque se supiese las soluciones son difíciles: aDe la sanidad se puede decir que nadie tiene solución, nadie tiene la varita mágica. Pero tiene un infinito potencial de mejora. Sabiendo que las mejoras que hoy son mejoras pueden generar incentivos perversos, más bien a corto que a medio plazo ${ }^{13}$. Las personas expertas en temas sanitarios (y en políticas sanitarias), muchas de ellas con una formación extranjera y con experiencia en varios países, son ideales para imaginar ese futuro incierto. A continuación se exponen y discuten algunas de las opiniones más importantes sobre los quince problemas centrales ${ }^{14}$. Los expertos respondieron con gran sinceridad ${ }^{15}$. Sus ideas, creencias y predicciones hay que enmarcarlas en un contexto social global. Como señala uno de ellos: aLa democracia española es una democracia joven. Como sociedad no estamos acostumbrados a reflexionar mucho. Nuestro sistema educativo además no forma a la gente con sentido crítico. ${ }^{16}$. Sin embargo, los/as expertos que contestan al Delphi contradicen todos/as esta afirmación inicial.

1. Es importante evaluar el sector sanitario español actual, de forma global, y analizar en una interpretación bolistica del sistema sanitario en el futuro. La mayoría de los/as expertos del Delphi reconocen que el sector sanitario español está en crisis. Hay una serie de argumentos para, a pesar de la crisis, considerar la situación como positiva, y también argumentos negativos. En la visión positiva se considera que: "El sistema español en comparación con otros países, y según ciertos indicadores, está bastante bien. Es un sector sanitario que tiene muchos profesionales médicos, mucho más que los otros sectores sanitarios europeos. Hay exceso de profesionales. Comparado con otros países hay un defecto de camas. Tenemos menos camas que otros sectores. Nuestro gasto del producto nacional bruto en sanidad es inferior a otros países. Sin embargo, algunos de los indicadores de salud son mejores que en otros países. Realmente no sabemos si es debido al sector sanitario o a otras variables. Tenemos la esperanza de vida mayor en toda Europa, prácticamente una de las mayores en todo el mundo occidental. ${ }^{17}$. Se llega a afirmar que: «Nunca España ha tenido un sistema sanitario como el actual, nunca. Pero al ser un reflejo de una diversidad socio-cultural-económica, el sistema sanitario posee tanto las grandezas como las mediocridades de las distintas culturas ${ }^{18}$. Se considera pues que es una crisis de crecimiento, debido a la transformación de un sistema de la Seguridad Social (centralizado) a un modelo de Sistema Nacional de Salud (SNS) descentralizado en Comunidades Autónomas, con un resto de Insalud. Se reconoce que: "El sistema español es sólido. Está atravesando una crisis. No ha dejado de ser de la Seguridad Social y sin embargo formalmente parece que ya no lo fuera. Tiene aspectos organizativos que necesitan cambiar. Pero básicamente aparece como uno de los pocos servicios de este país que razonablemente funcionan, sobre todo en relación con todo lo que no funciona en el país. ${ }^{19}$. Otro experto considera que: «España como hoy no ha estado nunca. En el futuro, si la racionalidad sigue adelantando, y mejorando, y expansionándose los niveles culturales y de mejoras del país, irá mejorando el sistema sanitario. Yo no identifico el riesgo con el siniestro; pero el riesgo de que no sea así y la posibilidad de siniestro existen ${ }^{20}$. Parte del éxito es un proceso de integración de todos los recursos sanitarios -privados y públicos - para superar los problemas estructurales: aEl sector sanitario español está ahora en una situación mejor que con respecto a años anteriores de su historia. Se hacen planteamientos para encarar algunos de los problemas estructurales que están presentes desde hace muchos años, pero que son difíciles de resolver porque cuestan mucho dinero, o implican una reestructuración muy dolorosa. El sector privado está encarando su integración en el conjunto del sector sanitario. Por una parte, el sector privado sin ánimo de lucro está engarzándose de forma mucho más transparente, complementaria y armónica con el conjunto del sector público. El sector privado con ánimo de lucro a través de un esfuerzo de reconversión duro está llevando a algunas empresas a la liquidación, y a las demás empresas a situarse, con una perspectiva más de mercado, para cubrir los servicios o los sectores de población de forma complementaria, con el sector público de cobertura universal. ${ }^{21}$.

Este mismo proceso de crecimiento y de integración puede ser visto como negativo, problemático: "Se trata básicamente de 
un sector sanitario, de un conjunto de servicios financiados en una inmensa mayoría por el sector público, y proveídos, ofertados y producidos también públicamente. En ese sentido, está en una situación que tiene mejor 'salud' de la que se le atribuye. Pero al mismo tiempo es un sector que está en una profunda crisis. No tanto porque vaya a explotar pasado mañana sino porque los supuestos, sobre los que se construyó han sido superados y las nuevas perspectivas todavía no están presentes en el mismo" ${ }^{22}$. El SNS no parece resolver algunos de los problemas básicos: «El sector sanitario español está en crisis profunda. Hay una ambigüedad en el desarrollo de las previsiones legales y constitucionales, que junto con la crisis financiera, hace que en estos momentos la desorganización sea total ${ }^{23}$. Otra experta remacha: "El sistema sanitario español no responde a las demandas de una sociedad con unas determinadas necesidades. El recorte de los costos yo creo que es terrible. Por un lado, ciertamente, hay que optimizar los recursos que se tienen. Pero, por otro, se tiene que aprovechar bien, gestionar bien. Porque claro, lo fácil es decir 'vamos a cortar prestaciones' ${ }^{24}$.

La crisis es pues doble: económica y de organización. Pero el problema económico no es de ahora: "Es radicalmente falso que el economicismo de la salud sea un fenómeno nuevo. Desde que en España, en el año 1917, se tomó conciencia del grado de subdesarrollo de la atención sanitaria que había en el país, el problema era económico. En la Conferencia de Seguros Sociales de Madrid, de 1917, Sanidad trató de engancharse al convoy de los seguros sociales porque el Estado no tenía un duro. La concreción, diría histórica, sería el Seguro de Maternidad y el proyecto de Largo Caballero del Seguro de Enfermedad de la República. Cuando ya se implanta como Seguro Obligatorio de Enfermedad es con la Ley de 1942, y entra en juego con la Ley del 1945. Toda su historia es una cadena de crisis económicas" ${ }^{25}$. El segundo problema estructural básico es la falta de organización y de coordinación: «En el momento presente hay problemas graves de organización, tanto interna dentro del sistema entre los distintos niveles de atención, como externa con otros sectores de la sociedad. Por ejemplo, hay muy poca coordinación entre el Ministerio de Sanidad y el Ministerio de Asuntos Sociales, y el Ministerio de Educación. La comunicación interministerial es muy mala. Se podría decir lo mismo a nivel local, por ejemplo, en el caso de los servicios sociales y sanitarios de los Ayuntamientos y los de las Comunidades Autónomas" ${ }^{26}$.

Una crítica más profunda del sector sanitario español es su estructuración curativa que se centra alrededor del sistema hospitalario. "En la construcción del sistema sanitario español —como en el resto de los países occidentales- predomina la concepción curativa sobre otro tipo de concepciones, con lo cual se prima el sector hospitalario sobre la asistencia primaria por ejemplo. Coincide además con los intereses de la élite profesio- nal médica; con los intereses de la Medicina como ciencia que necesita un espacio para investigar (que son los hospitales). Hay una serie de coincidencias que supone una concepción dominante de la salud: que la enfermedad hay que repararla, por lo tanto, el mejor lugar es el hospital. Luego además están los intereses de unas élites profesionales médicas, las élites, que necesitan espacio para investigar, que es el hospital; y los intereses de la industria sanitaria [...] Con lo cual al final lo que tenemos es un sistema hospitalario que es básicamente curativo, de 'cortar y pegar', una industria. En el sistema sanitario español, el hospital español es una fábrica de entrar piezas defectuosas y repararlas. Es en lo que se ha convertido" ${ }^{27}$.

Otro experto del Delphi reconoce que el problema fundamental es que la reforma del sector de atención primaria de salud (APS) no se ha completado. La transformación del sector sanitario no se logrará hasta que no se culmine esa reforma de la APS: «En estos momentos tenemos la mitad de la población que recibe atención primaria con un sistema reformado, digno, de cobertura razonable. Puede haber variaciones, pero en general es correcto. Cubre el grueso de las zonas rurales, y en las zonas urbanas normalmente los barrios más pobres. Pero sigue existiendo una mitad de la población que está recibiendo la atención primaria del sector público con un sistema absolutamente inapropiado, obsoleto, que es la Seguridad Social de los ambulatorios de los años sesenta. Ese sistema es masificado, malo, sin historia clínica, y en condiciones absolutamente deplorables incluso de trato al usuario. Esto incluye el grueso de las zonas rurales y el grueso de la clase media. Hasta que la reforma de la atención primaria no alcance potencialmente a toda la población cubierta por el sector público tendremos un déficit importante. Los fallos en la atención primaria se extienden o lo sufren luego el conjunto del sistema: con una demanda de servicios hospitalarios, de servicios de especialidades y con la falta de solución de problemas de salud para la gente. Es un tema absolutamente clave, que sigue pendiente. Hasta que no esté culminado el proceso de reforma de la atención primaria, la reforma es absolutamente frágil. Se puede poner en cuestión por motivos políticos en cualquier momento, y por intereses profesionales o económicos que cuestionan la reforma ${ }^{28}$. Otro experto añade además la falta de desarrollo de la salud pública contemporánea ${ }^{29}$.

Todos/as consideran pues que el sector sanitario español de los años noventa está en crisis. La solución a la crisis pasa por una mejor definición del sector sanitario en el futuro: «El sector sanitario español está en un proceso de definición, es decir, está pasando por un momento de crisis. Lo mismo está ocurriendo con cualquier otro sector sanitario de un país industrializado, aunque se tiene que destacar un proceso propio del sistema sanitario español. La suma del proceso global de los demás países junto con el proceso propio produce una necesidad 
de definición del sector sanitario. Hay que definir: cuál va a ser el sistema sanitario del presente-futuro; por qué el sistema sanitario actual no está capacitado para satisfacer todas las demandas que surgen de un avance científico y tecnológico que es excesivo; cómo se va a realizar la asignación de recursos; cómo se va a estructurar de cara al futuro; qué tipo de sistema va a ser; cuánto va a ser público y cuánto privado; cuál va a ser la contribución del usuario, etc. ${ }^{30}$. El sector sanitario va a cambiar considerablemente. Pero para algunos expertos este cambio puede ser - afortunadamente- lento: "Está en una etapa de cambio, pero por su propia naturaleza y envergadura. Afortunadamente creo que no van a ser ni muy radicales ni muy rápidos. Digo 'afortunadamente' porque los cambios pueden ser en un sentido positivos y en otros negativos. A veces uno se entristece porque los cambios son lentos, pero también se alegra de que sean casi imposibles ante algunos de los cambios que se proponen. Esta propia lentitud protege al sistema* ${ }^{31}$.

\section{Políticas públicas de organización}

2. No se está seguro de que se esté creando realmente un Sistema Nacional de Salud público, de buena calidad, y para toda la población española. Es importante entender lo que falta realizar en el futuro para lograrlo o perfeccionarlo. El ideal, según algunos/as expertos, es lograr un SNS único, puiblico y gratuito. Pero de entrada el carácter universal del SNS se pone en duda: -El sistema de Salud español no es universal desde un punto de vista técnico, ni legal, pero sí desde un punto de vista fáctico. El sistema sanitario español se ha construido a lomos y sobre la columna de los servicios sanitarios de la Seguridad Social. Por lo tanto, estamos ante unos sistemas sanitarios de base laboral, ligados a la condición del sujeto y de su familia. No estamos ante un sistema sanitario que otorgue derechos a los servicios a la gente por su condición de ciudadanía. El título de acceso al Sistema Nacional de Salud es distinto para cada ciudadano dependiendo de si uno es titular de la cartilla del seguro, o de si uno es familiar. Si es familiar, depende de la edad. Unos lo son por derecho como son los niños pequeños. Pero a partir de una cierta edad, lo son porque hubo un Decreto de 1989 que incluyó los mayores de 36 años sin empleo. Pero luego están los pobres que ni trabajan, ni están casados, ni son hijos de nadie que tenga cartilla de la Seguridad Social. Éstos tienen que demostrar que son pobres para tener acceso al sistema. Tampoco hay que decir que se pongan unas condiciones demasiado rígidas, y en ese sentido a uno le puede resultar relativamente fácil. Luego están los de arriba ${ }^{32}$. Otros consideran que el SNS sí es universal, pero que en la práctica no lo es: "En cuanto a si es un Siste- má Nacional de Salud para la población española, yo creo que teóricamente sí. La cobertura es universal, y las encuestas que nosotros hemos manejado indican que todo el mundo se siente cubierto. En cuanto a si el sistema cubre a todo el mundo de la misma forma es obvio que no, y que eso es muy difícil por muchos motivos. El sistema no es algo que se improvisa de la noche a la mañana sino que es algo que se hereda. Así, la herencia en cuanto a la distribución de los recursos es totalmente asimétrica: se ha potenciado el mundo urbano sobre el rural, se han potenciado incluso algunas ciudades sobre otras [...] Hay sospechas de que este Sistema Nacional de Salud no es igual para todos, aunque se intenta que lo sea " ${ }^{33}$. Un sistema único puede ser monopolista, con todos los efectos no queridos que puede conllevar esa estructura: "La demanda del sector público no depende de que a las personas les guste o no estar en la cama del hospital, o que sean tratados mejor o peor, sino que depende de que para la mayoría de la población es el único sistema. Hay claramente un monopolio de oferta de unos servicios. Tal y como pasa con otras situaciones monopólicas, sin competencia, el producto que ofrece no necesariamente responde a las necesidades de los usuarios, consumidores, o de los que pagan. Puede responder a muchos otros intereses, como los intereses profesionales, de las organizaciones, económicos, y los intereses de los gobiernos. ${ }^{34}$.

En segundo lugar, el SNS no es realmente un sistema público: aLa Ley General de Sanidad configura un sistema nacional de salud; no dice público, dice 'sistema nacional de salud'. Un sistema nacional de salud público no está en la agenda política hace ya muchos años. La idea es la creación de un sistema nacional de salud que combine la estructura sanitaria pública con la privada [...] El sector público no puede crecer más según los gestores del sector público, no tienen dinero para invertir más. Esto les obliga a tener que recurrir al sector privado. El sector privado necesita sobrevivir. Esto les obliga a negociar, luchar, intentar conseguir que sus prestaciones estén incluidas dentro del sector público; o sea, que al sector privado puedan asistir pacientes públicos. Por lo tanto, hay lo que ha habido siempre en este país: una gran dependencia del sector privado con respecto al sector público. El sector público se financia porque el sistema nacional de salud es una cobertura de enfermedad para toda la población. El Estado asegura la atención sanitaria para toda la población. Eso es una parte fundamental de la Ley General de Sanidad, y del Sistema Nacional de Salud ${ }^{35}$. El que el SNS no sea del todo público, y sobre todo que la población no utilice igualmente un servicio público, es un problema estructural básico del caso español: "Las élites laborales se escapan de los aspectos de provisión del sistema sanitario que resultan más disfuncionales, que resultan más molestos, o que resultan menos compatibles con los hábitos de las clases medias-altas del país. Los funcionarios, tanto civiles como militares, tienen la posibilidad de elegir su provisión por firmas privadas (a través de 
Muface). El 85\% de los funcionarios elige los servicios que ofertan las compañías privadas, pero hay evidencia (y no sólo anecdótica) de que muchos de los que eligen ser atendidos por una compañía privada cuando les sucede algo que de verdad es serio encuentran los mecanismos para retornar al sistema de provisión pública. Se puede decir que estas personas 'descreman' los servicios públicos. Utilizan lo mejor de los servicios públicos (porque sin duda son los que tienen mecanismos privilegiados de acceso a los mismos); mientras que para las cosas más de rutina, donde el componente percibido de calidad, de confort es más atractivo utilizan el otro esquema. Pero también los que podríamos considerar trabajadores de élite del país (Banca, Compañias Eléctricas, Cajas de Ahorros, RTVE y grandes empresas como Telefónica) tiene la condición de empresas colaboradoras. Esas personas están también liberadas de la parte de los servicios que una y otra vez aparecen como más disfuncionales para los ciudadanos de clase media-alta, es decir, de los ambulatorios, de la primaria, etc. El sistema tiene problemas de cobertura en cuanto a título de acceso, pero también de cobertura en cuanto a la provisión de servicios. Cuando un servicio público está descremado de su utilización por parte de los usuarios con más poder de articulación, de protesta, de exigir, y de derechos pierde calidad [...] Un servicio para pobres es más pronto o más tarde un pobre servicio. En este sentido, es un tema estratégico el que los servicios sanitarios sean utilizados por todas las capas sociales [...] Ésta es una reflexión que muy pocas veces es introducida en los debates. La equidad en este caso es también una condición de efectividad, eficiencia y de satisfacción de los usuarios. Sólo cuando toda la escala social de nuestro país utilice un servicio público como la sanidad se darán los estímulos precisos para transformar aquellos aspectos que no funcionan" ${ }^{36}$.

Tampoco parece que el SNS sea realmente gratuito. Algún experto considera que estamos todavía ante un sistema de beneficencia: "Lo que se está haciendo, en realidad, es crear un modelo de beneficencia más adecuado [...] Para perfeccionarlo habría que reformar la Ley General de Sanidad, modificando el capítulo de financiación, que tiene muchas lagunas ideológicas. No podemos olvidar que estamos en un sistema de seguros sociales obligatorios. Porque aunque le estamos llamando 'Seguridad Social' en realidad estamos técnicamente en un sistema de seguros sociales obligatorios" ${ }^{37}$. La demanda excede con mucho a la oferta, creando una estructura peculiar: "Uno de los grandes problemas del sistema sanitario es que se ha incrementado muchísimo la demanda sanitaria, en parte debido a la extensión sanitaria pública a toda la población. La extensión no ha ido compensada con un aumento de las inversiones en estructura sanitaria. Eso ha implicado que aumente la demanda, y ahí empiezan a surgir los problemas de masificación en los centros hospitalarios, y las colas de espera. Sigue siendo importante el hecho de que no exista una red de asistencia primaria eficaz y que verdaderamente se tiene que recurrir al hospital para cualquier tratamiento. Hemos convertido a la red de asistencia primaria un poco en el portero de la red hospitalaria, que decide si vas o no vas al hospital. No está cumpliendo un papel de prevención, realmente de asistencia, incluso de cirugía menor. Para cualquier cosa en este país tienes que ir a un hospital. La red asistencial está abierta por las mañanas. Si tienes un resfriado ningún problema. Pero si tienes cualquier complicación no son capaces de solucionarlo. Está mucho más burocratizada la red de asistencia primaria que la red hospitalaria" ${ }^{38}$.

Incluso hay opiniones de que el SNS en el fondo no existe, que es un mito. Así se afirma: "El Sistema Nacional de Salud es una de las cosas que forman parte de una cierta mitología. Existe porque se puede englobar dentro de un sistema todas aquellas cosas que forman parte de algo que tiene características estructurales o funcionales en común. Pero creo que cualquier persona de Leyes estaría dispuesto a certificar que el Sistema Nacional de Salud en cuanto a entidad no tiene una carta de naturaleza. Su visibilidad más aparente se la da el Consejo Interterritorial del Sistema Nacional de Salud, que no es una entidad con vocación de permanencia sino una reunión periódica que tienen los responsables de la sanidad del país" ${ }^{40}$. El éxito está en el proceso de descentralización, que fracciona el SNS, pero que crea un sistema más capaz de solucionar los problemas de la población: "Se está avanzando hacia un sistema de salud más amplio porque se está descentralizando. Dentro de este sistema de salud pública en tiempos del Insalud o del INP había sólo los hospitales propios. Después la ley situó a los hospitales de la Administración Local; y después con la figura del consorcio se ha situado a los de la red benéfico-privada. Yo creo que esto irá avanzando hasta los profit, porque en el fondo todo esto debe dirigirse hacia una descentralización. A nivel territorial (político-territorial) se empezó con un sistema muy centralizado: todo en Madrid, y muy supervisado. Lo de Sanidad Nacional era una broma, y lo privado un poco más importante [...] Esto de las Autonomías es un paso más, y luego, pasará a las comarcas, a las provincias, cada uno según se organice, y finalmente pasará a municipios. La descentralización es un proceso. Toda centralización lleva anejo que hay más gente que participe ${ }^{41}$.

El sistema sanitario español actual es doble. No existe realmente un servicio de salud (único, público y gratuito) para la población: «En definitiva tenemos dos sistemas: uno para pobres y otro para ricos. Pero el de los pobres se está utilizando también por los ricos de alguna forma. Mientras las clases más pudientes tienen acceso a los dos sistemas, y cogen lo mejor de los dos, las clases menos pudientes de nuestro país están abocadas básicamente al sistema sanitario público. Con lo cual hay una presión enorme sobre el sistema sanitario público" ${ }^{42}$. Faltan pues muchas cosas para lograr este servicio de salud. Uno de 
los expertos enumera algunas de esas carencias más importantes: "Falta una actuación más decidida por parte de los responsables del Sistema Nacional de Salud de todo el Estado que permita asumir las propuestas de las Comunidades Autónomas que ya las han elaborado, e integrarlas en un sistema de objetivos de salud coherentes. Falta también que el procedimiento de distribución de recursos atienda no sólo a los criterios de población, sino también a los criterios de necesidad de la población, y que tenga en cuenta el mantenimiento de la equidad a la hora de redistribuir los recursos disponibles por el SNS. Falta también, desde el punto de vista de los contenidos de las actividades, darle más importancia al papel confortador que siempre debe tener la asistencia sanitaria. Falta también promocionar las actividades de salud pública entendidas como el establecimiento de una política global de la Administración o del Gobierno; una política global que tenga en cuenta la influencia que sobre la salud de la población tienen las políticas sectoriales productivas en el sector industrial, en el sector del empleo, etc. ${ }^{43}$. Otro experto añade la necesidad de construir una sanidad más humana, más cercana a las verdaderas necesidades de la población: «Existen muchas dificultades para saber qué es buena Medicina, y cómo sería posible que se hiciese buena Medicina. Con frecuencia se habla de calidad de la asistencia, de programas y políticas de calidad, etc. Probablemente detrás de ello exista la preocupación por hacer buena Medicina. Empieza porque la relación entre el médico, el enfermo y el resto de profesionales tenga calidad humana y técnica. Estoy pensando en aquella Medicina que solía hacerse antes de la era tecnológica, en la cual una buena exploración, una mirada del médico al enfermo servía para diagnosticar e incluso para tratar tantas afecciones ${ }^{44}$.

3. En España nunca se ba generado un sistema extenso de sanidad privada. A pesar del supuesto deterioro reciente del sector sanitario público, no parece aumentar el sector privado, ni siquiera en seguros. No queda claro lo que puede ocurrir en el futuro. La mayoría de los/as analistas reconocen que no se ha producido un proceso de privatización en el sector sanitario español. Incluso se rechaza la idea de que pueda realmente producirse: «Nunca ocurrirá que tengamos un mercado absolutamente privado, o un mercado en el que domine lo privado. Esto no pasará porque nos hemos acostumbrado a ver la sanidad como un derecho, y como algo que nos paga el Estado. Por lo tanto, en ningún momento nos planteamos un sistema privado, ni en España ni en Europa. El Estado social ha transmitido a los ciudadanos que hay cosas que son públicas: una es la educación y otra es la sanidad [...] No conozco ningún país en que se haya privatizado el sector sanitario. Yo creo que eso es un camelo. Lo que sí ha pasado es que el sector público ha introducido elementos de gestión propios del sistema privado. Pero sigue siendo financiación pública ${ }^{45}$. Sin embargo, otro experto matiza esta afirmación: «Una cosa es que toda la pobla- ción en principio esté cubierta (no por el sector público sino) por el Estado, y otra es que la oferta de servicios sea exclusivamente pública. Ése era el planteamiento de los sectores más de izquierda cuando se estaba haciendo la reforma sanitaria. Planteaban que dado que era el Estado el que pagaba todo, que fuera el Estado el que diese todos los servicios, para asegurar una mayor equidad. Eso no ha sido posible, ni por intención política, y porque los socialistas no lo tenían claro. Además, eso costaba mucho dinero, y los socialistas no tenían ese dinero ni tenían esa prioridad. Además, eso implicaba el marginar totalmente al sector privado. Eso ha sido imposible porque es un sector que tiene presión política y partidos políticos a los cuales tiene acceso" ${ }^{46}$.

La privatización (relativa) se produce cuando el sector público ha definido bien su estructura. Hasta entonces el sector privado está en una situación de wait-and-see: «El sector privado siempre surge una vez el sector público está definido [...] Ésta es una de las cosas que aún falta por definir. No se sabe si desde el sector público interesará que se desarrolle una iniciativa privada complementaria, y por lo tanto el sector público le comprará servicios, si se seguirá manteniendo una iniciativa pública en que será gestionado con elementos de mercado (como si se tratase de una empresa privada) [...] Es posible que cuanto más se vaya definiendo el sector público (lo cual no es fácil, ya que juegan muchos otros factores como los políticos) se cree una iniciativa privada que complemente al público, porque sea capaz de ofrecernos determinados servicios a un menor coste, o porque sea capaz de ofertar en determinadas áreas en las cuales el sector público no está preparado o no le es rentable crear [...] Para que haya iniciativa privada, aparte de que debe haber un cierto período de expansión económica (para que al inversor le atraiga invertir en sanidad privada), debe definirse también el sector público, qué es lo que cubre y qué es lo que no cubre bien. Así, el sector privado podrá intentar suplantar esas áreas ${ }^{47}$.

La crisis de la sanidad se comunica así al propio sector privado: "Esto de que el deterioro del sector sanitario público no puede comunicarse al sector privado es falso. Al deteriorarse recientemente el sector sanitario público (porque el Estado y la Generalitat no pudieron invertir) metieron al sector privado para que les ayudaran a llevar la cruz del déficit. Claro, la cruz del déficit se les comienza ahora a hacer pesada también ahora a los del sector privado. Esto funciona a ciclos. Ahora el Estado está pasando un mal momento. Lo empieza a pasar mal también el sector privado, y entonces lo volverán hacia el sector público. Si en un momento dado quieren nacionalizarlo todo lo tiene fácil como nunca porque no sólo tienen el Insalud, la Administración Local, y el sector benéfico-privado sino que tendrán cada vez más el sector privado. Para que no hagan esto hay que invertir más en el sector público. Pero el Estado no tie- 
ne dinero. Esto es un pez que se muerde la cola" ${ }^{48}$. La crisis se nota en el aseguramiento privado de la población, y en toda la reconversión del sector privado: "Hay un proceso de reconversión y de transformación muy duro. La verdad es que el sector privado está en crisis total en casi todas las partes. En Cataluña prácticamente todo el sistema sanitario privado con ánimo de lucro está en quiebra; y el sistema sanitario sin ánimo de lucro está parcialmente en crisis (con excepción del Hospital de Barcelona). La Clínica Quirón está en venta, el Hospital General de Cataluña está en quiebra. Es decir, que este país no parece ser capaz de financiar un sector privado competitivo [...] Las multinacionales que invirtieron en hospitales en España se están marchando del país [...] En un sistema en el cual ya hay una cobertura universal por parte del sector público, ¿cuál es la razón de los servicios médicos privados? Yo creo que no va a haber una demanda de servicios privados integral. Entonces, el sector privado puede seguir proporcionando servicios complementarios del sector público; servicios que el sector público proporciona de forma poco satisfactoria para muchas partes de la población y que son (como es la Medicina general, pediatría, asistencia al embarazo); o bien aquellas áreas que el sector público no cubre (como dentistas) " ". Los ejemplos son sobre Cataluña, pues es donde este proceso de reconversión y de transformación es más evidente ${ }^{51}$. La conclusión es que: "El sistema privado es muy parasitario del sistema público y ocupa los nichos de confort, y de atención personalizada que el sector público no cubre " 52 .

Los/as expertos se debaten entre un éxito futuro de la sanidad privada de mercado y un sistema parasitario. Así, uno de ellos afirma que: "No creo que haya un gran futuro para la sanidad privada como tal: sanidad estrictamente privada, con financiación privada; pero sí para la sanidad privada con financiación pública. En la medida en que el Estado sea capaz de concertar servicios de calidad con la sanidad privada, podremos esperar que se desarrolle más el sector privado" "S3. Otro experto analiza la situación con otra perspectiva: "La sanidad privada va a aumentar. Tendrá que tecnificarse, que hacerse más sólido el sistema de seguros privados, pero se va a seguir desarrollando a costa, por supuesto, de las lagunas del sector público, tanto en las prestaciones sanitarias medias, desde el punto de vista financiero tecnológico, como en el confort. Ya ahora mismo se está desarrollando. No sólo en una posición de competiciones estratégicas, sino que se está metiendo en el mercado ampliamente ${ }^{54}$.

La explicación está en el propio sistema de mercado: «Vivimos cada vez más en una sociedad dominada por el mercado [...] Cada vez más vemos cómo intenta reducir lo que entraría dentro de prestaciones públicas. El problema es que estamos en un momento de crisis y la población no tiene capacidad adquisitiva para un nuevo producto sanitario. Pero el sistema sanita- rio público va a seguir teniendo problemas de masificación, y burocratización, se va a hacer viejo, no va a realizar inversiones, y proporciona mala atención a la población. Ahora que vivimos en una sociedad cada vez más desarrollada, cada vez más rica, en la cual la población exige ser tratada como consumidor que tiene derechos, es muy posible que aumenten los seguros privados y también las prestaciones privadas en ciertas áreas de la sanidad. Básicamente es en la atención primaria donde aumentará cada vez más. El sector público quizá se mantenga en la parte más cara, que es la hospitalaria ${ }^{55}$. El éxito del sector privado está asegurado así por el fracaso burocrático del sector público: "Si vas al sector sanitario público todo está muy burocratizado. Eres una cosa, no eres una persona. El sector privado, por necesidad, mejora la atención al público porque sino la gente se va a otro sitio. Las clases más pudientes tendrán acceso a ese tipo de servicios y las no pudientes tendrán que estar masificadas en la asistencia sanitaria pública, haciendo colas, masificados, con mala atención, tratados como cosas, tratados como tontos". Y luego continúa: "No es lo mismo ir a un médico para cualquier problema, aunque sea menor, y tener a un señor o señora que te trata como si fueras una cosa (te trata mal porque su trabajo no depende de que estés contento o no) que ir a alguien que se preocupa un poco más de ti porque sabe que si no lo hace así no vas a ir otra vez. Éste es el gran problema de los profesionales de la Medicina en asistencia primaria en nuestro país: tú puedes ir a un médico y lo puede hacer mal o bien, te puede tratar mal o bien, pero su puesto de trabajo no depende de eso. Tú no tienes capacidad de presionar sobre su calidad de asistencia ${ }^{56}$. El sector público no pretende realmente mejorar la calidad de la atención (no sólo atención estrictamente "Sanitariaa) a la población: «El sector público no intentará mejorar la calidad de sus servicios, en comparación con los servicios del sector privado. No le interesa. En términos globales de rentabilidad el sector primario de la Medicina pública es menos rentable; gasta mucho, en exceso. Es un sector recetario básicamente. Entonces, eso al sector público le preocupa. Para los profesionales ése es el sector de menos prestigio dentro de la Medicina. Por ejemplo, los profesionales del sector primario no van a intentar nunca cambiarlo ni mejorarlo. Ya les va bien que esté burocratizado y que no haya presión sobre ellos. Van allí, dan sus recetas, hacen lo mínimo y fuera; se van a otro sitio. Además, si se quita demanda al sector público mejor, que está demasiado cargado. Siempre hay personas que intentan mejorarlo, que piensan que se puede mejorar; pero no está en la agenda política en absoluto. En la agenda política sólo está el objetivo 'cobertura universal': que todo el mundo se cubra independientemente de como sea el servicio. Y así aseguras ya la igualdad. ${ }^{57}$. Esta idea remacha la teoría del sistema doble en sanidad, que son mutuamente parasitarios (más bien simbióticos), y que en el caso español caracteriza su estructura actual ${ }^{58}$. Un exper- 
to llega a señalar que en el caso español sector privado y sector público en el fondo es lo mismo.

Por supuesto, hay expertos que defienden una posible expansión del sector privado: "Como el sistema sanitario es un proceso en el que intervienen todos, para poder conseguir un comportamiento corresponsable todas las carteras de todos los protagonistas tienen que verse afectadas. Si no tienen recursos habrá que instrumentar el procedimiento para facilitárselos para que puedan pagarlo. Jamás en una ordenación como ésta tiene que ser gratuito. La gratuidad queda sencillamente para la marginación, no para las personas responsables. El sistema tiene también que prever los muelles para la marginación que todo proceso social lleva consigo" ${ }^{59}$. Pero en general la idea es que -de cara al siglo XXI- los cambios van a ser mínimos: "No creo que las cosas vayan a variar. Obviamente dependerá de en qué medida la percepción de los ciudadanos sea que el sistema público se deteriora y de hasta qué medida los esquemas de provisión privada sean inteligentes y bien organizados. Hasta ahora, no percibo en el horizonte, excepto algunos destellos (como en Cataluña llevados por algunas gentes valiosas), o signos de que exista un empresariado sanitario español en el mundo privado capaz de ofertar productos. Entre otras cosas porque técnicamente es muy difícil hacer rentable esto de la sanidad; porque al final todos los ciudadanos terminan muriendo, y antes de morir somos tremendamente caros ${ }^{60}$.

\section{Se ba avanzado mucho en el proceso de transferencias - a} las Comunidades Autónomas - de la sanidad. Existe una polémica sobre si en el futuro esta descentralización generará más o menos desigualdades en la población, y sobre todo los tipos de desigualdades que pueden incrementarse. Los dos procesos políticos más importantes que se producen en España a partir de 1976 son la democratización y la descentralización. Para el sector sanitario el segundo es incluso más importante que el primero. Se reconoce que: "En realidad en España se está avanzando hacia un país casi federal. Aunque formalmente no se diga que es un país federal, el camino que está siguiendo es éste. En media España, la gestión del sistema, y de facto el sistema, está traspasado a las Comunidades Autónomas. En la otra media España está traspasado al sistema de salud pública, y los servicios de atención sanitaria públicos serán probablemente traspasados. Ha habido un esfuerzo muy importante en los diez últimos años en pro de la equidad, con una inversión muy notable en aquellas partes del Estado que tenían coberturas menores, que eran causas de conflicto. Pero básicamente el volumen de la mejora de la red hospitalaria pública ha sido espectacular ${ }^{61}$.

Pero algunas personas consideran que no ha existido una verdadera descentralización sanitaria, sino tan sólo una desconcentración de recursos: «El proceso de transferencia se ha caracterizado, sobre todo, por una desconcentración ad- ministrativa, más que por una descentralización de funciones. Las Comunidades Autónomas están asumiendo unas actividades que han venido muy determinadas por su origen. Además, siguen recibiendo unas transferencias económicas para hacer frente a estas actividades que son en la mayoría de los casos finalistas. De manera que la capacidad de maniobra de las Comunidades Autónomas respecto de la organización sanitaria es relativamente pequeña. No creo que el proceso de transferencias haya sido un proceso de descentralización más que un proceso de desconcentración * ${ }^{62}$. Esta desconcentración ya se había iniciado durante el régimen de Franco ${ }^{63}$.

Los beneficios de la descentralización son evidentes. Así lo explica un experto y político sanitario: "La teoría de las Autonomías es que al acercar la gestión al ciudadano se podrán dedicar más recursos de sanidad si son necesarios allí. Se trata de la teoría del concepto de la descentralización autonómica. Descentralizar la gestión significa poner el poder político a un nivel más cercano al ciudadano. Pero no sabemos lo que pasará con la descentralización llevada a la práctica. Tampoco hay evidencia de que esta descentralización haya generado desigualdades. Lo que sí está claro es que en las Autonomías en las que se ha transferido la sanidad se ha desarrollado mucho más la sanidad: se han creado nuevos centros de asistencia primaria y se ha invertido más en sanidad [...] Quizás parte del proceso de descentralización lo que hace es permitir que en aquellas áreas donde haya más necesidad o sensibilidad se puedan dedicar más recursos ${ }^{64}$. El problema de que se puedan crear desigualdades se ve como un mal menor, $\mathrm{e}$ incluso como un beneficio debido al estímulo de la competitividad: "No es necesariamente malo que alguien no esté bien atendido. La diversidad es una fuente de riqueza y es una fuente de competición en algo positivo [...] No me preocupan mucho las desigualdades de este tipo. Hasta pueden ser incluso beneficiosas y pueden ser un elemento de debate y de dinamización" ${ }^{65}$.

Pero en general los/as expertos acentúan más los perjuicios del sistema de descentralización. "Cuando todas las transferencias estén desarrolladas habrá las desigualdades correspondientes al desarrollo que cada Comunidad haya podido conseguir. Una dinámica comunitaria mayor provocará una desigualdad. Pero, supuestos unos mínimos básicos para todos los españoles, eso a mí no me parece mal. Las desigualdades serán del tipo de asistencia sanitaria tecnológica, de mejor acceso a la formación profesional en unas Comunidades que otras, y de niveles de asistencia distintos. Que no es una cosa distinta a lo que está sucediendo ahora. Porque en estos momentos un ciudadano de Badajoz obviamente tiene peor asistencia médica que un ciudadano de Madrid, o que un ciudadano de Barcelona ${ }^{66}$. En general, se ve en términos de desigualdades regionales y de dinero ${ }^{67}$. La solución puede ser un poder moderador: "Todavía no se ha inventado ningún sistema por el cual los pobres no 
dejen de pagar las frivolidades o las veleidades de los poderosos. Por lo tanto, un proceso de transferencias no lleva consigo una mayor equidad. Al contrario, lleva consigo la necesidad de un apoyo estructural de poder para compensar a los débiles, y poder neutralizar los abusos que ineluctablemente se producen de los poderosos sobre los débiles. Teniendo en cuenta la diversidad cultural en que nos movemos en España: el proceso de transferencia de descentralización de poder y desconcentración de funciones puede ser un bien o un mal, de todo habrá [...] Si no hay un poder moderador para forzar las transferencias del que tiene hacia el que no tiene, entonces aumentarán las desigualdades. Si hay un poder de moderación habrá una redistribución de recursos y por lo tanto una aminoración de desigualdades, pero no habrá una igualdad " ${ }^{68}$. Se acepta que se producen diferencias, y que el principio de equidad se hace problemático, aunque se insiste que esto no es necesariamente negativo ('para quién?): «Si realmente se produce o se sigue produciendo una descentralización puede generar más desigualdades dependiendo de cómo se hiciera en cada sitio. El hecho de que se descentralizaran realmente las políticas de salud supondría que las Comunidades Autónomas podrían establecer prioridades distintas, y por lo tanto tendrían impactos y consecuencias distintas sobre la población. Los organismos políticos o las representaciones políticas que tienen el poder político en las Comunidades Autónomas asumen junto con el Gobierno central, la necesidad de que la política sanitaria respete una finalidad genérica y equitativa. Se pueden establecer convenios y acuerdos, de manera que se concrete y se formule adecuadamente el principio de equidad, y se pueda respetar. Es evidente que una descentralización real supone una diversificación, y una diversificación siempre implica que puede haber más desigualdades. Lo cual no tiene por qué ser precisamente negativo" ${ }^{69}$.

Una posición más analítica es que el proceso de transferencias reproducen o cristalizan el modelo actual de desigualdades. "Las zonas más ricas tienen la capacidad de tener una mejor asistencia sanitaria. Pero no es un problema de si genera o no desigualdades, sino un problema de que reproduce las desigualdades. Ya de por sí nuestro país tenía desigualdades en recursos sanitarios, en oferta sanitaria; las zonas más ricas tenían una mejor oferta sanitaria. Cuando se construye un sistema más regional, más autonómico, lo que se hace es perpetuar este tipo de desigualdades y que no existan nivelaciones. Una Comunidad Autónoma pobre no puede invertir tanto en sanidad como una Comunidad Autónoma rica [...] Por dinámica la descentralización lo que asegura es que cada Comunidad Autónoma tenga un sistema sanitario propio, adecuado a sus necesidades. Con lo cual sistemáticamente las zonas más ricas tendrán un sistema sanitario mejor ${ }^{70}$. El sistema de transferencias añade burocratización al sector sanitario: "La descentralización puede dar paso a una mayor agilidad y a una mayor rapidez en la toma de decisiones. Pero el peligro que se está viendo ahora mismo es que, paradójicamente, hay una mayor burocratización. También hay una toma de decisiones más, o por lo menos igual de, arbitraria que la que podría haber con un Gobierno central, ${ }^{71}$. El sistema pues no cambia casi nada: "Las desigualdades que puedan generarse en la población, como consecuencia de las transferencias, no es un tema de gran relevancia. Para empezar, la salud de la población depende relativamente poco de los servicios sanitarios. Con el actual esquema la equidad en el reparto territorial de recursos creo que está razonablemente asegurada dentro de ciertos límites" ${ }^{72}$. Otro experto razona igualmente la inutilidad del proceso de descentralización para producir cambios en la estructura básica de la salud de la población: "Las transferencias no están cambiando la forma como el sector sanitario actúa. Debería de haber un cambio muy radical en cómo un sistema sanitario es gestionado por una determinada Comunidad Autónoma, para que, teniendo en cuenta el limitado impacto del sector sanitario, esto aumentase o generase menos desigualdades de las que ya había. ${ }^{73}$.

Una idea es que el proceso de descentralización no se acabe en las Comunidades Autónomas, sino que continúe hasta el nivel más local (e incluso llegue hasta la población): aSi estamos descentralizando en Autonomías, creo que mejorará la homogeneización de la salud dentro de las Autonomías. Pero es posible que entre las Autonomías haya diferencias. Pero es que estas djferencias de sanidad no se deben a que el centralismo vaya mejor. Para avanzar tienen que tener un mayor poder económico, y si no lo tienen, no van a avanzar, por mucho que se hable demagógicamente de 'solidaridades'. No sólo son los hospitales y los duros [dinero] que se puedan gastar en asistencia, en la primaria, o en la salud pública, o en lo que sea. A medida que las comarcas o los municipios avancen socioeconómicamente va a aumentar la demanda, y los otros van a tener menos demanda. Si no se colma la demanda de los que están más avanzados dirán que no es igualitario [...] Las transferencias no se van a acabar. Habrá un momento en que la gente deberá corresponsabilizarse de su salud, que no lo dejen todo en manos de los médicos, de los hospitales, y de los gerentes, sino que tendrán que tomar más parte ${ }^{74}$. La segunda idea es que hay que profundizar en las transferencias hacia la Unión Europea: "Debe haber también una transferencia bacia arriba. Es decir, va a haber un momento en que los Estados nacionales van a tener que pasar muchas transferencias a la $\mathrm{Co}_{-}$ munidad Europea, y éstos algún día lo habrán de pasar a la comunidad mundial. Veo las distancias intermedias cada vez más complicadas ${ }^{75}$

5. Algunos estudios afirman que la mejora de la salud de la población no depende tanto de los recursos sanitarios como de la estructura social y del desarrollo económico global de la sociedad. Conviene saber lo qué se podria cambiar en la estructura social para mejorar el nivel de salud de la población. Lo dificil es 
pensar cómo se puede realizar eso en el futuro. Elevar el nivel de salud de la población no es un objetivo final único, sino que debe ser evaluado en relación con la calidad de vida global. Un experto en salud pública reconoce incluso esta dependencia de la salud respecto de una política general más amplia: "Cambiar la estructura para mejorar el nivel de salud de la población implicaría que una de las prioridades políticas, en lugar de incrementar la riqueza, fuera conservar y promover la salud de los ciudadanos. Es un desideratum que no ha establecido ningún gobierno [...] Aumentar la salud de la población tampoco es un objetivo en sí mismo, sino que en todo caso el incremento de salud de la población es un instrumento para que la gente viva mejor. También sirve para incrementar las posibilidades de producción y riqueza de una sociedad [...] Aunque la salud tenga dificultades para considerarse un objetivo prioritario de los gobiernos, ha de considerarse como un objetivo al menos instrumental. El derecho a la protección de la salud es un derecho de la población que reconoce explícitamente la legislación vigente en nuestro país. Supone un ejemplo de concreción en disposiciones positivas que permitan llevar a cabo o conseguir las máximas cotas posibles de protección efectiva de la saludd ${ }^{76}$.

Las desigualdades sociales influyen —cada vez más— en el nivel de salud de la población. Así como la salud es un componente importante de la calidad de vida global: sa salud y la enfermedad tienen, no solamente una distribución social desigual, sino una causación social (condiciones de vida, condiciones de trabajo, estilos de vida, educación) causan enfermedad o causan salud, o tienen como producto salud o enfermedad. Una gran parte de la enfermedad tiene causación social. Existe un aparato, que es el sanitario, que no hace frente a la causa del problema. La causa del problema según la Medicina son unos gérmenes; según los sociólogos la causa del problema son elementos variables sociales y culturales [...] La sanidad es un mal 'parche' a los temas de salud. De hecho, la Medicina lo que asegura es que siempre haya enfermedad, porque no ataca la raíz de la enfermedad, sino a los elementos que muestran la enfermedad. Siempre va a haber enfermedad porque no tenemos una organización social dedicada a atajar la enfermedad. Si una parte importante de los problemas son estilos de vida, pues necesitamos un aparato que haga frente a eso. La sanidad no lo va a hacer. Si son las condiciones de vida, sanidad no hace nada al respecto. Si es la pobreza, la sanidad no hace nada al respecto. $\mathrm{Si}$ son las condiciones de trabajo, la sanidad no hace nada al respecto, si es el estrés tampoco. Ese tipo de variables son las que afectan y las que crean enfermedad. La sanidad no es nada. Solamente es algo intermedio que intenta solucionar lo que se le presenta, pero no soluciona el problema " $"$. Ambas desigualdades - sociales y sanitarias - se refuerzan. No está clara la forma de realizar cambios estructurales para mejorar esa combinación de desigualdades ${ }^{78}$.
Los factores sociales de desigualdad son múltiples: "El nivel de salud depende, fundamentalmente, de la estructura social y del desarrollo económico de la sociedad. En este momento en España tenemos varios ejemplos. Las personas jóvenes se mueren fundamentalmente de droga, sida y accidentes de tráfico. Son tres problemas de nuestra estructura social. Así podríamos continuar con otros muchos temas o sectores de la sociedad " ${ }^{79}$. La (mala) distribución de la renta es históricamente uno de los problemas estructurales más importantes en España; sobre todo si se compara con otros países de la Unión Europea. El sector sanitario no puede solucionar este problema: aLa Medicina intenta, pero no afecta (jGracias a Dios;) cómo viven las personas. Por tanto, su incidencia en la salud es mínima; es una Medicina reparadora. Hay una enfermedad; muy bien, yo la curo, y al día siguiente vuelve otra vez. Claro que vuelve otra vez: el señor o la señora vuelve a sus malas condiciones de vida, malas condiciones de trabajo, malos estilos de vida, estrés enorme. Eso no lo solucionan. Una mejor distribución de la renta contribuiría a mejorar, pues comenzaría a evitar algunos problemas de salud que tenemos en nuestro país. En nuestro país hay enormes bolsas de pobreza, cada vez más acuciantes. Los problemas del paro y la salud no están demasiado estudiados [...] Pero sin duda el paro, y la pobreza, en nuestro país, provocan niveles de enfermedad altísimos que podrían ser reducidos con una mejor distribución de la renta" ${ }^{80}$. De cara al siglo XXI el paro se considera como uno de los problemas con una mayor incidencia (negativa) sobre la salud de la población: el desarrollo en sí mismo es un factor de mejora de la salud. El paro es un elemento que en estos momentos está distorsionando todos los niveles sanitarios. No tiene ningún sentido el tener un sistema económico como el actual, y una población en paro como tenemos. La solución del problema del paro mejoraría las cosas que en la estructura social española están dependiendo de los elementos estructurales de los sistemas. También influirá, en términos generales, la modificación de la política ambiental que en estos momentos no es excesivamente ecológica; la política de transportes y la política de urbanismo de las grande ciudades que cada día están menos a medida del ser humano, y más en contra de él ${ }^{81}$.

Otras desigualdades, difíciles de evitar, dependen de las redes sociales y de la capacidad de influencia social de los grupos sociales: aQuién puede utilizar el sistema sanitario más y a quién puede servir más? Pues a veces quien sabe manejarse mejor, porque hay listas de espera. Pero si hay unas relaciones personales o profesionales, uno puede tener acceso a ser atendido en menos tiempo, por el especialista que prefiera y en el centro que desea. Al final resulta que son otras cosas ajenas al sistema las que hacen que puede funcionar para unos mejor y para otros peor. Es importante que cambie la propia estructura social, que cambie la estructura de clases, de manera que haya una mayor igualdad social. Tiene que empezar por un reparto de la riqueza más equitativo (y no lo que está pasando ahora: un estrangulamiento de algún agente), $y$, por otro lado, por un 
reparto mayor de la educación, es decir, que con el tiempo la gente vaya adquiriendo una mayor formación ${ }^{82}$.

Los estilos de vida son cada vez más causantes de las desigualdades en el nivel de salud de la población. Un experto lo ve asi:: "Más que la estructura social, son importantes los factores de riesgo social. Los estilos de vida determinan mucho más de lo que creemos el nivel de salud general de la población. En los países industrializados somos muy negligentes al respecto del tema. Que la gente deje de fumar, que pasee 30 minutos al día, que cuide un poco de la dieta y que tome alcohol con moderación es el mejor tratamiento del accidente vascular-cerebral, contra las enfermedades coronarias. Esto es algo de lo cual creo que no somos conscientes, sobre todo en una sociedad como la española en que las tasas de fumadores siguen siendo muy altas. Es decir, no todo es cuestión de recursos sanitarios. Los recursos sanitarios están para los enfermos, pero hay otras muchas medidas que están para que la gente no enferme ${ }^{83}$. Pero las actitudes y comportamientos individuales son dificiles de cambiar: "Todo es importante. Hay un nivel de implicación individual: las personas cada vez son mas responsables de su propia salud. Pero por otra parte es muy difícil cambiar actitudes y comportamientos. No se trata quizás tanto de mejorar el nivel de salud como de mejorar aspectos de la calidad de vida. Aunque el nivel de salud sea de los aspectos de la calidad de vida, lo que es importante no es que se esté mejor o peor en el nivel biológico sino que uno perciba que se siente bien o que se siente mal. Puedes tener la pierna rota y los pulmones hechos un desastre, y a lo mejor pues te sientes bien porque estás contento porque te sientes con apoyo, gente cercana, etc. Por lo tanto, a mí me parece que el esfuerzo es más en calidad de vida, que no en nivel de salud ${ }^{84}$.

La educación se ve como una de las formas mejores de elevar el nivel de salud. "La primera medida relacionada con la estructura social y el desarrollo económico de población para mejorar el nivel de salud es combatir las desigualdades. Las luchas contra esas desigualdades donde tienen mayor impacto de futuro es en la educación; y dentro de la sanidad en el acceso a los servicios para los grupos sociales más marginales ${ }^{85}$. La educación sigue siendo la solución liberal, educada, para transformar la sociedad. Aun cuando su efectividad ha sido pequeña, e incluso - a veces - generadora de más desigualdades en el nivel de salud de la población ${ }^{86}$.

\section{Impacto de las políticas en la salud de la población}

6. No queda claro la razón por la que actualmente el nivel de salud de la población de nuestro país parece ser tan alto. Es inexplicable la buena salud de los españoles (sobre todo de las españolas). La esperanza de vida de las mujeres en nuestro país ba superado los 80 años; es una de las esperanzas de vida más altas del mundo. No se sabe muy bien cómo se explica ese excelente nivel de salud de la población española. Tampoco se sabe si esa buena posición internacional cambiará en el futuro. Conviene definir mejor las causas que pueden producir un cambio de esa posición en el futuro. Los/as expertos entrevistados en el Delphi suelen ser más pesimistas que los propios datos de la realidad. No terminan de creerse que el nivel de salud de los españoles/as sea tan alto: "No es verdad que la salud de los españoles sea tan buena. Lo que pasa es que seguimos utilizando indicadores de salud que quizás no sean los adecuados. Lo importante no es que la esperanza de vida de los españoles llegue a ser tan alta; lo importante es cómo son los últimos años de vida de los españoles. Seguimos teniendo un grupo muy grande de población que entre los 50 y 70 años viven bastante con la enfermedad crónica (sobre todo tumores). La impresión es que la calidad de vida de los españoles no es tan buena como nos creemos en cuanto al nivel de estado de salud. ${ }^{87}$. Se tiende a decir que la esperanza de vida no es un buen indicador de salud de un país (o grupo social). Técnicamente: «Medir el nivel de salud de la población con un indicador tan grosero [sic] como la esperanza de vida no es adecuado. La esperanza de vida es un indicador sensible y adecuado en aquellas situaciones en que hay grandes diferencias de salud en la población. En los ámbitos en los que se produce unas esperanzas por encima de los 65 ó 70 años, la esperanza de vida mide demasiado groseramente las diferencias. No creo que tenga demasiada importancia el hecho de estar un año arriba o un año abajo en la esperanza de vida " ${ }^{88}$. La esperanza de vida como indicador puede ser rechazado con una explicación diferente: "Los indicadores sanitarios que se utilizan actualmente (esperanza de vida, mortalidad por enfermedades cardio-vasculares, etc.) son indicadores que proceden del paradigma médico. Ésa es una razón por la cual yo no estoy trabajando demasiado en temas de salud últimamente. Todavía no he sido capaz de construir una visión alternativa y propia para liberarme del dominio médico-sanitario cuando hablamos de temas de salud. Como sociólogo hay que romper con ese tipo de indicadores, con ese tipo de análisis [...] Estamos haciendo una sociología de la medicina o de la salud para ellos. Con sus indicadores, con sus paradigmas, con sus formas de explicar las cosas, frente a una sociología de la salud propia, nuestra. Pero eso es más difícil de hacer, cuesta más. Hay intentos de hacer una sociología de la salud propia. Sin embargo, la parte financiada a nivel internacional de la sociología de la salud es la parte que se dedica a mejorar el sistema sanitario pero no es un problema de mejorar el sistema sanitario, sino la salud de la población. Mejorarla 0 asegurarla pasa por otras cosas además de la sanidad. El tema 
es encontrar indicadores nuevos, formas de verlo nuevas, discursos nuevos ${ }^{89}$.

Una forma de analizar ese indicador es medir no sólo la supervivencia, sino la calidad de vida de los últimos años: La esperanza de vida global no da cuenta de los problemas de salud de la población superviviente. Cada vez se expresan más en patologías que no son letales, o que tienen una letalidad baja. Un aumento de la esperanza de vida sin mayores complicaciones puede ser completamente compatible con problemas de salud graves en la población. Lo que se intenta es calcular indicadores un poco más refinados, como la esperanza de vida libre de incapacidad o en buena salud [...] La esperanza de vida de las mujeres, que es mucho más alta que la de los hombres, se reduce drásticamente al considerarla en buena salud, libre de incapacidad. De manera que a partir de los 65 años los datos españoles señalan que la esperanza de vida libre de incapacidad es menor en las mujeres que en los varones" ${ }^{90}$. Se trata primero de añadir años a la vida, luego de añadir vida ( $y$ salud) a esos años ${ }^{91}$.

Sigue siendo un misterio la razón de la buena salud de la población en España; y hay explicaciones variopintas ${ }^{92}$. La razón más esgrimida es la supuesta cultura y dieta mediterránea. "Tiene que ver mucho más con las condiciones de vida de los ciudadanos de nuestro país y en su estilo de vida. La forma mediterránea de aproximarse a la vida de alguna forma, la dieta mediterránea, el estilo de vida mucho más alegre y que disfruta de la vida, pienso que tienen mucha influencia en la buena salud de los ciudadanos españoles. Pero como ahora queremos ser europeos, pues cada vez somos más sosos, aburridos, preocupados, con más estrés, disfrutamos menos de la vida. Eso va a implicar, a la larga, bajadas en los niveles de salud ${ }^{93}$. Dicho de otra forma, pero más optimísticamente: "España tiene una de las mejores calidades de vida del mundo. Dentro de la calidad de vida está el clima, se come más saludablemente que en Estados Unidos (menos mantequilla y menos colesterol). Hasta ahora se vive con un poco más de calma que en esos países protestantes que viven más deprisa. Además, hay un sistema sanitario que no está mal; quizás mata menos que mataba antes [sic] Yo creo que si el país sigue progresando, España en su conjunto no tiene por qué disminuir el nivel de saludo ${ }^{94}$. Es un misterio que depende seguramente de varias variables: "Es un enigma, porque hemos sido un país bastante pobre. A pesar de eso, tenemos unos niveles de salud muy superiores a los de países con nuestro mismo desarrollo económico, incluso países más desarrollados que el nuestro [...] El secreto es la calidad de vida. Más concretamente podríamos hablar de nuestra red social, de nuestra red de apoyo social, y de factores bastante psico-sociales como son las relaciones entre las distintas personas, la estructura familiar, las relaciones en la falta de competitividad, la seguridad en muchos aspectos de la vida, tanto afectivos como económicos. Otro aspecto importante de nuestra calidad de vida es nuestra nutrición. También está demostrado que la nutrición en el área del Mediterráneo es muy sana, con muchas verduras, frutas y pescado, que son todos ellos componentes de una dieta sana, y con un consumo relativamente bajo de grasas animales" ${ }^{95}$.

Otra posible explicación es el cambio social acelerado en unas pocas generaciones: "Los que están viviendo ahora mucho, esta generación de personas mayores, es la primera generación que está viviendo tanto. Es gente que apenas iba al médico, qué sistemas de trabajo han vivido, iy la guerra! Sin embargo, han llegado hasta aquí más que todas las generaciones anteriores. Porque en el fondo ha habido unas condiciones generales que han cambiado: de higiene (en las casas empezó a haber agua corriente), las mujeres empezaron a tener menos hijos. $\mathrm{Ha}$ habido unas condiciones generales" $"$. Puede ser una combinación de país todavía poco desarrollado en unas cosas, y con los beneficios del desarrollo: "Ahora estamos disfrutando de formas de organización social y de formas de vida de los años cincuenta y sesenta, que es cuando esta población que ahora vive tanto era joven y llevaba un tipo de vida determinado. En algunos sentidos uno estaría tentado de pensar que llevaban un tipo de vida más sano, y de especular incluso que más feliz del que llevamos ahora. Los años sesenta permiten pasar ya de las penurias, y empezar a disfrutar de un cierto nivel de vida sin perder ciertas formas de vida, no diré austeras, pero sí más sanas o más saludables" ${ }^{97}$. La mejor explicación de la esperanza de vida elevada en España (sobre todo en las mujeres) es la propia estructura familiar. La familia española es muy cuidadora: aLa mujer española ha cuidado de la casa, de los hijos, de los ancianos, y esto ha repercutido (sin estar institucionalizado, sin estar contabilizado como recurso) en la mejora del nivel de vida. Lo cierto es que los niveles de vida de la población (medidos con indicadores sanitarios) no se corresponden al nivel de salud que nos correspondería como nivel de desarrollo. Ahí hay algo que no está explicado [...] Si esto es así, estamos vaticinando que dentro de 15 años el nivel de salud va a bajar porque la mujer se incorpora al trabajo, y va a dejar de hacer estas funciones. O bien van a ser tenidas que tomar institucionalmente por parte de unos servicios especializados ${ }^{98}$.

Los/as expertos son pesimistas respecto del futuro. El nivel de salud empeorará. En parte porque la coincidencia de desarrollo/subdesarrollo ya no se dará en la Europa meridional: "Estamos en un estado transicional de la evolución de las enfermedades en España, en que mantenemos lo bueno de no ser un país muy desarrollado, y lo menos malo de ser un país desarrollado. Es muy posible que dentro de unos años las tasas de tumores continúen aumentando. Las tasas de enfermedades cardio-vasculares no están disminuyendo tanto como nos gustaría (incluso no me extrañaría que estuviesen aumentando), el 
tabaquismo está aumentando mucho. Comenzamos a tener determinados patrones de estilo de vida ligados a ciertos factores de riesgo propios de la sociedad occidental como son tabaquismo (sobre todo mujeres, y por lo tanto cáncer de pulmón en mujeres), y determinados tipos de tumores. No podemos ser muy optimistas. Estamos en un estado de transición en el cual salimos de un país menos desarrollado, y por lo tanto vamos a tener unas tasas de esperanza de vida menores. Tengo serias sospechas de que en los próximos años no vamos a lograr mejorar esta posición, e incluso podríamos ponemos por debajo" " Lo mismo asegura otra experta: "En los próximos años va a haber una nivelación con el resto de Europa. Vamos a tener menos enfermedades infecciosas de países menos desarrollados (como serían las infecciones toxi-alimentarias) y vamos a tener más enfermedades de países desarrollados como el cáncer (determinados tipos de cáncer), o las enfermedades cardio-vasculares. Esta nivelación se deberá fundamentalmente a que estamos teniendo un gran aumento de hábitos tóxicos como el consumo de tabaco y el consumo de alcohol. El consumo de tabaco es mucho más elevado que en la mayoría de países europeos, y se puede esperar una epidemia grande de cáncer de pulmón en los primeros años del siglo XXI. También tenemos problemas de uso de alcohol fundamentalmente en los jóvenes. Aparecerán nuevos problemas de salud más parecidos a los que ya hay en Europa y menos parecidos a los de países del Tercer Mundo ${ }^{100}$. La visión pesimista lleva a prevenir las consecuencias negativas con una política adecuada: "Es posible que los cambios en los hábitos dietéticos inducidos por la moda, o por los intereses comerciales, puedan minar eventualmente esta buena posición. También es posible que algunos de los factores que tienen que ver con la salud experimenten una evolución hacia peor. Por ejemplo, en el caso del tabaquismo, sedentarismo, alto grado de urbanización de nuestra sociedad, práctica de deportes (cosa que está al alcance de pocos ciudadanos) [...] En ese sentido, sería muy recomendable la existencia de una política pública explícita que tenga objetivos cuantificados de salud para la población del país, o para sub-grupos de esta población" ${ }^{101}$.

7. Hay diversidad de opiniones sobre si las desigualdades sanitarias de la población son grandes en nuestro pais. Tampoco queda claro si en el futuro van a aumentar o disminuir, y por qué. Preocupan aqui todo tipo de desigualdades: por clase social, ingresos familiares, género, geográficas, campo/ciudad, etc. El tema de desigualdades no es sólo central a la sociología sino también a la sociedad. Es el debate histórico de la equidad y de la igualdad: "No estoy seguro de si cuando los expertos hablan de equidad, realmente están pensando también en justicia. Porque no creo que el concepto de justicia y sus diferentes dimensiones (lo que alguien llama 'las esferas de la justicia') sea algo en lo que estemos pensando lo suficiente. En el sistema espanol hay un volumen ingente de injusticias que se cometen con la población en general, con los pacientes en concreto, y con muchos de los profesionales que trabajan en él. Esto podría desarrollarse quizás con casos concretos muy cercanos al mal-trato y a la mala-praxis; pero también cercanos a la demagogia con la que el sistema trata en ocasiones los temas de prevención de las enfermedades y la llamada promoción de la salud " ${ }^{102}$. Pero curiosamente la igualdad ya no está de moda; en el sector sanitario actual se habla mucho más de control que de igualdad: "Ya hace muchos años que en España no se habla de desigualdades. Se habla en cambio de que los viejos consumen pastillas anticonceptivas o no sé qué. Se trata de echar la culpa a la víctima sistemáticamente. Pero no se habla de desigualdades. Se cree que aquí tenemos un sistema donde todo el mundo en teoría tiene acceso, y, por lo tanto, la desigualdad es falsa. Hay muchas desigualdades ${ }^{103}$. El problema es la carencia de datos y estadísticas sobre este tema central: «En España parece como si no hubiera clases sociales desde el punto de vista de las estadísticas. Esto impide tener a mano este tipo de análisis. Sería muy recomendable, y se ha pedido por diversas instancias y en diversas ocasiones, que haya una clasificación social de los españoles que permita saber en nuestro país quiénes mueren más frecuentemente y de qué cosas según su clase social ${ }^{104}$.

Las desigualdades sociales y sanitarias existen, aunque en España apenas si se han medido empíricamente: "El gran problema de las desigualdades sociales es que existen en todos los países. Ignoramos si son grandes o no. Sabemos que existen en sistemas privados como los americanos, en sistemas públicos como los británicos, y en Suecia. Por lo tanto, existen. Vinculadas al paro y a la crisis, las desigualdades han de aumentar. Tenemos desigualdades de clase social con cualquier medida que hemos tomado, con ingresos familiares, con género [...] Hay desigualdades geográficas sobre todo en lo que es lo rural y lo urbano por razones obvias: las ciudades concentran la alta tecnología y ello tiene un gran impacto sobre las desigualdades sanitarias de la población. También supongo que hay regiones que tienen más desarrollada la sanidad que otras: el nivel de desarrollo de Madrid y Barcelona es mucho mayor que el de otras regiones " ${ }^{105}$. Se defiende la idea de que las desigualdades por clase social no son demasiado elevadas en nuestro país, aunque no se tienen datos precisos: "Las desigualdades sanitarias respecto de colectivos concretos sí que son manifiestas: los ancianos están discriminados, la mujer está discriminada. No me atrevería a cuantificar, a decir si son discriminaciones numéricamente grandes o pequeñas. También hay unas desigualdades territoriales. Las zonas rurales están francamente por debajo en el tema de asistencia de las zonas urbanizadas. Estos tres elementos: la discriminación por sexos, por edad y por territorio, a mi modo de ver es grande. En cambio, por clase social la desigualdad es menor, porque la asistencia sanitaria está en estos momentos al alcance de todos. Sí que hay una discriminación cualitativa. El sistema sanitario español público permite a todos los españoles acceder al mismo, bien porque tengan car- 
net y paguen sus cuotas, bien porque tengan beneficencia y el Estado pague por ellos, o bien porque paguen ellos sus propios servicios. Entre todos estamos sosteniendo un dispositivo del cual se pueden beneficiar también los ricos (dicho entre comillas) sin que contribuyan. ${ }^{106}$. Pero no sólo hay más enfermedades en la clase baja española, sino que las consecuencias son mayores (peores): aEn las clases bajas los problemas de salud se cronifican mucho más que en las clases altas. En las clases altas los problemas de salud no llegan nunca a convertirse en crónicos o en handicaps. De alguna forma son parados antes. En las clases bajas no. El porcentaje de problemas graves de salud que acaban siendo un impedimento para el disfrute de la vida es enorme. Las diferencias son considerables, a pesar del sistema sanitario que les trata a todos igual en teoría; pero que no es asín ${ }^{107}$.

La crisis económica puede estar exagerando estas diferencias: "Desde el momento en que mantienes desigualdades en disfrute de la vida, o en calidad de vida, tienes desigualdades en salud. No sé si van a aumentar o disminuir, pero se van a mantener seguro. Deben estar aumentando ahora, con los problemas de la crisis, que afecta principalmente a las clases dependientes del trabajo. Así, por ejemplo, aparecen los problemas de los parados, con unos problemas de salud enormes $^{108}$. Las diferencias pueden, al mismo tiempo, disminuir (para la población general) y aumentar (para una clase marginada). Es la teoría de la underclass, o subclase, que es un grupo social marginado, dependiente y enfermo: aPara la mayor parte de la población, las desigualdades van a disminuir. Pero se va a aumentar la desigualdad entre la población marginal y el resto de la sociedad. La población que actualmente está en el estrato de personas sin formación profesional, sin ocupación, sin ingresos fijos, puede tener hoy mejor nivel de salud que el que tendrá en el futuro. La marginación se va a extremar, pero en cambio la mayor parte de la población se va a nivelar. Todo esto es más grave en España, porque tenemos una elevada proporción de desempleo en jóvenes que no tienen ninguna formación profesional, y que en el futuro van a continuar desempleados durante muchos años. Esto va a crear una clase marginal importante, y este grupo de personas van a tener peores niveles de salud. ${ }^{109}$.

En España, las diferencias regionales y campo/ciudad son también muy grandes. No se trata -como señala un expertode gastar más recursos: "Según los médicos, cuanto más gasten en medicina mejor irán las personas. Tampoco estoy del todo seguro. Cuanto más dinero tengan más podrán gastarse en medicinas. Quizás deberían ir de vacaciones para mejorar la salud, quizás deberían tener un coche con air bag. Es complejo. Evidentemente, hay más oferta de tratamiento médico en la ciudad, es más fácil el acceso, la gente es más consciente, van mucho más al médico cuando conviene. ¿Es esto salud? No lo sé. En el campo parece ser que la gente vive bastante bien, va menos al médico, se hace menos scanners y se opera menos del corazón" ${ }^{110}$.

Ya desde el Informe Black sobre Gran Bretaña, en agosto de 1980, se demostró que las desigualdades sanitarias máximas no están en mortalidad, ni siquiera en morbilidad, sino en prevención de las enfermedades y en promoción de la salud: "Recientemente estamos asistiendo a un tipo de nueva yatrogenia (que es posible que se exprese de forma desigual respecto a mujeres y varones, por zonas geográficas y clases sociales) que es la yatrogenia asociada al preventivismo y a los mensajes, con una clara componente ideológica, que el sistema sanitario lanza en sus campañas de promoción de la salud. No sólo por la crítica legitima del blaming the victim, sino también porque el sistema desvía así la atención de los problemas reales. En este sentido, la calidad de la asistencia oncológica en España es francamente mejorable. La población no conoce en profundidad los déficit de la asistencia oncológica, que empiezan ya en atención primaria, pero que son problemas patentes dentro de los hospitales. El sistema sanitario en parte sabe, pero en parte no quiere saber, la magnitud del problema y lo mala que es la medicina que se está haciendo. Se está contribuyendo no sólo a desviar en parte la atención de ciertos problemas, sino a crear una determinada yatrogenia. A la gente le están lanzando un cúmulo de mensajes que muy a menudo lo único que tienen en común es una visión unidimensional. Está el mensaje sobre la osteoporosis que viene desvinculado del mensaje sobre el cáncer de endometrio, que viene desvinculado del mensaje sobre el cáncer de mama. Hablan de la disminución del colesterol sin hablar de la mortalidad total, etc. Claro que quizás aquí deberíamos mencionar el papel que la industria biomédica tiene en la venta de aparatos de mamografía, o en medicamentos para el colesterol. Ante esta información parcial, unidimensional, que copia el modelo norteamericano, intuyo que la población española está todavía recibiendo estos mensajes con un sano escepticismo e ironía, teñida de sarcasmo e incluso cinismon ${ }^{111}$.

La información es una variable esencial en salud: LLa situación social en cuanto a capacidad adquisitiva, y en cuanto a conocimientos culturales, permite una mejor supervivencia y tiene una importancia decisiva en cuanto a salud de la población. Esto se puede apreciar en algunos comportamientos. Por ejemplo, el consumo de tabaco parece mayor en las clases sociales más desprotegidas que en las clases sociales más desarrolladas, que han sido capaces de desarrollar la información o las recomendaciones preventivas con más intensidad que las clases sociales desfavorecidas. Ocurre también con el género, las mujeres tienen una tendencia al consumo de tabaco mucho mayor que los varones, lo que ocurre es que en estos momentos su consumo absoluto está muy por debajo del de los varones ${ }^{112}$. 
Se trata de información para algo, no sólo de mera información general: "Cuando hablamos de información, no hablamos de información objetiva, sino de que el paciente tenga oportunidad de compartir sus preocupaciones, de contrastar sus modelos explicativos de enfermedad con el médico, de entender el porqué, y de traducir a su propio universo emocional y cultural las razones para someterse a cierto tratamiento. En enfermedades emblemáticas como el cáncer es donde todas estas contradicciones, que en realidad permean el sistema sanitario, son muy graves, y a la vez están en un proceso de cambio. Se observa un muro de silencio que envuelve el cáncer. Estos pactos de desinformación del paciente (en el cual se mezcla familia, paciente y profesional) producen la pérdida casi absoluta de capacidad de decisión, de autonomía, de libertad del paciente para decidir ${ }^{113}$. La información está relacionada además con la posibilidad de recibir una atención sanitaria desigual o preferente. En el caso español, las redes de "recomendación "y de aenchufe" son ampliamente conocidas y utilizadas ${ }^{116}$.

Las desigualdades vienen generadas por el propio personal, y por la práctica médica: "La práctica de la Medicina implica, de un modo inherente e inseparable, la relación de tipo humano, que yo creo que la inmensa mayoría de la población no recibe. Recibe un trato inhumano, y en una amplia mayoría de casos descortés. Por supuesto, que los profesionales sanitarios no siempre son los únicos responsables de este tema. Creo que en parte son también víctimas de ello porque una de las cosas más satisfactorias de practicar la Medicina es establecer una buena relación con las personas. Suele hablarse del problema de las listas de espera, de la burocratización, pero creo que simplemente esos son los aspectos más identificables o más visibles" ${ }^{115}$. Los médicos/médicas tratan distinto a los/las pacientes dependiendo de la clase social de éstos. Es un proceso casi inevitable: "Los médicos se sienten mucho más cómodos y tratan mejor (sea en el sector público o en el privado) a personas de la misma categoría socio-profesional o del mismo nivel educativo. Para personas de nivel educativo alto y de categoría socio-profesional medio-alto les es mucho más fácil. Tienen más recursos económicos, de capital cultural, saben más, tienen más recursos sociales, y de relaciones, para utilizar bien el sistema sanitario. Aunque aseguráramos un sistema sanitario absolutamente igual para todos, hay un sector de la población con muchos más recursos de capital cultural y social para acceder y utilizar bien el sistema sanitario [...] Cuando vas al médico, eres menos objeto si eres de clase media-alta que si eres de clase baja. La clase baja es más rutinaria, más objeto. Son gente que no tiene el mismo valor para los profesionales, a pesar de que el sistema intente tratarlos de forma igual ${ }^{116}$.

Los expertos/as no se ponen de acuerdo sobre el futuro. Algunos consideran que las desigualdades están disminuyendo: "La tendencia es a una disminución de las desigualdades. La so- ciedad española tiene una aspiración de equidad importante. Cuando se pone de manifiesto la existencia de desigualdades sanitarias o de otro tipo, suele haber un impulso por corregirlas. La descentralización de los servicios se ha orientado a la reducción de estas desigualdades. Desde el punto de vista de las desigualdades geográficas, yo creo que estamos presenciando una mejora. ${ }^{117}$. Aunque prevalece la posición pesimista de que las desigualdades sanitarias van a aumentar en el siglo XXI: "Ya hay muchas desigualdades y es probable que surjan más. Lo básico es que si no hay pastel no puede repartirse. Si hay algo a repartir se puede pensar cómo; pero el problema, o lo grave, es cuando no hay mucho a repartir ${ }^{118}$. El problema es que las desigualdades sanitarias van a depender en buena medida de las desigualdades sociales, y sobre todo de las diferencias de renta. "En buenas condiciones de bonanza y desarrollo económico y social, lo que hay, incluso con un partido socialista, es una gran distancia social y de condiciones de calidad de vida entre las clases pudientes, media y media-alta, y clase mediabaja y clase baja, y la clase trabajadora, que es grande. No hay una política social orientada a sobrepasar el mercado y a redistribuir la renta de una manera más equitativa. Dado que una gran parte de los problemas de salud o de enfermedad son debidos a problemas asociados a la distribución de la renta, si no hay una mejor distribución de la renta, seguirá habiendo desigualdades en enfermedad, en salud y en disfrute de la vida ${ }^{119}$. Una posible solución - a pesar de las desigualdades de la renta que son elevadas - es la actuación de la población hacia un posible ACT UP sanitario global: "La presión de los usuarios del sistema va a ser muy fuerte, y eso es lo que va a hacer que algo se mueva. Porque, en definitiva, si la gente ha aceptado como funciona hasta ahora es porque quizás venían de una formación diferente de la que se tiene ahora. Las personas de nuestra generación se la van a ir planteando [...] Las personas que ahora tienen una cierta edad pues, a lo mejor, han vivido condiciones diferentes que les hacen aceptar más, y resignarse frente a algunas situaciones. En cambio, a lo mejor, nuestra generación nos vamos a resignar menos ante algunas cosas y vamos a hacer mucha más presión. Por lo tanto, alguna respuesta habrá que dar ${ }^{120}$.

8. Uno de los factores más importantes de cambio social en España es el proceso de envejecimiento de la población. Es importante analizar cómo va a influir ese proceso en el sector sanitario en los próximos años, sobre todo de cara al siglo XXI. La dificultad mayor está en prever los cambios a largo plazo. El envejecimiento de la población y el cambio de la estructura de la morbilidad - factores que se condicionan mutuamente- son las dos transformaciones más impartantes dentro del sector sanitario. Se reconoce que: aEl envejecimiento va a influir poderosamente en el sector sanitario; entre otras cosas para defenderse de la medicalización y de la quimificación, porque lo que quieren es vida, qué duda cabe qque por ser población más vulnerable necesitan más cuidados? Sí, pero la edad no es una enfermedad. ${ }^{121}$. No es una 
enfermedad, pero la sociedad actual tiene una visión negativa de la vejez. Con las palabras (extremas) de uno de los expertos: "El anciano en nuestra sociedad no tiene ningún valor. El viejo es viejo. El concepto de 'viejo' socio-culturalmente es un concepto de desecho; lo viejo no vale. El esfuerzo que va a hacer el sistema sanitario, el coste del sistema, los políticos también, para personas que no valen, para personas que ya no son productivas, es una especie de esfuerzo de recursos tirados [...] Hay que analizar el sistema sanitario de los países occidentales como un sistema sanitario capitalista, en que su base es asegurar una fuerza de trabajo sana para un sistema productivo iLos viejos qué juegan ahí si no van a ir al sector productivo? No tienen sentido en la sociedad. Los viejos ya no tienen espacio social, pero tiene menos sentido todavía cuando tienes que gastar muchos recursos para dejarlos sanos, cuando no van a ser productivos ${ }^{122}$.

Morbilidad y mortalidad no correlacionan necesariamente. La esperanza de vida es prolongada, pero cada vez hay más personas enfermas. "Lo ideal sería que la esperanza de vida de 80 años significara que uno enferma a los 79 . El problema (supone un gran gasto sanitario) es que la gente que vive 80 años empieza a consumir recursos sanitarios a partir de los 60 porque enferma. Esto conlleva un doble problema: la calidad de vida del individuo deteriorada por su enfermedad y los recursos que se consumen durante 20 años ${ }^{123}$. Hay una crítica explícita al sistema sanitario, como generador de nuevos problemas: "Todo este sistema sanitario que estamos creando es para crear parados. Esto es muy duro de decir, y parece muy raro, pero en el fondo es un poco así. Porque a base de poner parches hemos logrado que estas señoras lleguen a los 80 años, y los hombres a los 73 [...] Lo que se habría de mirar es la calidad de vida. Hay que mirar cuando un señor dice: ¡Yo ya no tengo suficiente calidad de vida, pues que me saquen de en medio! Que sea la propia sociedad la que lo saque de en medio. Esto de la eutanasia está avanzando y se está metiendo en la cabeza de la gente y de la sociedad. Llegará un momento en que se tendrán estas opciones, porque sino el sistema sanitario nos va a sanitarizar a todos" ${ }^{24}$. La crítica es importante

Hay, sin embargo, una visión menos catastrofista. El incremento de gasto sanitario debido al envejecimiento de la población parece ser pequeño ${ }^{125}$. Un experto considera que la salud de las personas ancianas mejora: $\mathrm{EL}$ proceso de envejecimiento de la población no supone forzosamente que las necesidades sanitarias aumenten con la misma proporción que lo harían si las necesidades sanitarias de nuestros ancianos, actualmente, fueran las mismas que las de los ancianos de hace veinte 0 treinta años. Me da la impresión de que no solamente se ha aumentado la supervivencia, sino que también se ha aumentado la salud de la población anciana; de manera que una persona oficialmente anciana a los 65 años, no tiene por qué tener las li- mitaciones de salud que era previsible que tuviera un anciano hace treinta años. Mi impresión es que la capacidad funcional, la independencia, es en general mayor para las personas que tienen 60 ó 65 años en este momento" ". Otra experta considera igualmente que en el grupo de las personas más viejas se mantiene una cierta calidad de vida: "Al aumentar las personas mayores, las más mayores entre las mayores - lo que se llama el envejecimiento del envejecimiento - lo que puede ocurrir es que aumenten más las tasas de dependencia, invalidez, enfermedades crónicas, etc. Pero no hay constancia de que esto tenga que ser así. Si esto fuese así, claramente se aumentarían los gastos sanitarios. Pero no se puede saber muy bien si esto va a ocurrir exactamente así. A lo mejor puede ocurrir inmediatamente. Pero no sabemos si esto va a continuar. Otra hipótesis sugiere que los factores sociales que han influido en la prolongación de la vida, y en la mejora de salud de las personas que están viviendo cada vez más años y en mejor estado de salud como nunca habían vivido, puede que influyan también en que en los últimos años de su vida se viva con una mejor calidad. De manera que la dependencia se posponga más, hasta el último momento, hasta el período inmediato a la muerte ${ }^{127}$. Son visiones positivas - y optimistas - de la realidad.

Prevalece la visión negativa de la vejez, y de sus posibilidades de elevar su nivel de salud. Un experto considera imaginativamente: "Es bonito fijarse en los progresos de la esperanza de vida, pero también habría que fijarse en los últimos años de vida de la gente, y en cómo los pasan. Me parecen bien los indicadores más cuantitativos, pero los estudios cualitativos tienen aquí un papel muy importante para en los últimos dos o tres años de vida saber qué tal vive la gente, qué tal de feliz era. Siempre me apetece soñar que algún día seré capaz de hacer la epidemiología de la felicidad y la epidemiología de la muerte. iQue es al fin y al cabo lo que nos interesa! Vivir más o menos, la verdad es que no está claro. Como dice Andreu Segura: ¿Valdrá la pena ser viejo en el año 2000? Pues no está claro que cuando nos toque ser viejos - si es que llegamos- valga la pena. Hay muchas decisiones que toma el sistema sanitario" ${ }^{128}$. La visión negativa de la vejez es creada por el propio sistema sanitario: “Un problema grave es que el sector sanitario es parte del problema. Consiste en considerar a los viejos como población de riesgo. La concepción negativa de la vejez, de los viejos como desecho, como inservibles, está dando lugar a políticas sociales y sanitarias que los consideran como tales y que los convierten en tales. En lugar de tener políticas sanitarias que consideren a los viejos como personas hábiles, capaces, con derecho y obligación a disfrutar de la vida y con capacidad de contribuir socialmente, las consideramos como personas que ya no pueden contribuir en nada, que ya tienen muchos problemas. Entonces hemos creado aparatos enormes de ayuda. Les ayudamos para todo. Es una ayuda indiscriminada, que provoca dependencia. El problema es que la política social y sanitaria lo 
que está provocando es dependencia. No estamos enseñando a las personas de más de 65 años a ser independientes, sino más bien a ser dependientes, con lo cual aumentan los costes sanitarios y sociales [...] Es la marginación a la que sometemos a los viejos lo que crea problemas de tipo crónico a nivel de enfermedad y crea dependencia total. Los estamos convirtiendo en inútiles y el sistema sanitario contribuye a ello" ${ }^{129}$. Incluso se produce un modelo de control social de las personas ancianas desde el sistema sanitario ${ }^{130}$. "En este momento parece que hay una carga importante de cuidado informal que está asumiendo la sociedad, la familia, las mujeres básicamente, lo que llamamos cuidado informal. Está mucho en manos de mujeres, de las mujeres familiares. $Y$ hay situaciones verdaderamente muy dramáticas en este sentido, muy duras para el familiar, cuidador, etc. ${ }^{131}$.

Hay una presión por parte de la población más anciana sobre el sector sanitario. Esto es un problema que no existía hasta ahora. "Lo grave no es que exista una presión desproporcionada, lo grave para el sistema sanitario es que su paradigma curativo no tiene mucho que hacer con los problemas de los ancianos, que suelen ser de tipo crónico en una gran parte, a los cuales no puede hacer frente ${ }^{132}$. El proceso de envejecimiento influye en dos modos: «Uno va a ser un aumento de los costes. La población anciana necesitará más servicios, y por lo tanto va a pedirlos más, a consumirlos más. Esto ya está pasando de hecho. Por otra parte, se observa una reorientación (que en parte ya está en marcha, pero que va a tener que acentuarse) de un sector sanitario que va a poder aspirar a curar menos cosas para dedicarse a paliar, mitigar los problemas de la población anciana que son crónicos, y no se curan. Éste es el proceso que hace que en nuestro sistema sanitario sea tan importante el proceso de reforma de la atención primaria. Si los cuidados se pueden proporcionar cerca de la población (con equipos de atención primaria que puedan atender a la gente en su casa, en su barrio) va a ser mucho mejor que si este escalón asistencial fracasa. Entonces la población española se desplaza hacia niveles hospitalarios o de otro tipo para obtener las respuestas que no le están dando y que tampoco podrá darle muchas veces el sistema hospitalario " ${ }^{133}$. Se requiere, pues, un tipo de servicios distintos: $S \mathrm{Si}$ bien es cierto que hay una asociación entre mayor frecuencia de problemas de salud y mayor frecuencia de utilización de servicios sanitarios respecto de la edad, también es cierto que la mayor frecuencia de problemas sanitarios y el mayor consumo de servicios sanitarios está modulado o condicionado por el tipo de oferta de servicios sanitarios que se presta a la población. Aun siendo inevitable que el envejecimiento comporte una mayor necesidad sanitaria y una mayor necesidad de atención, no es inevitable que las formas que adquiera esta prestación de servicio sanitario se adapten a los requerimientos de la población y no reproduzcan miméticamente el tipo de atención que se ha pensado y elaborado para una población adulta en edad productiva. El encarnizamiento terapéutico no tiene ningún sentido en la población anciana, con independencia del coste que ello origina en la comunidad, pensando sobre todo en la calidad de vida que se le puede proporcionar a la población anciana* ${ }^{134}$.

El sector sanitario debe cambiar su enfoque dedicado a $\mathrm{cu}$ rar y sustituirlo por el de cuidar. Como señala una experta: "Depende de que el sistema sanitario continúe con una visión médica curativa, o que se transforme en una coordinación de servicios sociales y sanitarios para las personas mayores. Porque el problema de las personas mayores no es en realidad su enfermedad crónica, sino su incapacidad funcional, es decir, su incapacidad para permanecer en el medio ambiente habitual, en su comunidad con independencia, con autonomía, dependen de que el sistema sanitario se adapte al tipo de problema sanitario-social que presentan las personas mayores con incapacidad, y que se abra el espectro de servicios, un abanico de servicios que permitan adaptarse a las distintas situaciones de las personas mayores ${ }^{135}$. Estos nuevos servicios requieren mucha más atención de enfermería y menos recursos médicos ${ }^{136}$.

Se necesitan innovaciones. Algunas se están aplicando más como propaganda que como cambios estructurales. "Este sistema sanitario se encontrará con una población creciente que lo que necesita será que la cuiden, alivien y la traten bien; que sepan no añadir el enésimo fármaco a la pauta terapéutica de un anciano, y si puede ser disminuir las dosis, ajustar las dosis. Este tipo de Medicina, muy soft, la buena Medicina de siempre, es lo que el sistema hace peor. Podrán surgir nuevas especialidades, subespecialidades incluso de la Gerontología y de la Geriatría, pero ésta no es la solución. Es bonito que haya panfletos que hablan del programa de vida a los años. La idea es buena. Existen iniciativas interesantes, como por ejemplo los programas que la Generalitat catalana ha puesto en marcha para los enfermos terminales. Hay unos equipos de apoyo, que intentan tener un planteamiento multidisciplinar, y que se inspiran en el bospice movement británico. Aunque a veces algunos de estos programas no pasan de ser experiencias piloto para enseñar al consejero de sanidad de la Junta de Extremadura o de CastillaLa Mancha cuando vienen de visita. Lo llevan alli, y después a comer, y se quedan todos contentos" ${ }^{137}$. La ironía esconde una buena dosis de verdad. Los problemas son vistos como estructurales, difíciles de cambiar: "Atender a este grupo de población significa dedicarle tiempo. Esto va un poco contra la lógica del sistema sanitario, que racionaliza, rentabiliza, reduce estancias, etc. En muchos casos, por el tema de la reducción de la estancia media, quizás se fuerza un poco las altas hospitalarias de personas, que vuelven a su domicilio en condiciones que necesitan mucha atención del sisteman ${ }^{138}$.

9. España es actualmente el país de Europa con más casos de sida (en tasas respecto de la población total). Existe ya desde 
bace años un debate sobre las politicas que podrian adoptarse. Es importante dar una visión ajustada del futuro de esa epidemia en nuestro país. Ningún experto $-\mathrm{y}$ hay varios de ellos que han escrito e investigado directamente sobre el sida- explica por qué la situación es tan mala en España. Consideran que hay una falta de política coherente. El primer punto sería adoptar una política. Hasta ahora no ha habido ninguna política. Es realmente escandaloso que tengamos ya tantos años de epidemia en España y no haya una política frente al sida cuando en todo el mundo se reconoce que es un problema de la mayor importancia. Entonces, lo primero sería adoptar una política, es decir, crear algún plan nacional de sida, intentar abordar el tema de una forma integral, intersectorial, y desde luego no puramente sanitaria* ${ }^{139}$. Se avecina pues una crítica importante en el futuro próximo: aLas generaciones futuras van a ser terriblemente críticas y duras con nuestra generación, con los que han tenido responsabilidades políticas y sanitarias en esta época de comienzo de la epidemia. Porque es una epidemia que si bien no tiene vacuna y no tiene cura, se ha logrado saber en tiempo relativamente breve cómo se produce y cómo se transmite. Las medidas que se han tomado por parte de los poderes públicos y las autoridades sanitarias distan mucho de estar a la altura de la catástrofe y del problema que representa el sida ${ }^{140}$.

Es un problema de alta política y de creación de un tabú social: ‘La falta de política en nuestro país se debe a que el sida es un tema maldito, que ningún partido político quiere tratar. Es un tema que se ha considerado hasta ahora, incluso hasta hace muy poco, por lo menos, como un tema marginal. Se considera un tema que afecta solamente a las personas que son malas, que son homosexuales, prostitutas o toxicómanos, y que esto no afecta al resto de la sociedad. Ningún partido político ha querido realmente planteárselo en serio. También porque el partido del Gobierno tiene miedo a adoptar políticas que le llevarían a enfrentarse con sectores muy poderosos en la población (como la Iglesia católica) en el caso de la educación sexual, y en el uso del preservativo. Es un problema muy grande, porque esta falta de decisión, de voluntad política, nos ha llevado a la situación en que nos encontramos ${ }^{141}$. Es una política difícil, por las propias razones técnicas de la enfermedad: -Podemos aspirar a que el número de sero-positivos no aumente. Esto es una obligación. La lucha contra el sida no es una lucha cuyos resultados se vean de inmediato porque los ciudadanos que desarrollan la enfermedad del sida son un pequeño porcentaje de los que han sido infectados a partir de un determinado plazo de tiempo. Es una lucha que da frutos a largo plazo, y dentro de unos años veremos el fruto de lo que hemos hecho hoy, o la catástrofe de lo que no hemos hecho: ${ }^{142}$. Ideas similares son expresadas por otro experto: aLos resultados de una política útil de prevención no se pueden comprobar hasta unos años después de haber hecho las inversiones necesarias para llevarlos a cabo. La capacidad de asumir riesgos por parte de los responsables políticos de nuestra comunidad, probablemente no sea tan alta como para jugarse el puesto con unas inversiones que no van a poder justificar con resultados, quizás hasta que no vengan dos o tres sucesores de su cargo. No es una crítica a los políticos, es una crítica a la comunidad, porque creo que la comunidad exige al político resultados concretos, y no le exige tanto el que se pueda equivocar o acertar en el largo plazo. Se juega con mucha oscuridad. La comunidad no son las personas que más gritan o que más se oyen en los medios de comunicación" ${ }^{143}$.

La realidad es que no hay una organización sanitaria y social eficaz contra el sida. "En este momento no hay una organización. Los enfermos de sida se tratan en los hospitales, como se puede, pero no hay realmente un protocolo de atención de la persona VIH positiva, que puede estar enferma 15 ó 20 años, o puede estar infectada sin enfermedad, no sabemos cuanto tiempo. Esto requiere un sistema de atención que integre los diferentes niveles de los servicios sanitarios: atención especializada, atención primaria, y también la atención social ${ }^{144}$. Se pide además que la población sea más responsable. Un experto confiesa: "No me gusta el paternalismo que se está utilizando con el tema, y tampoco el tema de intentar darle demasiadas connotaciones morales. Está claro que el preservativo puede prevenir; pero está aún más claro que si no lo haces previene más. Y esto hay que tenerlo en cuenta ${ }^{145}$. Igual $\multimap$ más— responsabilidad se pide a la comunidad gay: "Creo que hay que responsabilizar a la población de que no se puede hacer todo. Yo no critico que uno sea homosexual, pero al menos que tome precauciones, que no piense que cada uno puede hacer lo que le dé la gana y cargarle la responsabilidad a otro. Hay un momento en que uno se debe responsabilizar ${ }^{146}$.

Pero el problema del sida en España no es de gays $\multimap$ no tanto como se supone- sino fundamentalmente de personas que se inyectan droga: "En España la mayor parte de los infectados por el VIH son personas de la sub-cultura de la drogadicción, y más en concreto de la drogadicción intravenosa. El problema de la droga es así un problema de salud pública. La consideración de este problema con criterios sanitarios de medicalización es una obligación imprescindible. Es una exigencia de los responsables políticos y sanitarios de nuestro país" ${ }^{147}$. Se propone una politica de reducción del daño: aLas políticas más útiles para disminuir la incidencia del sida serían las que permitieran que las personas que utilizan drogas por vía parenteral lo hicieran sin tanto riesgo de contagio. Ello supone, por un lado, actuar en general respecto de la droga como un fenómeno importante (sobre todo la de uso parenteral) y hacer un análisis realista de la situación en que las posiciones morales no sustituyan a la realidad. Es muy importante tener referencias morales, políticas e ideológicas sobre el uso de drogas. Pero en ningún caso estas referencias políticas y morales pueden anular lo que 
ocurre en la realidad. Y lo que ocurre creo que tiene suficiente peso como para merecer una política realista al respecto [...] La politica de reducción del daño supone que si no es posible conseguir que la población consuma menos drogas por vía endovenosa, por lo menos que se proteja cuando lo haga ${ }^{148}$. Pero un análisis más sociológico considera que no es un problema de drogas inyectables, sino de pobreza. El razonamiento es poderoso: "El sida intravenoso es un problema de bolsas de pobreza, básicamente es un problema de la desigual distribución de la renta. En España la pobreza es el mecanismo de transmisión del sida. Como sucede con todas las enfermedades infecciosas, siempre han sido los pobres. Los que tienen más capacidad cultural y económica saben evitar el problema. La comunidad gay como tiene una capacidad cultural mayor que los drogadictos intravenosos tiene una mayor capacidad de defensa. Entonces utilizan la prevención, los condones, etc. Mientras que a las personas que utilizan las drogas intravenosas, les importa un pito la vida. Tampoco les da nada la vida. La solución es, como siempre, mejorar la distribución de la renta, acabar con las bolsas de pobreza. Eso aseguraría que las tasas de sida fueran menores en nuestro país" ${ }^{149}$. Otro experto llega a una conclusión semejante: "El sida es un problema más de los drogadictos. Pero los problemas de los drogadictos, y sobre todo los de vía parenteral, son otros antes que el sida. Uno es la droga y la dependencia, otro es la marginación social, y otro es el problema de que son gente cuya vida se acaba y comienza en el momento en que se chutan. Todo esto no tiene nada que ver con el sida ${ }^{150}$. Es pues un tema social más importante, que requiere una estrategia sociológica: "Mientras sigan existiendo bolsas de pobreza, y exista tanta pobreza y desigualdad en nuestro país, y mientras haya jóvenespobres sin futuro el problema continuará. Estamos hablando de jóvenes pobres sin futuro, para los que la vida no tiene mucho sentido, y usan las drogas. $\mathrm{O}$ a eso le das un vuelco de alguna forma, o no se consigue nada ${ }^{151}$.

La información sigue siendo el mejor método contra el sida. "No tenemos una solución vacunal, no tenemos una solución terapéutica que cure, sino sólo una que alarga la vida. Por lo tanto, la política a seguir es una política de información seria, honesta, rigurosa, científica, extensísima, y sobre todo que abarque la población en general ${ }^{152}$. El problema es que esa información llegue a la target population ("población diana" en traducción horrible), y que esa información sea efectiva. "El problema del sida es que las políticas lleguen a las personas de alto riesgo. La paradoja del sida es que los que están mejor informados son los que tienen menos riesgo" "153. Hacer llegar, bien, esa información a los grupos sociales adecuados está resultando una empresa difícil: "Las políticas de información no tienen sensibilidad respecto a la vida o los problemas de las clases más pobres. No saben leer. Luego les están hablando de un mundo, de una cosmovisión que no es la suya. a ¿ Usted de qué me habla? ¡Déjese de puñetas!.. Claro, son políticas sociales hechas por clases medias que proceden de la universidad, sin sensibilidad respecto a los problemas. No tienen sentido, van al fracaso. Hemos visto algunos ejemplos. Es una barbaridad: concepciones, folletos que se han hecho desde departamentos gubernamentales. Una cosa tan sesgada de una clase social, y de una concepción social, que esa gente no los van a entender nunca. ¿Quién se lo va a leer? Pues la clase media. Al final el problema se convierte en un problema de pobres como han sido todas las pestes, todas las epidemias. $\mathrm{Da}$ igual ique los pobres se mueran qué más da! Es un peso menos. Además, como son drogadictos, son delincuentes, si se mueren ipues menos problema! ${ }^{154}$

\section{Políticas de recursos}

10. El proceso de envejecimiento de la población, y el cambio de las estructuras de morbilidad, llevan a que uno de los problemas sanitarios básicos sea el de las enfermedades crónicas. El sector sanitario español parece estar mal preparado para ese cambio. Es importante conocer los tipos de recursos que los expertos/as creen que se necesitarian para cuidar adecuadamente todos los casos crónicos en nuestro país. Hay más enfermos/as crónicos porque hay más personas ancianas; pero no sólo por eso. Se produce en España un cambio considerable de la estructura de morbilidad, para el que el sector sanitario no tiene una respuesta inmediata. El primer recurso sanitario no es el sistema sanitario, sino la familia. Cambia el sector sanitario, pero también se está transformando la familia. "Habría que dedicar más recursos a la atención de problemas crónicos. Pero dado que una parte importante de los problemas crónicos tienen su origen en variables socio-culturales habría que prestar mucha más atención a tales variables. El sistema sanitario tiene un papel limitado con respecto a la enfermedad y a la salud; de hecho cada vez un papel más limitado. Debería darse un papel más importante a la sociedad, o a las reformas sociales (de calidad de vida, de rentas, de condiciones de vida) como mecanismos que asegurarían una mejor salud. Pero esto no interesa a nadie. El sistema sanitario puede ser muy caro, pero la distribución de la renta puede ser mucho más cara ${ }^{155}$. Como reconoce otro experto: «No hay mucho que inventar ahí. El problema es que no tenemos dinero para pagarlo. Todo eso cuesta mucho dinero. La sociedad no dispone de los recursos necesarios para cuidar adecuadamente de todos esos casos. Si no había recursos no era porque no se hubiese pensado que se necesitaban, sino simplemente porque estaba la familia; y mientras existe la familia ese es el mejor recurso. Ahora las personas empiezan a trabajar. Las mujeres se han incorporado al mercado laboral, y se produce una situación en la que no hay tiempo para cuidar de las personas mayores. No sé cuál puede ser la solución. ${ }^{156}$. 
Existe una idea romántica sobre la familia y los lazos amorosos que alcanza, incluso, a los expertos en sanidad: "El ser humano necesita valerse de instituciones humanas, es decir, basadas en la comunicación y en la palabra, y si están robustecidas por el afecto tanto mejor. Entonces, probablemente vayamos a descubrir la institución básica de la afectividad -llámese amor o llámese como se llame- que es la familia, o la tribu para otra cultura. En cada cultura tiene su forma, su comunidad de amcr. No entro ahora a discutir si el problema es greco-latino del Mediterráneo. Hago abstracción de ello. Lo que sí quiero afirmar es que todavía los hombres son tan frágiles que necesi$\tan$ de la afectividad y de instituciones afectivas". Sobre los recursos necesarios eel primero es la familia; el segundo la atención domiciliaria; el tercero la hospitalización de día; y el cuarto... hombre, si no queda más remedio, el instrumento más peligroso que existe en toda ciudad, que es el hospital, ${ }^{157}$. Familia y amistades (incluyendo vecinos/as) siguen siendo recursos sanitarios excelentes en España; "En una pareja de ancianos, en que uno de los dos está enfermo, es más importante que el otro pueda moverse, acompañarlo al hospital, ayudarle a moverse por el maremagnum del hospital, que lo que pueda hacer el sistema sanitario propiamente. Es importante que esa gente viva en una vivienda digna, tenga unos medios de transporte, pueda ir a la compra, pueda tener acceso a una pensión digna, y pueda tener espacios donde relacionarse. La red de relaciones familiares y de amigos sigue siendo vital. En un país donde la familia es todavía algo importante en relación a lo que es la familia en Norteamérica, y donde los amigos representan una realidad completamente distinta a lo que los amigos y las redes de relaciones son en Estados Unidos, el mayor impacto seguirá estando ahí: en la familia y en los amigos, por decirlo de forma coloquial" ${ }^{158}$.

El planteamiento es utilizar primero los recursos familiares, y segundo los recursos de la organización sanitaria. "Todo el tema de ancianos hay que pensarlo en base al mantenimiento de la persona mayor en su casa el mayor tiempo posible, y el mantenimiento de su capacidad funcional. Para eso, no es que haya que dedicar muchos recursos, sino empezar por organizar los que ya existen. Aproximadamente el $80 \%$ de las plazas de residencia están ocupadas por personas perfectamente válidas, lo que deja fuera a las personas que realmente lo necesitan. Son los enfermos crónicos que se mantienen en la sociedad en condiciones de incapacidad y que suponen una gran carga para su familia ${ }^{159}$. Nuestro país dedicaba un gran esfuerzo (femenino) a cuidar: infancia y ancianidad. La situación está cambiando, como observa bien una experta: "España es uno de los países donde las personas ancianas viven más en familia. En cambio, en otros países de Europa, decididamente es el Estado quien se hace más cargo. Son diferentes maneras de enfocar el problema. En el caso español es donde parece que la gente convive mucho más con la familia y son menos proclives a dejar a la perscna anciana. Hay un gran sentimiento de culpa, porque esta idea de las obligaciones familiares se vive muy fuerte. Hay un sentimiento de tenerse que ocupar. No se piensa que pueda ser de otra manera. Esto va a conllevar que se debe reforzar todo el sistema, teniendo en cuenta la estructura familiar y posibilitando otras alternativas. No se trata tanto de si más o menos residencias. Siempre habrá una parte de estas personas que deban estar en una residencia, porque las otras posibilidades son peores para ellas" ${ }^{160}$.

Debido a la evolución histórica de familia a sanidad, los recursos sanitarios para enfermos/as crónicos son pocos, de calidad dudosa y desorganizados. Hay que tener en cuenta que: "Las enfermedades crónicas son problemas en la medida en que son incapacitantes. Lo que habría que pensar es en desarrollar los servicios que permitan la adaptación a la vida con las enfermedades crónicas y que permitan mantener la capacidad funciona! el mayor tiempo posible. En este momento en España hay muy pocos recursos para esto. Hay muy pocos servicios y recursos destinados a estos servicios. Prácticamente hay una casi inexistencia de programas de atención a domicilio" " ${ }^{161}$. Y como añade otro experto: "Los enfermos crónicos tienen múltiples necesidades, y hay que atenderlas teniendo en cuenta que es una sola persona que las padece, no compartimentalizándolas. Los recursos que se requieren son fundamentalmente de atención primaria. Probablemente no haya un déficit importante; otra cosa es que se preparen o adecuen cualitativamente este tipo de recursos. Las actividades de rehabilitación, de soporte psicológico, de atención psicológica, etc., deben de enmarcarse en el equilibrio de atención primaria" ${ }^{162}$.

Una de las ideas clave es la necesidad de completar la reforma de la atención primaria de salud (APS). Es también la medida más importante para mejorar la situación de los enfermos/as crónicos: "El recurso clave en estos momentos es completar la reforma de la asistencia primaria, o sea, garantizar el primer escalón de la asistencia cerca de la gente hasta cubrir a toda la población. Hasta que esto no estẹ́ completado, cualquier esfuerzo por aumentar este tipo de recursos (como son los recursos más especializados, residencias socio-sanitarias, etc.) no llevará más que a un aumento mucho mayor del gasto para una pequeñísima proporción de la población necesitada. Una vez realizada la reforma de la atención primaria, podemos plantearnos qué tipo de recursos hacen falta para aquellas personas cuyas familias no son capaces de atenderles, o para los que no tienen familia que los cuide, y hace falta reforzar probablemente los recursos 'de atención socio-sanitaria" ${ }^{163}$. También se sugiere que: "Habrá que buscar mecanismos para cuidar a los ancianos y no para curarlos. Esa distinción hay que hacerla en breve tiempo, y una vez que la hagamos buscar recursos para cuidarlos. En la práctica sería un traspaso de transferencias entre hospitales de agudos y hospitales de enfermos crónicos. Hay que 
buscar sitios donde estas personas puedan, o podamos, estar en un futuro próximo; y no enmascarar con curación o tratamientos terapéuticos algo que no tiene que ver con terapéutica y tratamientos, sino con el cuidado de la persona " instituciones sanitarias (y no-sanitarias) para crónicos/as de larga cluración es un problema importante en España: "Cada vez hacen más falta hospitales de larga distancia, que es lo que eran los asilos en la Edad Media [...] Están disminuyendo cada vez más los hospitales de agudos. Ya se están cuestionando estos hospitales de mil y pico de camas que ha construido la Seguridad Social, de los que estamos tan orgullosos. Ahora han de ser más pequeñitos, porque si a un señor lo operan del corazón, a los seis días se puede marchar. Harán falta menos. En cambio habrá todos los tarados que la cirugía del corazón no los deje bastante bien y se vayan haciendo viejos, que se habrían muerto si no los operan. Habrá que ir metiendo a esta gente en algún sitio. Lo mismo con los enfermos crónicos mentales. Quizás con las pastillas se curarán bastantes locos, pero habrá algún loco que no se podrá curar, algún remanente de épocas anteriores. Así se irá recluyendo a los sidóticos periódicamente, igual que antes se iba recluyendo en sanatorios a los tuberculosos. Falta saber la responsabilidad de la sociedad. Primero para no crear enfermos crónicos ella misma, y segundo para ver qué solución tiene con los que irremediablemente se hayan vuelto crónicos " ${ }^{165}$. Entre las necesidades están el "que haya apoyos para las personas que en un determinado momento entran en el sistema sanitario pero no tienen por qué quedar allí para siempre. Por supuesto, no tienen por qué pasar de esa situación de hospitalización a institucionalización en una residencian ${ }^{166}$.

11. Durante las uiltimas tres décadas ba babido una producción excesiva de médicos/as. A pesar del numerus clausus existe todavia mucho paro ( $y$ subempleo) en la profesión médica de nuestro país. La situación se agrava debido a algunos problemas de la organización del sistema MIR. Conviene dar ideas de cómo se podria arreglar ese problema en el siglo XXI. Es importante predecir el futuro de la profesión médica española. Uno de los mitos del sector sanitario son los médicos. Pero se observa un proceso acelerado de deterioro, tanto en el prestigio/salario, como en el status social: "La profesión médica ha dejado de ser la gran señora del sistema, de ser la primera, aunque todavía está muy centrada en él. Antes la sanidad era el sistema de los médicos, y de los sanitaristas. La enfermería ha cogido mucha importancia en los últimos años. Ahora lo es también de los farmacéuticos, los biólogos, hasta de los arquitectos, e incluso de los economistas que son los que mandan ahora. Espero que en el futuro manden los sociólogos y los éticos, porque aquí lo que se necesita es orden" ${ }^{167}$. Es parte de un marco general confuso de capital humano y otros recursos dentro del sector sanitario:" "la confusión entre sindicatos y colegios, la confusión entre títulos universitarios y no universitarios y la organización absolutamente obsoleta, anquilosada, del mundo médico son algunos de los problemas con que se encuentra la sanidad española" ${ }^{168}$. El resultado es que el prestigio de los médicos/as se deteriora: aLa profesión médica está yendo hacia una progresiva proletarización, burocratización. Cada vez nos acercamos más al médico que trabaja ocho horas al día. Ya no son médicos todo el día; y eso tiene sus desventajas. No es una persona totalmente dedicada a su trabajo, tiene menos estímulos para avanzar, o utiliza mecanismos burocráticos para hacerlo, está menos motivado porque cobra menos. La burocratización de la Medicina, a su vez, implica una peor calidad de los profesionales ${ }^{169}$.

El problema se resume en una tasa excesiva de médicos/as; una de las más altas del mundo. Esta tasa llama más la atención por la baja tasa de camas hospitalarias. El problema es histórico: "Ha habido excesivo número de médicos/as porque era una buena profesión; sobre todo a partir del Seguro. Porque el Seguro, que es una forma de financiación colectiva como antes eran las mutuas, hace que entre una gran cantidad de dinero. Entonces, claro, hubo muchos aficionados. Esto llevó a una expansión enorme del sistema. Con la Seguridad Social, ahora la sanidad se ha empezado a cuestionar. Quizás el coste-beneficio no es tan grande. Vamos a medicalizar todo el país [...] La salud es un momento de calma entre dos tormentas de enfermedad. Si llegamos a esto, todo el mundo será médico, no habrá nada más que médicos. Yo creo que no se va a corregir, ${ }^{170}$. No son sólo muchos médicos/as, sino además mal formados: «Tenemos una producción excesiva de médicos, que se centró a finales de los setenta, principios de los ochenta. Hay un boom de médicos, muchos de ellos mal formados y subempleados en nuestro país. Pero éste no es un problema de ahora, sino que se creó en los años setenta; y ahora estamos viendo en todo caso sus consecuencias. No hay muchas maneras de arreglar este problema. Se dice claramente que el país no está dispuesto a sufragar los servicios de médicos mal formados, o bien que el país está dispuesto a suíragar los servicios de médicos mal formados y quizás innecesarios. Todo lo demás son florituras [...] El país arrastra un lastre de médicos mal formados, fruto de decisiones políticas equivocadas en los años setenta. Pero las generaciones anteriores a éstas tuvieron probablemente programas de formación muchísimo más ineficientes cuando el sistema MIR no estaba introducido" ${ }^{171}$.

El sistema final de control - aplicado demasiado tardefue el llamado numerus clausus en la entrada a las Facultades de Medicina: "El numerus clausus español no responde a ningún cálculo de necesidades, de planificación de mano de obra médica para el futuro. Responde a unas dinámicas de poder e influencia dentro de las Facultades de Medicina, y a presiones sociales. Ha habido una especie de lucha de las autoridades sanitarias contra las autoridades académico-universitarias, para reducir el número de estudiantes de Medicina. Al terminar la carrera los licenciados en Medicina se consideran médicos. Sus 
exigencias de entrada en el mercado laboral repercuten en los responsables sanitarios (que son totalmente inocentes) y para los cuales no hay en el sector público perspectivas de trabajo ${ }^{172}$. Pero hay una reflexión interesante en este experto cuando afirma: "No tiene sentido, por ejemplo, que en España los estudiantes de enfermería tengan que tener más nota que los aspirantes a médico. Aquí hay una perversión obvia en el sistema. La Medicina es en sus orígenes y su práctica una profesión humilde y de servicio, para la cual no siempre están mejor equipados aquellos intelectualmente más orgullosos, más ensoberbecidos [...] La Enfermería es una profesión de cuidados de enfermería. No deben ser enfermeras habitualmente aquellas personas intelectualmente más ambiciosas, las que luego se encuentren desajustadas, porque tienen una profesión de servicio con poco glamour intelectual ${ }^{173}$.

Los propios médicos señalan que la calidad de educación médica (de las Facultades de Medicina) es mala: $\mathrm{El}$ problema de las Facultades de Medicina no es cuántos estudiantes entran, es la mala calidad de la enseñanza. Se está funcionando con un plan de estudios que no es útil a la sociedad en muchos aspectos. Cómo se va a ir al paro, ipara qué vamos a renovarlo! El que tenga suerte de aprobar el MIR ya se formará bien. Es un error porque la carrera de Medicina son seis años en los cuales se puede hacer mucho" ${ }^{174}$. Se requiere una reforma del Plan de Estudios de Medicina; que ya está en marcha. "Hay que renovar el Plan de Estudios actual. Es decir, plantear qué médicos vamos a formar en nuestra sociedad: si se necesita tanta bioquímica, física, biología, biología patológica o tanto detalle absurdo (que yo creo que no se necesita) o si se necesitan, por el contrario, médicos que sepan de economía de la salud, de organizaciones sanitarias, etc. Es una guerra perdida, porque el gremialismo, el corporativismo y el ser un país que en muchas cosas nos aislamos del resto del mundo nos ha perjudicado. Nos hemos aislado de lo que se tendría que hacer " ${ }^{175}$. Pero el paradigma médico (biomédico) sigue vigente: "Hay un interrogante interesante que es la reforma de los planes de estudio en Medicina. Sobre el papel los planes de estudio han cambiado, y ahora vamos a ver el proceso de su incrementación. No olvidemos su impacto en la relación médico-paciente, la capacidad de concederle libertad al paciente para decidir, de aceptar críticas, etc.. En parte hay una selección de estudiantes menos dispuestos a ello, con una determinada ideología; pero en otra parte en las Facultades de Medicina termina de reforzarse y de legitimarse esta medicalización, el enfoque puramente biologista y reduccionistan ${ }^{176}$.

El sistema MIR (médicos/as internos y residentes) es la clave del sistema de formación: aLa formación universitaria de los estudiantes de Medicina acaba con la capacitación profesional para el ejercicio de la Medicina General, y no se corresponde para nada con las expectativas laborales existentes. El ejercicio profesional tiene que pasar casi obligatoriamente por un período de especialización posterior que en la mayoría de los casos es de tres años o más. Este cambio en la situación no ha supuesto la reforma de los planes de estudio de la Facultad de Medicina, ni una adecuación de los planes de estudio a la nueva situación. Por lo tanto, veo el futuro de la profesión médica incierto" ${ }^{177}$. Sin embargo, el modelo MIR no es muy criticado por los expertos/as. Más bien lo consideran un logro: «Producimos licenciados en Medicina que los hacen las Universidades, y luego producimos médicos que los hace el sistema MIR. Me resisto a considerar como médico aquella persona, que después de su graduación universitaria en Medicina, no haya pasado por un proceso de aprendizaje supervisado con responsabilidad creciente y supervisión decreciente a lo largo de este proceso. Esta confusión es permanente, y es muy propia de un país que no ha tenido estructuras sociales sólidas; donde uno iba con el título universitario debajo del brazo al Colegio de Médicos, y sin más preguntas ni cuestiones era inscrito como médico. Éste es un problema que afortunadamente se ha terminado. Se ha acabado de facto desde hace ya muchos años porque la gente que no pasaba por el sistema MIR tenía una colocación profesional muy problemática " ${ }^{178}$. Y el problema está ya en vías de solución: aDentro de quince años el problema no va a existir. Al revés, va a haber demanda. El problema lo van a tener los que se han ahogado en la piscina de los médicos generales hace diez años ${ }^{179}$. En el futuro este problema desaparecerá por sí mismo". Pero todavía el fenómeno más claro es el exceso enorme del número de médicos/as, y el paro; cosa que no va a arreglarse con el actual numerus clausus (y ni siquiera con el MIR): "El gran problema del exceso de médicos es que hemos dedicado una gran cantidad de recursos a formarlos, y después los tenemos en paro o mal utilizados. Gastamos millones y millones de pesetas en formar a médicos, mejor o peor, y después los tratamos a patadas porque no les damos trabajo ni tan siquiera en el sistema sanitario. Hay una gran incongruencia e incoherencia entre los recursos que se dedican a su formación, y después su utilización (que es ínfima, mala) con lo cual engañas a la gente, a los estudiantes de Medicina, y les haces sufrir ${ }^{180}$.

Un problema adicional es la existencia de un modelo profesional mixto, es decir, público y privado al mismo tiempo, y desempeñado por los/as mismos profesionales: "El que este país tenga un sistema mixto, donde un profesional pueda tener al mismo tiempo una dedicación al sistema público y al sistema privado, abre la puerta a posibles abusos a nivel concreto en la asistencia de determinados pacientes. Pueden ser atendidos en el sector público, y son derivados al sector privado mediante el pago; o bien que pueden ser atendidos por el sector privado, pero son derivados al sector público para algunas operaciones. Este fenómeno que sabemos que existe en algunas capas, representa un flujo constante de disfunciones en el sistema. Es un 
problema difícil de afrontar sin una inyección muy fuerte de recursos. Los médicos españoles no están muy bien pagados en comparación internacional y por esto se les permite a muchos de ellos compatibilizar el ejercicio privado con el ejercicio público. Para hacer una separación más tajante entre los dos ejercicios, sería necesario pagar mucho mejor a nuestros profesionales. Esto ahora es difícilmente asumible, debido a las otras tensiones de aumento de gasto que tenemos ${ }^{181}$.

Parte de un relativo proceso de bajada de status social es la asalarización y la feminización de la profesión médica española: "La profèsión se va a feminizar, y el mecanismo de la feminización hace que, debido al mecanismo competitivo en el que estamos viviendo, evolucione hacia una profesión residual. Va a haber trabajo en la profesión médica, pero no con los mismos ingresos económicos que en estos momentos tiene, o que se tenía hace diez años. A lo mejor es un asalariado medio-medio, aunque sin problemas profesionales" ${ }^{182}$. La hipótesis de uno de los expertos es que la profesión médica española se proletariza: "La profesión médica, yo la veo cada vez más como una profesión proletarizada, más dependiente, ya sea por la estructura del sistema sanitario. Son sus estructuras organizativas las que hacen que cada vez sea más difícil que el profesional médico tenga capacidad para tener su consulta privada propia. Con lo cual los niveles de dependencia de los médicos con respecto a organizaciones públicas o privadas son cada vez mayores. En nuestro país, hasta hace pocos años, todavía una mitad de la profesión médica trabajaba en el sector privado. Había mucha consulta privada. Pero las nuevas generaciones de jóvenes, a partir de 1975 , son generaciones de médicos que trabajan exclusivamente en el sector sanitario público. Es decir, que son trabajadores, no son ya profesionales; están proletarizados. La profesión médica va hacia la proletarización progresiva y la burocratización, con los consiguientes problemas que eso implica: problemas de estímulo y de avance profesional ${ }^{183}$. Los Colegios de Médicos (y la OMC, Organización Médica Colegial) no parecen poder solucionar estos procesos de deterioro de la profesión médica española: "Los Colegios de Médicos no funcionan en consonancia con la sociedad. Siguen siendo estructuras corporativas que se preocupan mucho de cosas como la autonomía, o que no haya control en cuanto a lo que hacen, o dejan de hacer los médicos. No se preocupan de algo que es vital como los salarios. Uno de los grandes problemas es que los salarios de los médicos en España son bajos si los comparamos con los salarios de los médicos en otros países occidentales [...] Deben ser los Colegios los que se sienten a reflexionar qué tipo de profesión médica queremos ${ }^{184}$.

12. El sistema sanitario español es bastante barato, medido en proporción del PIB. Sin embargo, en los últimos años se están produciendo recortes importantes en el gasto sanitario (por ejemplo, en farmacia). Es posible que se produzcan algunos tíquets moderadores en el futuro. Hasta abora estos recortes ban sido pequeños y bastante racionales. Es importante entender cómo puede ser la situación presupuestaria del sector sanitario espanol en el futuro, y qué soluciones se podrian tomar. La mayor parte de los expertos/as reconocen que el presupuesto sanitario es bajo. Varios proponen un aumento, pero sugiriendo un gasto más racional y coordinado: "Yo propondría un aumento del gasto. Un $6 \%$ es muy poco. Ahora bien, un aumento del gasto si es para gastárselo como se lo están gastando ahora ya está bien que esté así: cuanto menos mejor. Porque lo están gastando mal, lo están malgastando. Si hubiera un proyecto positivo, y mejor para gastarlo, creo que se podría gastar un poco más de dinero, un par de puntos más. Podríamos así llegar a tener un mejor sistema sanitario" ${ }^{185}$. Otra opinión matiza el gasto público total, redistribuyendo hacia sanidad: "Yo considero que es injusto el recorte, y que es injusto el nivel. Propongo que uno de los mecanismos para resolver los problemas actuales es que se amplie el presupuesto dedicado a sanidad. Sé que la tarta es limitada, y por lo tanto hay que sacarlo de otros lados. Por supuesto que lo sé. No me importa decir que se saque de gastos suntuosos, de gastos inútiles, o gastos menos precisos: de gastos militares, o de carreteras" ${ }^{186}$. El gasto público debería decidirlo el público, la población. Aunque casi todos/as coinciden en que el gasto que se realiza no es adecuado: "Creo que debería ser, y no lo es en estos momentos, competencia de la población. Es la soberana en decidir si gasta del producto interior bruto público, lo que gasta en sanidad y lo que gasta en otras cosas. Esto debería poderse plantear desde un punto de vista comprensible por parte de la población viendo qué es lo que compite para gastar, el dinero público en qué se gasta, y si vale la pena gastárselo en esto o sería más conveniente gastárselo de otra forma. Desde este punto de vista, creo que debería darse entrada a la población a expresar sus preferencias sobre el destino del gasto público y sus preferencias en el caso de sanidad del gasto sanitario. Porque podría pasar que estuviéramos gastando poco. Lo admito como sanitario; preferiría que se gastara más en sanidad porque me tocaría algo más seguramente. Pero además no es seguro que se gaste bien. Es probable que no se esté aprovechando el rendimiento del dinero como se puede estar aprovechando en otros sectores, y esto también es muy importante" ${ }^{187}$.

El razonamiento es que todo gasto lleva un malgasto, y que las desigualdades sanitarias no parecen disminuir con un mayor gasto sanitario: "Es difícil cambiar que uno sea más rico o pobre, más educado o menos educado. Desgraciadamente lo hemos intentado cambiar durante muchos años y no lo hemos logrado. Yo pienso que hay un mínimo de recursos sanitarios que son necesarios, y a partir de ese mínimo dedicar muchos más recursos sanitarios es quizás peor que mejor ${ }^{188}$. Un factor que incide en este gasto es la política de personal: «Hay que eliminar este sistema obsoleto que tenemos de organización sani- 
taria en sus aspectos propiamente organizativos, en los aspectos de gestión de personal. Somos el único país del mundo - una vez caída la Unión Soviética- que mantiene una especie de ejército nacional o autonómico de médicos, enfermeras y otros profesionales sanitarios. Nuestros centros sanitarios no contratan a sus empleados; éstos pertenecen a unos hipotéticos servicios autonómicos o nacionales. Es una gestión muy poco eficiente. No hay apenas organización (excepto el ejército) que funcione con estas premisas de gestión de personal" ${ }^{89}$.

Un peligro de elevar el gasto es que no se utilice racionalmente: $\mathrm{El}$ gasto sanitario es muy importante y da unas aportaciones tremendas a la sociedad y a la sanidad. Pero estamos tocando techo. El gasto es tan sólo de un 6\% del PIB porque los profesionales y los médicos ganan menos que en los países en que es más alto (como Estados Unidos o Alemania). ¿Y la tecnología quién la mueve? La mueve la industria farmacéutica, la electromedicina. Cuanto más gente participe más va a subir. Aquí podemos caer en medicalizar o sanitarizar toda la sociedad y todo el mundo. No sé si éste es el camino" 190 . Es también un problema de educación de la población, según uno de los expertos: "Hay que definir las cosas que sirven, y de las que dudamos. Hay que realizar estudios que nos permitan discernir sobre las dudas. El problema es que no se educa a los médicos de las Facultades de Medicina para pensar así, ni se educa muchas veces a los médicos con el sistema MIR para pensar así. Tampoco se educa a los gestores para pensar así. El usuario no está educado para pensar así, y la industria farmacéutica tiene sus propios intereses. Por lo tanto, el problema es de educación ${ }^{191}$.

Los "recortes" en sanidad se interpretan más bien como un proceso de racionalización - necesaria- del sector sanitario especial, sobre todo del sector público: "No se debería hablar de recortes sino más bien de racionalización, que es otra historia. Si el sistema sanitario es el que paga, el sistema sanitario tiene derecho a saber qué es lo que paga. En el caso de farmacia, si el sistema sanitario cree que hay unos fármacos que no se deben pagar porque el usuario mismo se los puede pagar por ser muy baratos, o bien porque se duda de la efectividad de los mismos; que no los pague y punto. Creo que tenemos una idea equivocada del sistema sanitario del Estado que tiene que pagar todo por definición. Yo creo que no. Precisamente en tiempos de crisis conviene que se pague aquello que sabemos que es útil, y si tenemos serias sospechas de que no es efectivo pues no lo pagamos. Que a igualdad de efectividad paguemos aquello que es más barato. No hay que gestionar un sistema sanitario como si se tratase de un sistema de Disneylandia. Es decir, se ha de gestionar bien y por lo tanto hay que aplicar unos criterios de racionalización" ${ }^{192}$.

Un área que tiene que mejorar su gestión es farmacia, es decir, recetas, gastos farmacéuticos, industria farmacéutica e investigación farmacéutica: ‘En España 19 de cada 100 pesetas sa- nitarias nos las gastamos en farmacia. Creo que en Estados Unidos son un $5 \%$, en Inglaterra un 7\%, y en Suecia un $8 \%$. Nuestro gasto farmacéutico es anómalo y merece una investigación. Cualquier cosa que se haga en esa dirección debe ser en principio bienvenida. Eso no es un signo de recorte sino un signo de buena gestión, o cuanto menos de preocupación por un fenómeno que es atípico. En ese sentido, no es pertinente hablar de 'recortes' en este campo. Sencillamente es un problema de gestión. Deberían producirse algunas intervenciones para eliminar fármacos que se están subsidiando y que no hay ninguna evidencia de que sirvan para nada" ${ }^{193}$. La utilidad práctica de muchos fármacos es dudosa: "Razones de tipo industrial, comercial, hacen que la población española siga estando expuesta a fármacos que para la inmensa mayoría de indicaciones no sirven para nada, y que en una minoría importante de los casos pueden causar efectos indeseables graves o moderadamente graves. La relación beneficio-riesgo es muy mala y la relación entre efectividad y coste pésima" ${ }^{194}$.

Pero los expertos/as no llegan a definir un culpable exacto del problema del gasto excesivo -y posiblemente irracionalen farmacia. Queda claro que la población es inocente: $\mathrm{El}$ problema de farmacia no es culpa de nadie, o es culpa de todos. El gasto en farmacia es porque se construye una Medicina de tipo farmacéutico. Al construir una Medicina muy burocratizada y muy masificada se genera una Medicina muy 'recetaria'. Confluyen intereses de todo el mundo. La industria farmacéutica se beneficia de ese tipo de Medicina. Los médicos que se ven obligados a trabajar en ambulatorios tienen una salida rápida, que es la receta. El hecho de que la creación del sistema implica una mayor demanda sanitaria de golpe, pues también da una salida rápida si no hay suficientes profesionales [...] Hemos educado a la población no a ir al médico para tener una persona que analice los problemas, y como persona puede afrontarlos, sino que hemos acostumbrado a la población a que vaya al médico a pedir recetas. Ahora el sistema se queja porque nuestra factura de recetas es altísima. Pero es un problema generado por el sistema sanitario [...] La población no iba al médico para que le dieran recetas, iba al médico para que le solucionara un problema. La forma en que el sistema le solucionó el problema fue dándole una receta. Ahora que la población está educada a ir al sistema a que le dé una receta, porque ya ha averiguado el tipo de receta que le soluciona el problema, resulta que no se la damos. "iUsted tiene que venir al médico ahora para otras cosas!'. Siempre se juega y se echa la culpa a la población" ${ }^{195}$. Pero hay también una defensa clara de la industria farmacéutica: "La industria farmacéutica hace lo que hay que hacer. Es una industria y como tal su objetivo es vender fármacos. Por lo tanto, no es ella la que se ha de imponer criterios de racionalización. Obviamente todo negocio tiene sus intereses. Por lo tanto, la industria farmacéutica defiende sus intereses, y el Sistema Nacional de Salud defiende los suyos. El consenso o el conflicto 
será el que resolverá las cosas. Los farmacéuticos defienden sus intereses, y los usuarios los suyos. Yo no creo en esa política inquisitoria 0 acusatoria contra la industria farmacéutica. La industria farmacéutica es una industria que produce fármacos, y que por lo tanto cuando produce un fármaco quiere venderlo al mayor número de gente y al precio más alto. No deduzcamos que el tener un determinado tipo de industria implique un sentido ético. No tiene por qué haberlo. Aparte, la industria farmacéutica puede estar incluso convencida de que se venden pocos fármacos" ${ }^{19}$.

La racionalización del gasto está realizándose contra la industria, no contra la población, según este experto: "Los recortes en el gasto lo que están haciendo es intentar transferir a la industria farmacéutica el coste, no a los usuarios. De todas maneras, sí que es cierto que hay un discurso ideológico creciente orientado a políticas del tipo del tíquet moderador como formas de reducir el uso de servicios innecesarios, de recaudar más recursos para el sistema, y como formas de corresponsabilizar al usuario [...] En Europa es difícil introducir un tíquet moderador de impacto real. Lo que se introducen son tíquets moderadores modestos, que tienen un impacto prácticamente nulo tanto sobre la recaudación como sobre la provisión de servicios. Su instalación responde más a presiones políticas que a gestión" ${ }^{197}$. La opinión es contraria a los tíquets moderadores, fundamentalmente porque moderan y tienen efectos negativos sobre las personas que más ayuda necesitan: El tíquet moderador es un problema muy grave porque se considera que puede controlar los costes, pero no se tiene en cuenta que precisamente los usuarios del sistema sanitario son las personas con mayores necesidades de salud. Las personas con mayores necesidades de salud suelen ser las personas con mayores incapacidades funcionales. Pueden ser los ancianos, los niños, las mujeres, y pueden ser personas con un nivel adquisitivo inferior. Con el tíquet moderador se está dificultando el acceso de las personas con mayores necesidades de salud. Esto podría redundar en que entra dinero en el sistema con el tíquet moderador, pero puede redundar en que sólo se beneficien los que ya ahora tienen menos necesidades de salud. En realidad, se está beneficiando a la clase económicamente más privilegiada y se están poniendo obstáculos al acceso a los servicios a las clases que tienen peor salud, que coinciden con las que tienen peor nivel económico. El tíquet moderador es un buen procedimiento para aumentar las desigualdades en saludd ${ }^{198}$. La opinión es prácticamente unánime entre los expertos/as: "La sociedad española no toleraría los tíquets moderadores. Desde una óptica de racionalidad carecen de sentido, porque si sirven para recaudar, entonces discriminan a los más pobres (posiblemente a los que más necesitan desde el punto de vista sanitario). Representarían una especie de impuestos a la enfermedad. Su utilidad disuasoria de gastos es totalmente ilusoria, dado que la deman- da más importante de servicios sanitarios es una demanda referida e inducidan ${ }^{109}$.

No se sabe qué pasará en el futuro. El problema económico es claro: "A largo plazo el problema es doble. Habrá más consumidores de la sanidad que además tienen unas prestaciones reconocidas, y por otro lado entre el paro y la pirámide poblacional que tenemos (que se está estrechando por debajo) no habrá, o habrá muy pocos, contribuyentes (o se exigirá mucho a un solo contribuyente). Entonces, no sabemos qué pasará a largo plazo, pero va a ser un problema grave ${ }^{200}$. La solución la ofrece uno de los expertos: resistir. E intentar controlar el gasto de los dos sectores con más poder dentro del sector sanitario, que representan a la industria y al poder profesional: "Aquí la única cosa que importa es que hay que defender al Estado y a los funcionarios del Estado. Aquí lo que hay que ir es aguantando la vela hasta que salgamos de la recesión, y haya más dinerito para todos. Aguantar y decir que no a la industria farmacéutica, y decir que no a los funcionarios del Insalud. ${ }^{201}$.

\section{Las políticas públicas en el futuro}

13. Interesa predecir el futuro del sector sanitario español antes de que se desarrollen problemas dificiles de resolver. Es importante saber si se producirá un deterioro del sector público. Se pregunta a los expertos/as sobre las consecuencias de la crisis económica sobre el sector sanitario. Interesa conocer los nuevos problemas sanitarios que puedan crearse como consecuencia de la crisis. Los problemas sanitarios españoles son comunes a los de otros países: "El sector sanitario español no se puede desvincular del sector sanitario de los países industrializados. La sanidad española tiene algo que es inherente a cualquier sistema sanitario: los recursos se están agotando, los avances de la tecnología y del conocimiento científico (aun cuando no se agoten los recursos) exigen más recursos de los que tenemos. Por lo tanto, hay un factor que nos exige dedicarle mucho más a la sanidad. ${ }^{202}$. El sector público en sanidad está solucionando muchos problemas que son sociales más que sanitarios: «El sistema sanitario, en un país como el nuestro, actúa de 'colchón'. También es el lugar donde tienen reflejo los desequilibrios sociales, las situaciones de carencia, los trastornos que provoca el desempleo y las situaciones de ansiedad ${ }^{203}$. Pero la sanidad es parte de los recursos sociales, y tiene que ser puesta en relación con el resto de la sociedad (sobre todo del sector público). El consejo es claro: «Como sociedad hemos de definir cuál es el sistema sanitario que queremos para nuestros hijos. Una vez 
que definimos cuánto queremos, hemos de definir cuánto estamos dispuestos a pagar por tal sistema (sea de recursos comunes o de recursos individuales). Una vez sabemos cuánto estamos dispuestos a pagar como sociedad, que seamos conscientes de lo que sacrificamos. A lo mejor tenemos un sistema sanitario excelente, pero un sistema educativo pobrísimo, o una infraestructura pobrísima. La sanidad no está aislada del resto de las otras áreas del bienestar social " ${ }^{204}$.

Uno de los expertos lo explica bien con una paradoja que circula por Harvard University: "Hay tres cosas importantes. Una es que todo el mundo acceda al sistema sanitario. Otra, es que la asistencia sea de calidad. La tercera es que sea a coste razonable. De estas tres cosas sólo podemos tener dos. Si tenemos un coste razonable, limitamos el acceso o limitamos la calidad. Si tenemos un acceso para todo el mundo, limitamos la calidad o tenemos un coste muy grande. Las tres cosas son bastante difíciles en cualquier sistema sanitario. Es un problema que muchos han llamado el triple sistema sanitario: el sistema clase turista, el sistema de primera clase y el sistema de lujo. A ese triple sistema sanitario es al que vamos a ir en el futuro desde cualquier sistema sanitario. Se trata de un sistema que intentará garantizar el máximo de servicios o prestaciones posibles pero habrá algunas prestaciones que no podremos garantizar, por lo que dependerá un poco del usuario" ${ }^{205}$. En el caso español este escenario es peculiar, pues todo se politiza en el sector sanitario: "En estos quince últimos años ha emergido una nueva cultura política que no sólo no censura el derroche sino que en algunos casos lo anima, lo incentiva. Se ha establecido esta idea de tipo cultural por la cual las decisiones políticas están por encima de todo lo demás. Por lo tanto, si la Consejera/o de Sanidad no es un asiduo feligrés de la parroquia del Consejero de Economía entonces se puede derrochar todo. Esto supuestamente es una decisión política, aunque estamos hablando de la Diputación Provincial de quién sabe dónde. El mundo de la política ha hecho mucho daño aquí. Se han politizado en extremo cosas que son absolutamente de gestión ${ }^{206}$.

Una hipótesis interesante es que no hay una diferencia clara entre el sector público y el sector privado: "Yo quisiera que se me explicase de una vez que es esto del 'sector público' [...] A la larga esto de público y privado va a llevar a una confluencia, son dos vasos comunicantes. Si va bien uno se chupa las entrañas del país, y si va bien el otro también se las chupa. La cuestión es la de mantener esto equilibrado. Esta diferenciación tan absoluta entre lo público y lo privado creo que tiene raíces hegeliano-marxistas o hegeliano-fascistas. Esto se va a ir borrando. La crisis conseguirá que la gente pague más si puede. En los hospitales aumentan las listas de espera. ¿Por qué aumentan? Porque no tienen dinero. Si pusiesen aparte todos los tíos innecesarios y todo el material innecesario, entonces mejoraríamos el país. Siempre es el ciudadano el que paga, ya sea con la antigua
Unión Soviética o con el capitalismo rabioso americano. No hablemos aquí de España porque sería mucho más comprometi$\mathrm{do}^{207}$.

Algunos expertos/as consideran que no hay un deterioro del sector público sanitario español; e incluso que la situación ha mejorado manifiestamente: "A pesar de que en los últimos años no se han aprovechado a fondo las posibilidades que tenía el sistema con su actual nivel de recursos de ofertar buenos servicios a la población del país, las cosas han mejorado. Yo no creo que haya habido un deterioro. Sin embargo, sí que son preocupantes algunos signos: por ejemplo, la moral del personal sanitario, el grado de identificación de los trabajadores sanitarios con su organización (a nivel micro con su hospital o consulta, y a nivel macro con el sistema). También es preocupante si las personas que pueden económicamente permitírselo eligen servicios sanitarios privados alternativos. Bien es verdad que guardar en la recámara la posibilidad de un acceso privilegiado al sistema público, que es donde todo el mundo sabe que están la tecnología, la capacidad y el buen hacer científico. Pero personalmente no creo que se produzca un deterioro del sector sanitario público" ${ }^{208}$. La situación ha mejorado el sector público, aunque en varios aspectos la gestión (pública) es ineficaz: aLa sanidad es el mejor servicio público que tenemos en el país. No cabe duda, sobre todo si se compara con algunos otros. La sanidad tiene enormes posibilidades de cara al futuro, pero depende mucho de cómo se muevan otras cosas del país. Desgraciadamente, los aspectos organizativos y de reforma de la sanidad española parecen ir unidos a la Administración pública española. La sanidad que bajo el sistema de la seguridad social tenía un status organizativo y gestor diferencial, cada día está más en un proceso de asimilación a la Administración pública. Nuestra Administración pública no es particularmente famosa por la agilidad de sus procedimientos o por su eficiencia ${ }^{209}$.

Otros expertos/as sí son partidarios de la idea de que se está produciendo un deterioro del sector público sanitario español. La causa es la propia crisis económica (que dura ya más de dos décadas aunque en los años finales de la década de los noventa parece que se mejora un poco). "La mayor consecuencia de la crisis económica del sector sanitario es la disputa por los recursos. La crisis económica lleva a una desestabilización, a una baja del empleo, menos cotizantes al sistema, menos recaudación fiscal; mientras que el volumen de los usuarios crece por la tendencia al envejecimiento de la población. Por lo tanto, la crisis económica general se manifiesta también como crisis económica en el sector sanitario" 210 . El deterioro se observa también en los nuevos intentos de reconversión del sector público: ¿El sector público se va a ir deteriorando progresivamente. Básicamente porque la defensa y la mejora del sector público no es una prioridad para el Estado. Más bien lo que se está haciendo 
es manteniendo lo que hay. Todos los intentos con respecto del sector público buscan desembarazarse de él. En los últimos años, se está empezando a crear empresas públicas autónomas. Lo que caracterizaba al sector sanitario español es que era parte del Estado (parte de la estructura del Estado) no el que fuese público. Las tendencias dominantes actuales muestran cómo una cosa es que sea financiado por el sector público, y otra cosa es que sea parte del Estado. Se está haciendo una progresiva conversión del sector público en empresas de carácter público: como si fuesen empresas privadas pero de capital público. En ese sentido, no hay una política de Estado clara ${ }^{211}$.

La reconversión del sector público sanitario español se plantea como una buena solución a la crisis: "Una crisis económica y una crisis social (porque yo creo que es más de una crisis lo que tenemos en estos momentos) tiene la característica de forzar y estimular a nuevas soluciones. Las consecuencias de la crisis pueden ser negativas como estamos acostumbrados a ver con un recorte en las prestaciones, pero también pueden ser positivas en el sentido de exigir que las prestaciones sanitarias sean más adecuadas, y que se ponga el acento en evitar los efectos indeseables de las intervenciones sanitarias (que los tienen, y muy importantes). El efecto es positivo, no sólo desde el punto de vista del ahorro económico (que para mí es secundario) sino desde el punto de vista de evitar a la gente las complicaciones que se derivan de un intervencionismo demasiado agresivo. "212. La crisis puede ser; pues, una oportunidad beneficiosa para un cambio necesario: "Un problema importante es que no seamos capaces de aprovechar la conciencia colectiva de situaciones de crisis e instituciones en emergencia, para hacer reformas que serían difíciles en época de bonanza. Es el caso de las plantillas sobredimensionadas del bajo nivel de rendimiento; de los centros sanitarios que funcionan a horas ridículas respecto a los de otros países. Son elementos que sería muy de lamentar que no fueran utilizados en la crisis, para producir precisamente un saneamiento del sector. No estoy llamando a una 'reconversión' del sector sanitario público, pero tampoco rehuyo el - término. Aquellas cosas que han de ser planteadas, la 'cirugía' que haya que hacer, no encuentran mejor momento que estos momentos de crisis. Haríamos un mal servicio al país si no tuviéramos estas reflexiones precisamente en estos momentos, y pensáramos que es más fácil hacer planteamientos de destrucción de la cobertura universal y de su financiación pública, antes que abordar esas cosas" ${ }^{213}$. Pero el peligro es que no se utilice esta crisis para producir mejoras, para lograr una gestión mejor: "Sobre los problemas que pueden derivarse de la crisis para el sistema sanitario el más peligroso puede derivarse de la ignorancia acerca del papel que cumplen los servicios sanitarios universalizados y financiados públicamente en una sociedad democrática, y de la alternativa que hay a los mismos. Me preocupa que como consecuencia de la crisis económica en vez de profundizar en los mecanismos para tener una gestión más efi- ciente, para sacar chispas al dinero público, para hacer que las cosas funcionen mejor, nos debatamos en un cuestionamiento permanente de algo que es considerado afortunadamente por nuestra sociedad como una conquista irrenunciable, y parte de una especie de pacto sociab. ${ }^{214}$.

Hay una llamada —casi angustiosa - a conservar las instituciones sanitarias públicas. Representan un logro. Son parte (como señala el experto anterior) de un pacto social implícito: "En España aparte de un sistema de pensiones generalizado (más bajas que en toda Europa), un sistema educativo, sanitario, y alguna cosa más, no tenemos nada más. En otros países como Alemania o Gran Bretaña están recortando las prestaciones. sociales. Es terrible que esto ocurra en ciertos aspectos. Pero es que aquí no pueden quitarlo porque no hay. Entonces, ¿de dónde van a quitar? Yo creo que no van a poder quitar de ese pilar básico que tenemos. Pase lo que pase, lo que hay que hacer es una buena gestión y no creernos que somos midas. ${ }^{215}$ Está claro que la gestión del sector público no es adecuada ${ }^{216}$. Pero tampoco hay una buena gestión en el sector privado: ala planificación y la gestión del sistema sanitario español en términos técnicos todavía deja mucho que desear. No hay una tradición de buena gestión en la Administración Pública. Incluso el gestionar en aras a la eficiencia es una mentalidad ajena a gran parte de quienes trabajan en la Administración. Muchos de ellos ni siquiera son profesionales de la gestión. El sector privado español tampoco tiene una tradición de buena gestión ${ }^{217}$. Hay una crítica aguda al papanatismo generalizado sobre el poder de los nuevos expertos en gestión: ‘La preocupación por la eficiencia, y por el control de costes, ha venido para quedarse con nosotros durante muchos años. Si eso se ha de traducir en una especie de nueva religión de los gestores, pensando que la contabilidad analítica es la píldora mágica que ha de resolver los problemas de la gestión, sería una de las muchas estupideces que se podrían hacer. Pero yo creo que lo más sólido que va a quedar de la crisis económica; es que los recursos sanitarios son limitados y que necesitan una gestión cuidadosa ${ }^{218}$.

Hay alguna opinión tendente a favorecer el sector privado, aunque es minoritaria entre el grupo de expertos/as, y además matizada: "Se podría ir en la dirección de favorecer los servicios privados financiados por el sector público. Esto permitiría una mayor competitividad, siempre que se mantuviera un control de calidad del sector público. El Estado debe de controlar la calidad en los servicios que se prestan, y solamente concertar servicios con las organizaciones privadas que den los servicios de acuerdo a los criterios de calidad. Sería una gran ventaja si empezaran a abrir el campo de trabajo a la medicina privada, pero dentro de unos criterios de calidad establecidos por el sistema públicon ${ }^{219}$. La crítica de la privatización de la gestión (pagada por el sector público), y de la "nueva religión. de los gestores, es clara y con un buen análisis: sLa forma que ven de que pue- 
da funcionar el sector público es haciéndolo un poco más autónomo, convirtiendo cogestión privada aunque sea con propiedad pública. En cualquier caso, eso implica que es una empresa que compite en un mercado; porque la mentalidad es que sea una empresa aunque sea pública. Ésta es la mentalidad dominante porque son los economistas conservadores y de derechas los que dominan la política sanitaria. Eso lo que hace es poner al sector público (poner a un hospital público) en el mercado, y se quiere que sea competitivo en el mercado. Pero un hospital de la Seguridad Social no puede ser nunca competitivo en el mercado porque juega papeles diferentes: está jugando el papel de educación, y de alta tecnología frente a hospitales que no lo hacen [...] Nos olvidamos de que la parte esencial de que fuera público, era que procurara un acceso igual a toda la población, que asegurara buenos recursos, una alta tecnología, que fuera a la vez parte del sistema educativo. Si para hacernos competitivos tenemos que empezar a cortar por ahí, nos encontramos con que quizás serán organizaciones competitivas, pero no necesariamente organizaciones que aseguren la equidad. En ese sentido, se puede deteriorar el sector público, no como empresa, sino como prestaciones sociales [...] El sector público juega la labor de más calidad, de educación, de investigación, con lo cual tiene muchos médicos y enfermeras. Eso cuesta mucho más dinero, pero es la función pública. Si lo convertimos en empresa que juega en el mercado, esa función no la va a jugar. Ése es el problema por donde se puede deteriorar la oferta pública. ${ }^{220}$.

Parece que la sanidad ya no está de moda. Lo estuvo $-\mathrm{y}$ mucho- en los años setenta, e incluso ochenta. Pero ahora al filo del siglo XXI es un tema marginal de discusión. Supone además un gasto importante, y en épocas de crisis eso puede ser exasperante: "La sanidad no es una prioridad en nuestro país, no es una prioridad política. Lo fue durante unos años, pero ya no lo es. No sé cual es la prioridad política ahora. El Ministerio de Sanidad siempre ha sido una parte pequeña, con poco poder. Pero durante años, la construcción del Sistema $\mathrm{Na}$ cional de Salud era importante. En estos momentos no lo es" ${ }^{221}$. Sin embargo, uno de los expertos con más perspectiva sentencia: «El sector público existirá y seguirá existiendo porque es la columna vertebral de todo el sistema. Permítanme la paradoja: sólo los pobres se pueden pagar el lujo de tener las buenas instalaciones. Fue el fondo de salarios el que permitió financiar el equipamiento hospitalario español. Eso puso en evidencia todo el equipamiento que existía anteriormente en orden a dotación, pero porque no tenían capacidad suficiente para poder transferirle ese coste al presupuesto del Estado" ${ }^{222}$.

14. Es importante analizar el impacto de un Gobierno central conservador sobre el sector sanitario. También conviene saber los efectos - diferenciales - que tendrian diversos tipos de Gobierno sobre el Sistema Nacional de Salud, sobre el nivel de salud de los españoles/as. Preguntados justo al final de los gobiernos socialistas españoles -en el Delphi- el mencionar que el Gobierno de la nación puede ser conservador es suficiente para que varios expertos/as consideren la situación como negativa y problemática: «El futuro lo veo muy negro. Los gestores actuales sanitarios, sostenidos por un grupo político que se llama socialista, no lo están haciendo bien. Un grupo político que no se llame socialista, sino que se llame popular, va a disminuir lo que de público tenga el sistema sanitario español, y esto no es la mejor forma de actuar. Con estas dos cosas: el desprestigio actual del sistema sanitario español por gestión inadecuada, no correcta; y con el argumento de 'si no lo hemos sabido hacer nosotros es que esto no tiene remedio' se va a acabar cumpliendo que el sistema sanitario se va a la puñeta. La alternativa de cambio desde el punto de vista público - desde mi punto de vista- no puede ser peor ${ }^{223}$.

Varios expertos coinciden en que en un gobiemo del Partido Popular (PP) no ocurre nada especial en el sector sanitario. Los argumentos políticos son interesantes: "Esto de socialistas del PSOE y conservadores es mala cosa. Porque socialista ya no se puede ser mucho. Porque antes cuando los partidos eran marxistas, creaban una nueva clase dominante. Ahora todo el mundo ya se llama 'socialista', 'social demócrata', o 'socialistasliberados'. Si un partido se llama conservador, va mal, porque en esta vida lo único que no se puede ser es conservador. Porque conservar quiere decir consolidar, congelar al que manda. Esto es lo que les ha pasado a los comunistas que iban a consolidar y a conservar a los que mandaban. Si los del PP ya empiezan diciendo que van a consolidar lo que tienen, malo. Unos señores que digan: 'Lo que nosotros queremos es seguir mandando siempre', no los va a votar ni Dios [sic]. Quizás habrá un predominio de los regionalistas y los nacionalistas, y veremos cómo esto se articula a nivel de Madrid. Yo creo que se va hacia una descentralización. El poder va a ir más para abajo [...] Yo creo que los del PP hablarán y hablarán y no harán nada. En el resto de España fuera de Cataluña, Madrid, y quizás en el País Vasco, y no sé si empieza a haber algo en Valencia, no hay sector privado porque no hay sociedad civil. ¿Cómo van a privatizar en Murcia o en Andalucía? Quizá en Sevilla haya algo [...] Esto va con una dinámica propia que está ligada al avance social y ético. Mucho hablar, mucho hablar pero -como la señora Thatcher - no van a hacer nada. Porque cualquier cosa que quieran privatizar les va a costar mucho dinero y caerán en bancarrota. ${ }^{224}$. El PP no va a cambiar nada (no privatiza, sobre todo) porque el coste sería enorme: si uno hace caso de lo que dice el $\mathrm{PP}$ en sus programas, habría una tendencia muy radical a introducir más fuertemente el mercado y el sector privado dentro de la sanidad española. Al mismo tiempo hay un reconocimiento tan explícito de los derechos de los trabajadores del sector público, que lo que creo es que el programa tal y como está pensado es irrealizable. Por tanto, una de dos: o el gobier- 
no del PP entra en una espiral de gasto absolutamente increible en una época de crisis, o bien no va a realizar su programa salvo gestionar los servicios existentes con algunos cambios cosméticos [...] La verdad es que desmontar el Sistema Nacional de Salud que tenemos, y sustituirlo por un sistema más privado, probablemente dispararía los costes al doble. Y un aparato productivo en crisis, donde siempre se quejan de que gastamos dinero financiando los servicios públicos, probablemente no podría soportar esto. A menos que entremos en una dinámica muy peligrosa para el futuro de nuestro país, un gobiemo conservador no realizaría cambios fundamentales en el sistema" ${ }^{225}$. No cambiaría nada, pues la experiencia gallega o catalana demuestra que los gobiernos conservadores no producen grandes transformaciones en el sector sanitario. Cabe la duda que un Gobiemo de la nación tuviese un impacto diferente a los Gobiernos autonómicos. "No creo de ninguna manera que con el PP (pues no serían coherentes con su propia política) deje de haber una sanidad universal. Sí que puede ser que potencien más un sistema mixto. Pero yo creo que el PSOE también va por esa línea. Los otros partidos políticos también. Si nos fijamos en el modelo gallego vemos que no es muy diferente de otras Autonomías parejas. Es una de las cosas en las cuales el cambio de Gobierno quizá no tenga influencia real en el sistema sanitario. Influyen en el sentido de que todos los cargos políticos cambian obviamente. Pero no influye mucho porque ahora mismo la política sanitaria no da para mucho más juego. Está muy determinada y condicionada por la crisis económica del sistema que es universal ${ }^{226}$.

Hay algunos expertos/as (no necesariamente de derechas, aunque sí de una cierta izquierda "desencantada") que consideran que un Gobierno central de derechas (o de centro-derecha) es positivo e incluso renovador. En la perspectiva de los años noventa: "Realmente es muy posible que el próximo Gobierno sea del PP. Cualquier demócrata debería congratularse de que esto sea así. Esto llevará a algunos perjuicios desde la óptica de quienes compartimos las ideas de izquierda. Pero no está claro que estos perjuicios sean superiores a los beneficios que es posible - yo diría incluso que es probable- conlleve el acceso de una nueva maquinaria, de un nuevo partido al poder. Me refiero a la renovación de las formas de trabajo, de las formas de hacer gestión, de las formas de hacer política. La permanencia en el poder conlleva una progresiva contemporización, benevolencia y complacencia con intereses económicos y de todo tipo. Cada vez resulta más difícil llevarles la contraria a la gente que lo único que pretende es ganar dinero y trabajar menos. Por lo tanto, yo creo que esta renovación podría superar los perjuicios que desde una determinada óptica ideológica algunos creemos que puede conllevar. Puede que se privaticen cosas que algunos creemos que no deberían privatizarse. Que esto tenga un impacto negativo sobre la salud de la población, también habría que verlo.
Yo creo que no influirá mucho. Quizás habría que ser más valientes, y ver qué ocurre ${ }^{227}$.

Pero el resto de expertos entrevistados enumera los problemas que se generan con un Gobierno central conservador, en el sector sanitario: «No creo que el PP vaya a acabar con el Sistema Nacional de Salud. Es posible que potencie los intereses del sector privado dentro del sistema nacional, y que el sector público sea más competitivo en términos económicos (no en términos de servicios sociales). A la :vez defenderá una parte importante de los intereses médicos, con lo cual puede haber transformaciones. Los médicos no quieren ser funcionarios, quieren tener más libertad, más espacio [...] Al PP le preocupa menos el tema de las desigualdades regionales o entre grupos sociales. Sobre el tema del coste farmacéutico, la relación con la industria farmacéutica es mayor que la que puedan tener los socialistas, por lo tanto no tendrán tanto interés en recortar ${ }^{228}$. La primera consecuencia (de un Gobierno del PP) en sanidad es un cambio hacia el proteccionismo como parte de un proceso general (aunque tímido) de privatización: «No me parece que el PP presente una propuesta de política de salud radicalmente diferente. No recuerdo haber visto nunca una formulación de objetivos de salud y de distribución de recursos del sector público en asistencia sanitaria suficientemente clara. Con todo, es previsible que se plantee un aumento en la privatización. Es posible que se produzca un aumento de la privatización, que incluya dimensión financiera. Ocurre a menudo que los defensores teóricos de ideologías más liberales no son consecuentes, en el sentido de que no plantean la introducción de fórmulas de mercado sino de protección a una parte de la oferta. Las prácticas monopolistas son bastante típicas de los liberales, aunque sea una contradicción. Por eso no sé si realmente el PP se plantearía una liberalización tradicional del sector sanitario; o, por el contrario, podría ser una actividad proteccionista más corporativa de intereses empresariales o intereses profesionales ${ }^{220}$.

Se supone pues que un Gobierno central de derechas orienta su política pública más hacia un sistema mixto: "El gran debate es quién presta los servicios. Los socialistas tienen todavía un poco de ideología socialista, pública, por lo tanto todavía priman el sector público sobre el privado. Los del PP no van a hacer eso necesariamente. Se puede llegar a un sistema sanitario mucho más mixto. Eso me preocupa mucho, porque el sector sanitario privado no es un sector muy vital. Económicamente es un sector muy poco ágil, con poca imaginación. Además, básicamente no tiene ningún interés en solucionar los problemas de salud de la población, sino en sobrevivir en el mercado. ${ }^{230}$. Las consecuencias - según algún experto- de un gobierno conservador son malas ${ }^{231}$. El problema no es la privatización de una estructura de beneficencia, sino de una industria considerable: «El gran problema con el que se van a encontrar socialistas 
o conservadores es que la sanidad ya no es la Medicina. Ya no son tres hospitales por ahí. Es un gran complejo industrial, uno de los más potentes complejos industriales de toda sociedad [...] El objetivo es el propio objetivo económico de supervivencia de esa organización o complejo industrial. El complejo industrial incluye toda la industria sanitaria, farmacéutica, miles y miles de profesionales que trabajan a diferentes niveles. Es un gran complejo industrial. La salud es una excusa. Lo importante es la supervivencia y el beneficio generado por este complejo industrial. El PP por supuesto que agudizará esa vertiente porque permitirá el acceso de los intereses más económicos a la planificación sanitaria; frente al PSOE que quizás estaría más sensible a las preocupaciones de la población (o las preocupaciones más izquierdosas de ciertos sectores de los médicos) ${ }_{2} 232$. Esta privatización - ya sea de financiación como de gestiónpuede producir un incremento de las desigualdades sanitarias: alnicialmente se asume, y con toda seguridad ocurrirá, que el sector privado tendrá más oportunidades con un gobierno del PP. Me preocuparía si tal cosa ocurriera en el lado de la financiación de la sanidad. Me preocupa menos si ocurre únicamente en el lado de la provisión, y si no genera desigualdades de acceso, o desigualdades de equidad por clases sociales ${ }^{233}$. Esta desigualdad sería mayor en los grupos sociales más marginales: "Habría una mayor restricción de los servicios públicos, que aumentarían las desigualdades en salud. Por otra parte, se daría mayor cabida a los servicios privados, pero no sé hasta qué punto habría un control de calidad en los servicios privados. Probablemente tendríamos más tíquets moderadores, y tendríamos más recortes en las prestaciones de lo que hay ahora. Aumentaría la diferencia entre la clase más marginal y la mayor parte de la sociedad. Quizás con este tipo de Gobierno aumentaría también la clase más marginal" ${ }^{234}$. El tema de pobreza -como underclass- preocupa seriamente: «El cambio de Gobierno implicaría disminución del sector público y aumento del sector privado, y consecuentemente un aumento de la bolsa de pobreza. No me refiero a pobreza económica, sino de las personas marginadas que no van a recibir atención en el sector privado, sino que se tendrán que refugiar en un sistema público. Por eso afirmo que vamos en camino de un nuevo modelo de beneficencian 235 .

A algunos expertos/as les interesa más la aplicación de ese posible proceso de privatización a nivel micro: «Lo más fácil es pensar que habrá determinadas privatizaciones. La gran incógnita es si esto supondrá un cambio en las formas de gestión, de hacer política sanitaria al nivel micro. Me importa más el nivel micro: cómo actuarán pues los directores de hospitales, en función de qué parámetros se nombrará a los gerentes de hospitales, si se conseguirá incentivar a los médicos y las enfermeras para hacer la buena Medicina que hacíamos, etc. Esas intenciones flotaban en los aires que se respiraban en el año 1983. Pero. luego han ido desapareciendo, y ya se ha renunciado a trans- formaciones más profundas. (Y no lo digo como crítica a personas concretas, porque creo que es un error absoluto criticar a personas concretas). Toda la maquinaria del Gobierno ha ido renunciando a una reforma en la que el componente humano es absolutamente esencial. ${ }^{236}$. El futuro Gobierno del PP tiene pues que tener en cuenta que hay un cierto consenso social en que un extenso sector público sanitario, y una fuerte financiación pública de la sanidad, son ya características indeclinables de la sociedad española contemporánea: "Hay un consenso en que una sociedad moderna como la nuestra tiene una conquista sólida y estable que es que los servicios sanitarios públicos forman parte del pacto social y del acuerdo de convivencia. ¡Por supuesto que habrá cambios! Pero dada la experiencia de los últimos años, no se me antoja que sean variaciones dramáticas; salvo que alguien cometa locuras" ${ }^{237}$. También hay consenso entre los expertos/as.

15. A los expertos/as se les plantea que expliquen lo que cambiarian en el sector sanitario español. Es una forma indirecta de evaluar algunos problemas sanitarios más acuciantes que se van a generar en el futuro, $y$ de definir algunas soluciones innovadoras. Tras un análisis detallado del sector sanitario espanol de cara al futuro se concluye que la situación es mejor de lo que se pensaba al principio. El sector sanitario en España sobre todo el sistema público- es un logro al que no se puede renunciar. Las dos décadas y media de crisis económica han hecho mella en el modelo de Estado de Bienestar ${ }^{238}$. Como los expertos/as sugieren al principio no hay "varita mágica", ni soluciones sorprendentes. Las sugerencias de cambios se clasifican según los actores del sector sanitario: Gobierno, Sistema Nacional de Salud (SNS), capital humano y la propia población.

La crítica más general es hacia el paradigma médico-sanitario que conviene cambiar: aSanidad no es igual a salud, y salud no es igual a sanidad. Salud es una parte de la sanidad. Lo que pasa es que es la parte más barata. Tener un sistema sanitario es lo más barato para hacer frente al tema de salud. Es también lo más injusto para los ciudadanos, aunque tampoco les preocupa esto demasiado a los políticos. Es lo que más satisface los intereses de la industria farmacéutica, de los médicos, etc. Es un gran complejo industrial que asegura miles y miles de puestos de trabajo. Eso se perpetúa, se legitima en la sociedad. Se argumenta que un sistema sanitario es necesario frente a hacer casas mejores, tener más parques; es decir, otras muchas políticas que son costosas para el Estado, y no muy beneficiosas para ningún grupo en concreto, pero beneficiosas para la población en general. Yo cambiaría todo el sistema sanitario [...] Una buena salud se asegura con unas buenas condiciones de vida. El sistema sanitario tendría que estar orientado a la salud [...] Esto no se está haciendo en ningún otro país porque la concepción dominante -cuando hablamos de salud- es la concepción sanitaria, la intervencionista sobre el cuerpo, la que 'corta y pega'. Es la con- 
cepción de los profesionales de la medicina, de la industria médica-farmacéutica; frente a la concepción más de salud pública, más social que implica redistribución de la renta. Son conceptos diferentes ${ }^{239}$.

Otros expertos son más directos: solicitan que lo que cambie sea el Gobierno: "Lo que yo cambiaría de la sanidad española actual es el Gobierno. Yo pondría un partido con una politica de izquierdas de verdad, que piense en la gente, en los necesitados y en la solidaridad ${ }^{240}$. Otro matiza, sugiriendo el cambio de los/as economistas (y en particular de los/as economistas de la salud): "A mí lo que me preocupa es que haya demasiados dogmáticos. Hemos tenido el dogmático hegeliano-fascista, luego tuvimos el dogmático hegeliano-marxista, y ahora podemos tener el dogmático de la Escuela de Chicago. Lo malo son los dogmáticos que crean mitos. Los mitos son muy peligrosos. Aquí hay que saber que nadie tiene toda la razón y que todo el mundo tiene la culpa ${ }^{241}$. Ambas posiciones participan de la necesidad de un cambio generacional, sobre todo en las personas que ocupan puestos de poder en el sistema sanitario: "Se necesita un relevo generacional, pero no de la noche a la mañana. Se necesita formar nueva gente sobre todo en el extranjero, y que esa gente sustituya o releve a los que tienen una formación autodidacta [...] Hemos de abrir el sistema a nuevas ideas, a nuevas personas. Eso es la vida. Nos tocará a todos en algún momento también dejar pasar a los de atrás" ${ }^{242}$.

Un cambio de modelo en sanidad requiere el desarrollo de politicas sociales no-sanitarias, pero que tienen un impacto considerable en el nivel de salud de la población. El consejo es claro: "En primer lugar no construiría un sistema sanitario. No convertiría al sistema sanitario en la pieza central de la salud de los españoles porque no lo es. Le daría su peso concreto. Que sea eficaz contra ciertos problemas. Pero la salud de los espanoles requiere otro sistema, de otra estructura, otra política que no es exclusivamente sanitaria. Son políticas sociales que van orientadas a una mejor redistribución de la renta, a evitar las bolsas de pobreza, aumentar la calidad de vida de la población, reducir el estrés, mejorar las condiciones de vida en las ciudades, aumentar el tamaño de las casas de 40 metros cuadrados (en que viven gran parte de los trabajadores de nuestro país), y a mejorar las condiciones de trabajo. ${ }^{243}$. El nivel de salud de la población debe ser la variable dependiente fundamental del sector sanitario del futuro: "El sector sanitario español debería trabajar con la meta de la salud como referencia, con la conciencia de que muchos otros factores influyen más determinantemente sobre la salud que el sector sanitario. Pero que si alguna justificación tiene el sector sanitario que lo legitime delante del resto de la sociedad es poder contribuir a mejorar la salud de la población, sea de una forma global, o sea, a partir de mejorar la vivencia, la calidad de vida que los enfermos tie- nen de su enfermedad. Eso no es un problema técnico sino de adecuación de los recursos" ${ }^{244}$. Supone un nuevo enfoque -casi filosófico- del sistema sanitario, en donde el concepto de calidad de vida debe ser básico: "Lo más importante que se debería cambiar sería introducir, como uno de los elementos de reflexión cotidianos, el valor que significa, o la realidad de la muerte y de la enfermedad en la población. No es una cuestión del sector sanitario estrictamente, sino de la filosofía de la vida que caracteriza nuestra civilización. No es que debamos vivir preocupados u obsesionados por la muerte pero sí que la tuviéramos en cuenta. Probablemente algunas de las intervenciones sanitarias que ahora de forma decidida se llevan a cabo no se harían tan alegremente, y probablemente ello redundaría en una mejor calidad de vida de la población. Éste sería uno de los elementos que le faltan de contrapeso a los valores del sistema sanitario español, y del sistema de la civilización que nos ha tocado vivir ${ }^{245}$.

Otro de los expertos insiste, de nuevo, en que el problema fundamental consiste en completar la reforma de la atención primaria: "El gran reto es completar el proceso de reforma de la atención primaria, para poder encarar luego más cambios en el sistema. Pero todo el sistema sufre mucho ya que no ha avanzado más en este terreno" ${ }^{246}$. Se citan soluciones concretas, como sanidad dental infantil: "Extender servicios dentales a la población infantil es una cosa cuyo coste económico es despreciable, y cuyo efecto en la salud de la población es alto" ${ }^{247}$. También la mejora del trato bumano en el sector público: «Hay un aspecto simple en el sector sanitario que es que la gente que esté dando la cara al público sea amable y acogedora. Esto me parece importantísimo. Puede parecer una tontería pero la mayoría es gente muy desagradable, que parece que hagan un favor atendiéndote. Es al contrario; realmente hay que ser muy acogedor porque la gente que acude al sistema sanitario, no solamente tiene todo el derecho sino que además está en una situación seguramente difícil. Cuanto más fácil se lo pongan mejor. Es un aspecto básico: aparte de lo que haga el sistema que lo haga bien hecho, que atiendan amablemente ${ }^{248}$. Los problemas organizativos alcanzan también aspectos financieros que deberían cambiar ${ }^{249}$.

En el capital bumano, dentro del sector sanitario, la atención se dirige a un cambio en la forma de actuar (y trabajar) de la profesión médica. Una experta recomienda: "Debe haber un cambio de la mentalidad de los médicos. Tiene que haber una mentalidad más amplia del profesional sanitario en general y en particular de los médicos. Empezando por la Universidad, o sea empezando por incluir en el propio curriculum de Medicina y también de Enfermería los temas de política sanitaria, sistema sanitario, algunos temas de sociedad, muchos temas de salud pública clásica, dándole una mayor importancia. Que se viera que el producto sanitario es la salud de la población. Esto es 
algo que se pierde muchas veces en la educación médica que es muy curativa. Lo que puede ser bueno para un paciente a lo mejor si se hace con todos sería un desastre. Eso es algo que falta mucho en las Facultades de Medicina ${ }^{250}$.

Los expertos/as del Delphi sugieren cambios allí donde les aprieta el zapato. Quizás lo que más duele es que se les hace poco caso. Ellos/as saben cuáles son los problemas del sector sanitario, los investigan diariamente, pero luego los políticos/as no cambian (casi) nada. La mayoría de los mejores estudios sobre el sector sanitario $\longrightarrow$ sobre aspectos concretos de la sanidad- quedaron en un cajón ministerial; o del Consejero de Sanidad autonómico respectivo. Una de estas expertas desea: :Que los trabajos de los expertos no se queden en los cajones! A lo largo de mi vida profesional he participado en diferentes proyectos y estudios. No sé si muchas veces estas cosas que nos encargan, y que intentamos hacer lo mejor posible, y argumentar con una serie de datos, luego sirven para algo. Porque en algunas ocasiones una tiene la impresión de que no es así [...] En realidad, cuando se decide averiguar algo de una situación, es razonable pensar que es para intentar mejorarlo o arreglarlo. Pues que eso sea efectivamente así. Algunas veces parece que se ha invertido esfuerzo, tiempo, energía, ilusión y dinero seguramente en averiguar cosas de determinadas áreas y se ha intentado al menos dar información para decidir sobre ello. Luego pasa un cierto tiempo y parece que eso no haya tenido demasiada efectividad ${ }^{251}$.

Last but not least hay una llamada al consenso de la sociedad, para preservar y mejorar en el futuro el sistema sanitario actual y el buen nivel sanitario de la población (conseguido de forma casi mágica): «Lo que hace falta es un análisis global de la situación y meterse a fondo en ello. Pero con un acuerdo general de todos los grupos, de todos los organismos, de todos los actores sociales implicados en esto. Por supuesto, contando con los propios usuarios del sector sanitario. Yo creo que es muy necesario un estudio organizativo, serio. Para eso es muy necesario un consenso entre los distintos grupos políticos, entre los profesionales que trabajan alli, y los usuarios ${ }^{252}$. Este consenso requiere una nueva filosofía y una nueva práctica de entendimiento ${ }^{253}$. Los expertos/as realizan además una llamada, oportuna, a la responsabilidad de todos/as: políticos, sistema sanitario, profesionales, redes sociales de apoyo (familias, vecinos/as), usuarios/as o clientes, y población en general. Es necesario cambiar: "El sentido de responsabilidad. No se puede caer en la demagogia de dar soluciones simples a planteamientos y realidades complejas. El sistema sanitario es la empresa más compleja que existe. Es generadora y creadora de ciencia. Al mismo tiempo es el gran paliativo que está trabajando en dar respuesta al misterio que acompaña siempre al ser humano, que es el misterio del dolor y de la muerte, y sobre todo el misterio del dolor en una persona inocente. ${ }^{254^{\prime}}$.

El sistema sanitario español que hemos heredado -como casi todo lo que proviene del franquismo- es un sistema "otorgado. Quizás el cambio más importante de la sanidad en España, con vistas al tercer milenio, es precisamente la reconquista de la salud (y del sector sanitario) por la población. Como senala uno de los expertos: "Sería bueno que nuestro sistema sanitario surgiera de la sociedad, y del cual la sociedad se sintiera orgullosa. Eso es importante. Parte del problema es la Universidad española y el sistema educativo que funcionan muy mal en nuestro país. No estamos formando gente para reflexionar, estamos formando gente para decir amén. Y ése es el gran probleman $^{25 s}$. El logro fundamental sería que la salud de la población dependiese cada vez menos del sistema sanitario ${ }^{256}$. Así lo expresa contundentemente otro de los expertos: «Espero y sigo esperando que la salud de los españoles no dependa demasiado del sistema sanitario. A mí me gustaría que la salud de los españoles no dependiese para nada del sistema sanitario ${ }^{257}$. Eso puede ocurrir en el siglo XXI.
- Jordi CA's de la London School y Economics es profesor actualmente en la Universidad de Barcelona. Emilio J. Castrula enseña en Stanford University. Jesús M. DE MIGUEL es Vicepresidente de Ciencias Sociales, de European Cooperation in the Field of Scientific and Technical Research, de la Comisión Europea (Bruselas).

\footnotetext{
' Esta construcción en negativo es llamativa. La frase la tomamos prestada de Jorge Semprín, entonces Ministro de Cultura en el Gobierno de Felipe González. Se recoge aquí la reflexión que le hace llegar a tal afirmación: .En el curso de los treinta y dos meses pasados en el Gobiemo, he conocido a ministros que no tenian nada que decir. Algunos decían algo, cualquier cosa, a pesar de ello, sin duda para convencerse de que existían al oír su propia voz. Algunos no decían nada, o bien porque no tenían nada que decir o bien porque preferían guardar un prudente silencio. La palma a este respecto se la llevaba sin duda el Ministro de Sanidad. Era mi vecino por la izquierda en la larga mesa oval del Consejo. Un hombre afable, economista de profesión, que tenía en contra suya un molesto parecido con Groucho Marx lse refiere a Julián García Vargas]. Lo que no tenía en contra suya eran sus palabras, sin embargo,
}

puesto que no decía nada, apenas nada. Durante cerca de tres años no le habré oído prácticamente nunca tomar posición sobre una cuestión política de fondo. Nunca tampoco le habré oído exponer o proponer algo importante relativo a su departamento ministerial. Aunque sea difícil de pensar que no haya nada que decir sobre la salud pública durante tan largo tiempo. La sanidad no es la menor de las preocupaciones en un pais de democracia moderna, parece demostrable. Jorge Semprún, $\mathrm{Fe}$ derico Sánchez se despide de ustedes (Barcelona: Tusquets, 1993), p. 74. Julián García Vargas pasa luego a una responsabilidad aún mayor $-y$ más políica- siendo Ministro de Defensa.

' La frase es de otro Ministro en este caso la ex-Ministra de Sanidad y Consumo, $M$. Angeles Amador en un artículo suyo (no es una entrevista o un resumen de prensa) titulado .La protección de la salud, un compromiso. El País (31 enero 1994), p. 29.

'La entonces Ministra termina el artículo con las propuestas para el futuro: $\mathrm{Se}$ guir garantizando a todos los españoles la atención sanitaria en condiciones de igual- 
dad, mejorar la calidad de la atención, reducir los tiempos de espera a plazos razonables dentro del marco financiero posible, es nuestra tarea en los próximos años. M. Angeles Amador .La protección de la salud, un compromiso. El País (31 enero 1994), p. 29.

' Es el porcentaje más bajo de todos los países de la OCDE a excepción de Portugal $(5,3 \%$ del PIB).

"Es del $72 \%$ cuando la media de los países de la OCDE es del $77 \%$. España sólo supera a Portugal (61\%) y a los Estados Unidos (41\%); este último país con un sistema público sanitario marginal y problemático.

"El descenso es pequeño pero significativo: 69,9\% de camas públicas en 1949, a $68,9 \%$ en 1990 (los datos son oficiales, del INE).

- En 1949 (el primer censo hospitalario fiable en España) había 44,5 camas por 10.000 habitantes. En 1990 habian descendido a 42,6. A pesar de esta situación carencial llamativa los hospitales sólo están ocupados al 76\% de su capacidad.

${ }^{8}$ Tan sólo a un $9 \%$, el porcentaje más bajo en toda la OCDE. En la vecina Francia es el $21 \%$, en Italia el $15 \%$, Alemania $21 \%$, Suecia $20 \%$.

${ }^{2}$ M. Angeles Amador sLa protección de la salud, un compromiso. El País (31 enero 1994), p. 29.

in E2, p. 9 (se refiere a un texto que aparece en la página 9 de la entrevista 2). Otro experto añade: En nuestro país no se innova nada, se copia y mal. Es un país muy poco creativo a estos niveles. Es muy creativo -y lo era más todavia antes-a nivel de disfrutar de la vida. Pero a nivel científico nada. No creo que vayamos a ningún lado. (E12, p. 26).

" Hay circunstancias de las cuales sabemos poco. Entonces parece que no exista el problema. Pero no es tanto que no exista el problema sino que tenemos poca informacion. (E11, p. 6).

12. La pena es que no tengamos una bola mágica. ¡Cómo voy a responder yo si no lo sabe nadie!. (E7, p. 7).

"E1, p. 19.

"Se realizaron doce entrevistas en profundidad a expertos/as, que aparecen numeradas como E1 (entrevistas número 1), E2, E3, etc. Las citas aparecen con el número de la entrevista y la página exacta del transcrito de cada una de ellas. No existe un orden estratégico, salvo el cronológico de entrevista. Las entrevistas se realizaron en los meses de febrero y marzo de 1994. Los textos se elaboraron hasta mayo de 1999. Se concentran fundamentalmente en Madrid, Cataluña y el País Vasco. Un trabajo similar (que conviene consultar), y en el que participamos, es el de D. Vivas y E. SánCHEZ RUANO, Informe Delphi: El sistema sanitario español. Estrategias, tendencias y áreas de desarrollo (Valencia: M/C/Q Ediciones, 1993), 52 pp. Es el número 1 de la colección de Papeles de Gestión Sanitaria - Serie Monografias.

"Uno de ellos advierte irónicamente: $\bullet$ A lo mejor me cesan después de responderos algunas de estas preguntas. (E1, p. 2).

$$
\begin{aligned}
& 16 \text { E2, p. } 25 . \\
& 1 \text { E12, p. } 6 . \\
& \text { I8 E10, p. } 3 .
\end{aligned}
$$

*. La Salud Pública entendida tradicionalmente ha quedado como la vertiente que menos desarrollo ha tenido en los últumos años. Quizá porque se ha pretendido desmantelar la organización periférica de la Salud Pública tradicional heredada del franquismo sin que haya una altemativa clara de cómo se podría - se debería- organizar, es decir, todo lo que significa el control de los problemas epidémicos y las actividades de planificación y ordenación de una manera suficientemente explícita. (E3, pp. 1-2).
E2, p. 1.

"El, p. 1.

"E1, p. 3.

3 E2, p. 3.

3 E12, p. 3 .

3 E12, p. 7.

si E1, pp. 4-5.

${ }_{37}$ E4, p. 1.

E12, pp. 4-5.

3. En menos de tres generaciones lo que hay hoy como sistema sanitario español es un puro milagro, dado el nivel de indigencia del que se procede y el nivel de indigencia (no sólo material sino también de neuronas) para organizarlas. (E10, p. 4).

"E1, p. 2.

1 E6, p. 1.

II E12, p. 4.

(3) E3, p. 3.

$"$ E8, p. 2.

ts $\mathrm{E}$, pp. 4-5.

E12, pp. 7-8.

"E2, pp. 3-5.

E6, p. 2.

19) Muchas familias han tenido (y lo digo ya en pasado) seguridad privada pagada, además de la Seguridad Social. Esto está indicando que por un lado la gente no tenía suficiente seguridad y confianza en la pública. Y por otro lado que las prestaciones que ofrecía la sanidad privada eran de garantía y calidad [...] Sin embargo, sé que últimamente pues muchas personas están cerrando, retirándose, no siguen suscribiendo sus pólizas privadas. Hay que tener en cuenta (y esto creo que sería un poco extensible a toda Espana) que la crisis económica ha hecho también que las familias recorten sus gastos [...] Quizás en nuestro país, la preocupación por la seguridad no ha sido tanta como haya sido en otras sociedades [...] Nuestra cultura no es tanto esa previsión del mañana. Igual es porque somos muy mediterráneos. Creo que ha influido mucho en la gente esta crisis. (E7, pp. 3-4)

E9, pp. 3-4.

:No se ha generado un sistema extenso de sanidad privado, con alguna excepción. Una de las excepciones ha sido precisamente Cataluña, debido a la dejación o discriminación que desde el punto de vista de la distribución de recursos del sector sanitario público ha tenido tradicionalmente desde la Administración Central en el tiempo de la dictadura franquista. Hay algunas Comunidades, como la catalana, donde hay una sanidad privada notable. Nació con un ánimo de sustituir la sanidad pública que no hacía acto de presencia, y, naturalmente, como una actividad que podría generar beneficios económicos y profesionales. (E3, pp. 3-4).

$\because$ E1, p. 5.

E5, p. 2.

i) E4, pp. 1-2.

5 E12, pp. 9-10.

E12, Pp, 10-11.

E12, pp. 11-12.

\$ El sector privado tiene que responder a un mercado e intentar responder a este mercado, por lo tanto tiene que intentar adecuar sus servicios a ese mercado. La ventaja con la cual juega el sector privado es que la población que accede a él, la población con más capacidad adquisitiva, sabe perfectamente que en caso de problema grave puede acceder al sistema sanitario público, donde va a ser atendido a menudo por los mismos profesionales que le atienden en el sistema privado. Mientras que el sistema sanitario público tiene una gran presión para ofrecer un producto total, el sistema privado no necesariamente lo tiene. En caso de elementos de alta tecnología que no puede cubrir inmediatamente usa el sector sanitario públicos (E12, pp. 3-4).

(5) E10, p. 5 .

(i) E1, pp. 5-6.

(6) E9, pp. 1-2. 
62 E3, p. 5.

6. Los puntos fuertes de los países ricos en inteligencia han supuesto la descerebralización y desertización de inteligencias de las comarcas de alrededor. Y eso que la sanidad probablemente sea la institución que primero y principalmente ha contribuido a la repoblación cerebral de Espana, porque es la que ha dotado, por lo menos en médicos y farmacéuticos de calidad, hasta el último rincón del país. La saturación del personal ha llevado a que las mejores cabezas MIR de las últimas promociones sean hoy los staffs de los pequeños hospitales de las provincias españolas, de los sitios más remotos, en donde se facilita una asistencia de una calidad. Esto no era soñable hace treinta años, donde todo lo que no fuesen apendicitis ni hernias se intervenían en dos o tres puntos del país. (E10, p. 6).

${ }^{61}$ E2, pp. 6-7.

6 E1, p. 7.

(t) E4, p. 2.

${ }^{67}$ Lo veo en términos de dinero: las Comunidades Autónomas que generen más recursos podrán hacer más cosas, y eso tampoco parece muy justo. Entonces se crean tensiones porque si deben cubrir los mínimos de otras Comunidades pues eso parece injusto a algún nivel. (E11, p. 3).

E10, pp. 5-6.

(5) E3, pp. 5-6.

"N E12, pp. 12-13.

3 E5, p. 3.

7 E1, p. 6.

3 E8, p. 3.

त E6, pp. 2-3.

75 E6, p. 3.

${ }^{76} \mathrm{E3}, \mathrm{pp} .67$.

"E12, pp. 13-14.

${ }^{78}$ Hay variables externas a este paradigma que conviene tener en cuenta también: - La gran amenaza para el nivel de salud de la población es la utilización de la energía nuclear, concretamente con fines militares. Es el único problema de salud importante que debería preocupamos cuando pensamos a largo plazo: Existe una posibilidad muy cierta de que las armas nucleares estén cada vez más al alcance de un número mayor de países, de que se produzcan accidentes, o se utilicen de forma deliberada. Creo que esto es una posibilidad muy verosímil para los próximos 25 años. El día que esto ocurra el nivel de salud de las poblaciones afectadas cambiará de la forma más radical imaginable. (E8, pp. 4-5).

E5, p. 3. Así se reconoce que: Estamos en un punto de inflación, de estancamiento, donde hay muchos grupos de gente que lo están: pasando muy mal, que han pasado a ser marginales. Todo esto tiene que estar influyendo en la salud también de la población. (E7, p.6).

8) E12, p. 15.

${ }^{81}$ E4, p. 3.

8. E7, p. 7.

${ }^{83}$ E2, pp. 7-8.

81 E11, p. 4.

${ }^{85}$ E1, p. 8.

* ¿Qué se podría cambiar en la estructura para mejorar el nivel de salud? Una mejora cultural y una mejora responsable es muy difícil: se trataría de aceptar que cada uno es un egoísta y que sólo atacándole en su propio egoísmo es capaz de contribuir, porque si no contribuye no lo valora. Esto a los hombres les cuesta mucho porque todos se consideran muy generosos, aunque en el resultado, los pobres duerman en la calle y se mueran de frío; y no sólo en la propia ciudad, sino en la propia casa porque hoy el mundo es una aldea. (E10; p.7).

\footnotetext{
87 E2, p. 8:

${ }^{88}$ E3, pp. 7-8.

2) E12, pp. 41-42.

9) E3, p. 8
}

". Se ha alargado la esperanza de vida y esto es un hecho que constatamos. Pero lo más importante es que eso se perciba como un logro. Que si hemos alargado $x \cdot$ años, sean años para que la gente se lo pase bien, haga cosas que le interesen y no lo viva con resignación. Que se enfoque con satisfacción y con alegria [...] Que la gente lo perciba como algo positivo y con capacidad para hacer cosas. (E11, p.5).

2: El buen nivel de la salud de los/as españoles probablemente se deba al bajo índice de medicalización y de quimificación de la vida de los españoles, unido a las condiciones de medio ambiente o ecológicas del propio país. Cuando se sale de las zonas desertizadas y se entra en la vida, donde está el agua, en el paralelo de las temperaturas más soportables, donde se concentran las grandes culturas de la humanidad, donde está el Mediterráneo y se le da la vuelta al globo terráqueo, entonces pudiera ocurrir que el hecho de que fluya bien el agua da lugar a una situación de sanidad o de salubridad muy superior a los secarrales. Con lo cual resulta que uno de los grandes determinantes de la salud sea los ingenieros de caminos. (E10, p.8).

2. E12, p.16.

9. E6, p.4.

E5, pp. 45.

${ }^{x}$. Pero claro esto también ha pasado en otros países ¿Por qué nosotros aqui mejor? Pues porque bebíamos vino tinto siempre ¡No sé! (E7, p. 8).

$\because$ E8, p. 5 .

E4, pp. 3-4.

E2, pp. 8-9.

iii E5, p. 5. .La mortalidad ligada al consumo de tabaco está aumentando, y esto es bastante preocupante. El cáncer de pulmón está siguiendo un ciclo creciente, y otros cánceres y problemas relacionados con el tabaco, también. Esto lleva a un tiempo de evolución. Hay algunas tendencias interesantes: en ciudades como Barcelona está disminuyendo la proporción de fumadores de forma ya evidente. Pero, globalmente, España es uno de los paises donde fuma más población adulta. Está creciendo la proporción de mujeres fumadoras; y esto tiene un impacto negativo sobre la salud. (E9, p. 8).

lin E1, pp. 8-9.

[ii: E8, pp. 1-2.

lin E12, p. 9 .

(in) E1, p. 10

lin E2, p. 10

${ }^{160}$ E4, p. 4. La falta de datos permite que cada experto/a lo vea de forma un poco diferente: LLos problemas propios de una sociedad rica, de una mala dieta, del estrés, cardio-vasculares, del cáncer, son típicos de las sociedades ricas. Como España ha imitado a las sociedades ricas, son problemas que en estos momentos están aumentando en nuestro país. Son precisamente las clases más altas, que han imitado pero a las sociedades más ricas, las que tienen mayores problemas. Pero las clases más altas se dan cuenta antes y están empezando a cambiar esos tipos de hábitos, ese estilo de vida. Como la clase baja siempre imita a la clase alta, nos encontraremos que nuevos problemas, crónicos, cardio-vasculares, cirrosis y cánceres, etc., empezarán a aumentar cada vez más en la clase baja. (E12, pp. 19-20).

1is E12, p. 18.

lis E12, p. 21.

(in) E5, p. 6.

1110 E6, pp. 4-5.

${ }^{111}$ E8, pp. 11-12

11. E3, p. 10 .

${ }_{113}$ E8, pp. 9-10.

${ }^{113}$.El sistema sanitario público español es un sistema sanitario excelente para quien es un 'recomendado'; es decir, si tú conoces a alguien aunque sea un celador, si es un médico mejor, y no digamos ya si conoces a una enfermera que son las que saben moverse muchas veces mejor dentro de un hospital, dentro del maremagnum burocrático que representa un hospital. Si conoces un profesional sanitario, puedes moverte de forma cómoda y confortable y tener acceso a una Medicina de excelente calidad. Lo mismo con la atención primaria, que es un auténtico desastre en general. Esto implica que un porcentaje muy pequeño de la población se mueve con comodidad. Quizás ésta es una de las grandes desigualdades. Hay quien es capaz de aprove- 
char muy bien los recursos del sector privado y del sector público. Cuando es una cosa moderada y benigna, pues uno se va a la mejor 'hostelería' del sector privado; $y$ cuando es algo más grave, y sabe moverse en el sector público, y si tiene su arte, pues igual consigue una habitación para si solo. (E8, pp. 8-9).

11s. E8, p. 9.

116 E12, p. 17. Entonces vienen las desigualdades sanitarias y con una visión mecanicista: ¡Ah! Es que yo lo que quiero es tener a mi disposición todo el aparataje que es necesario para hacer, o para poder llegar. Es necesario el aparataje, quién lo va a dudar, si hay quien lo sepa manejar. Pero si falta la palabra no hay comunicación; que es lo que tenía el médico antes de la revolución científica. Por muchos aparatos que tenga, la asistencia con el aparataje es medicina veterinaria, no es medicina humana. La médicina bumana está basada en la palabra. (E10, p. 10).

"E9, p. 10.

118 E11, p. 3 .

119 E12, pp. 21-22.

19. E11, p. 2.

121 E10, p. 12.

12 E12, pp. 22-23.

${ }^{124}$ E2, p. 9.

121 E6, p. 5.

124. Ciertos datos que hay referentes al mundo del gasto, referidos al propio envejecimiento de la población (es decir, a los cambios demográficos) parece que es minoritario, o sea que es pequeña la proporción del incremento del gasto atribuible al envejecimiento. En este sentido, el envejecimiento de la población se ve un tanto catastróficamente. (E7, p. 12)

126) E3, p. 12.

$1:$ E7, pp. 10-11.

13 E8, p. 10

14) E12, pp. 24-25.

14i .Me preocupa mucho el tema de los viejos porque se empieza, no solamente a echarles la culpa de todo (de que gastan demasiado), sino que hay tendencias de guetificación de los viejos en el sistema sanitario, de considerarlos como población de riesgo especial. Hay una especie de control policial. Han de ir cada $\times x \cdot$ tiempo a hacerse revisiones. Hay un aparato de control casi policial del sistema sanitario sobre los viejos, que me parece un poco preocupante: La guetificación de los viejos en áreas especiales, y en centros especiales, el dedicarles recursos o no, el que valga la pena. (E12, pp. 23-24).

111 E11, p. 7.

1.2 E12, p. 22.

1.3. E9, p. 11.

131 E3, p. 11

135 ES, p. 7.

${ }^{14 \% ;}$.El aspecto de cuidado (care se dice en inglés) de los servicios sanitarios tiene una baja prioridad en España. Algunas reformas, como la de la atención primaria, que han arrojado un contingente importante de enfermeras fuera de los hospitales de salud, no han asumido explícitamente que su tarea fundamental es prestar cuidados de enfermería a la población, allá donde la población los precisa, y muy precisamente en domicilio. La tarea de crear una enfermeria domiciliaria, o enfermeria de barrio, es una condición esencial para atender bien sanitaria y socialmente a la población, para hacer un uso adecuado de recursos y para dar servicios de calidad. (El, pp. 10-11).

137 E8, p. 13.

1.8 E11, p. 7.

13.9 E5, pp. 7-8.

1*) El, p. 11

1.1 ES, p. 9.

1.2 El, pp. 12-13.

1.4 E3, pp. 13-14.

is ES, p. 8.
E2, pp. 11-12.

116 E6, p. 6.

$117 \mathrm{El}, \mathrm{p} .11$.

118 E3, p. 13.

1.9) E12, p. 26.

Ivi E2, pp. 12-13.

$15 \mathrm{E}$ E12, p. 27.

15: E4, p. 5.

13 E2, p. 12.

${ }^{15}$ E12, p. 27.

$\because$ E12, pp. 29-30.

(3) E2, p. 13.

15 E10, p. 13.

138 E8, p. 15 .

i5) E5, p. 11

Iiii E11, pp. 8-9.

161 E5, p. 10

16: E3, p. 16.

${ }_{110.3}$ E9, p. 13

(6) E4, pp. 5-6.

1 is E6, pp. 6-7.

16i E7, p. 15. Se necesitarían hospitales de crónicos. Lo cual sería una solución. Otra solución serían nursing bomes como las americanas. El concepto es una residencia que es clínica, pero además es de bienestar. Proporciona una serie de prestaciones a personas mayores que necesitan una estructura de cuidados. (E2, p. 13).

$16 \overline{7}$ E6, p. 8.

11189 E1, p. 16.

(ii) E12, p. 31.

${ }^{1 * i}$ E6, p. 7.

17 E9, pp. 14-16.

17 E1, pp. 14-15

${ }^{173}$ El, pp. 15-16.

17. E2, p. 14

17 E2, p. 16

${ }_{17}^{17}$ E8, p. 21.

17 E3, p. 18.

178 E1, p. 14

17) E4, p. 6.

19) E12, p. 30 .

${ }^{181}$ E9, p. 20.

182 E4, p. 6.

${ }^{183}$ E12, pp. 30-31.

18. E2, p. 15.

185 E12, p. 34.

${ }_{186}$ E4, p. 7.

${ }_{187}$ E3, pp. 19-20.

${ }^{189}$ E2, p. 7. Lo que tendrá que montar la sociedad es el instrumento de facilitar el dinero al que no tiene para que pueda pagar la asistencia sanitaria. Pero gratis no, porque la cultura, en ese sentido, generaría dilapidación. (E10, p. 16).
1985. E1, p. 18.
ixi E6, p. 8.
${ }^{191}$ E2, p. 19.
19: E2, pp. 17-18. 
19.4 E1, p. 17.

${ }^{191}$ E8, p. 17.

${ }_{10 .}$ E12, pp. 32-33.

${ }^{1 x i}$ E2, p. 19.

17i E9, pp. 16-17.

12 E5, p. 12.

19) E1, pp. 17-18.

gii E2, p. 11.

जil E6, p. 9.

$\because$ E2, p. 20.

E1, p. 21.

3il E2, p. 21.

E2, p. 20.

S68, pp. 18-19.

פii E6, pp. 9-10.

E1, p. 20.

(n) El, p. 19.

210 E9, p. 18.

211 E12, p. 34

21. E3, p. 22.

11. E1, pp. 21-22.

$\therefore$ E1, p. 21.

115 E7, p. 20.

216 Un ejemplo paradigmático: -Una de las mayores fuentes de ineficacia que tenemos son las especialidades no hospitalarias dentro del sistema de la Seguridad Social. Se trata de los especialistas de ambulatorio cuya capacidad de resolución de problemas es muy baja, pero que se están pagando. Quizás tendría más sentido que los niveles asistenciales fueran la atención primaria reformada y el hospital (para lo que se necesita que haya atención especializada). No tiene sentido tener miles de especialistas desvinculados del hospital, y sin tecnología disponible en los ambulatorios. Yo creo que ésta es una de nuestras mayores bolsas de ineficiencia. (E9, pp. 17-18)

:17 E8, p. 18.

IIs El, p. 20.

219 E5, p. 13.

291) E12, pp. 35-36.

21 E12, p. 36.

II E10, p. 17.

29 E4, pp. 7-8.

2 E6, pp. 10-11.

25 E9, pp. 18-19.

$2 x$ E2, p. 23.

2 E8, pp, 19-20. Otra opinión relevante: ·Yo hasta ahora creía que un Gobiemo de izquierdas o derechas tendría que marcar políticas distintas. Pero ahora ya no estoy muy convencida. [Con el PP] quizá podría mejorar un poco la situación de cara a la relación médicos-Gobiemo [...] Quizá se podría producir un mejor funcionamiento y organización del sistema. No lo sé. (E7, p. 21).

239 E12, p. 37.

$20)$ E3, p. 24.

24) E12, p. 38 .

${ }^{2} \cdot 1$. Mal, y lo digo sin paliativos. En la medida en que me he asomado a la producción escrita está en el mito de que lo mejor es lo privado; y lo privado está tan privado que está privado de interés general o de la percepción del interés general. Por lo tanto, yo creo que la realidad se impone y se rectifica, porque la necesidad humana reconduce cualquier ideología (E10, p. 19).

232 E12, pp. 38-39.

E1, p. 23.

(3) E5, p. 14.

23 E4, p. 8.

248. E8, p. 20.

237 E1, pp. 22-23.

23s Los expertos/as en el sector sanitario se atreven -a veces- a realizar un análisis más global del contexto socio-político de la crisis del sector sanitario. Una muestra interesante: sta situación actual revolucionaria es el de la convivencia acelerada, de la diversidad cultural interactiva en el tiempo y en el espacio. Actualmente conviven de modo interactivo la cultura del paleolítico superior con la del siglo XXI. Las catástrofes de las antípodas entran visualizadas en tiempo real en todos los hogares que tienen ya televisión. Por la vía de los satélites se han roto las fronteras nacionales. Esta planetarización lleva consigo probablemente una disminución de los niveles de los poderosos y por lo tanto habrá un cambio. El conflicto existirá, porque este presente que estamos viviendo está mucho más cargado de incertidumbre, de complejidad y de conflictividad que el de hace diez años. ¿Por qué? Porque le han robado el punto de referencia de organización de la vida social, le han quitado el enemigo. El hecho más revolucionario que ha habido en estos últimos años en Europa es la paz. (E10, pp. 9-10).

249) E12, pp. 40-41.

2ri E4, p. 9 .

211 E6, p. 12.

:1! E2, p. 24.

$21^{2}$ E12, p. 39

2" E3, p. 26.

215 E3, p. 25.

2:it E9, p. 20. LLa salud de los españoles lo que necesita es cuidados de salud adicionales, humanos, no veterinarios. Los veterinarios son estupendos..., pero para los animales (E10, p. 20).

217 E1, p. 23.

2:8 E11, pp. 12-13.

119. Un tema importante es la deuda, precisamente del sistema con los proveedores. Sale muchas veces en los periódicos. Eso me parece muy injusto y paradójico. la Administración es la primera que tiene que dar ejemplo. ¿Cómo puede la Administración pedir a sus administrados que cumplan con sus obligaciones cuando ella es la primera que no lo hace? Esto en el sector sanitario es muy grave [...] Es un asunto terrible, que no sé si es a causa de la corrupción, de la mala gestión, o de qué. Pero hay una deuda muy importante, que se está arrastrando durante mucho tiempo. Esto me parece contradictorio y paradójico, y es también una de las cuestiones que convendría que se revisara a fondo. (E11, p. 14).

Es: E5, p. 15.

:51 E11, pp. 13-14.

$\because 2$ E7, p. 22.

15. Conviene que esto funcione de una manera un poco budista. Que no se desmande porque yo creo que no está mal orientado. Es bastante equilibrado. Todo lo del sector priblico y el privado se va a combinar. Porque si metemos todo el seguro de enfermedad y el sector hospitalario en el Estado, no se sabrá quien manda alli. (E6, p. 12).

E10, p. 20.

35 E2, p. 25.

2* Como recomienda uno de los expertos: El futuro hay que verlo como los niños, con una cierta inocencia, para utilizar la inteligencia en unas condiciones en que la evidencia tiene que ver poco con la experiencia. (E10, p. 12).

5 E12, p. 39. 